Victoria University of Wellington

School of English, Film, Theatre and Media Studies

\title{
Blackout: Theatre, Rugby and Samoan \\ Masculine identities
}

\author{
Sepelini Mua’au
}

A thesis submitted to the University of Wellington in partial fulfilment of the requirements for the degree of a Masters in Arts (Theatre) 2016 


\title{
Blackout: Theatre, Rugby and Samoan Masculine identities
}

\begin{abstract}
This thesis examines key ideas concerning masculinity and Samoan identity, focusing on the external and internal pressures placed on Pacific Island athletes in New Zealand and abroad to inform the development of an original script, Blackout. In 2014, as part of an Honours script-writing course, I wrote a first draft for my first fulllength play. Inspired by the work of Samoan playwright Oscar Kightley, Blackout is a play that intersects the story of four young Pacific Island boys in their last year of College with the journey of a talented young Pacific Islander in his mid-20s trying to make his way in the Professional Rugby world. This thesis is part of a practicebased research project, comprising a $60 \%$ theory-based thesis (25,000 words) and $40 \%$ practical component, developing the script through three workshop productions. The two working questions the thesis and production process centre on are, firstly how the experiences of young second generation Samoan males can be explored through a contemporary theatre text, enabling the research to develop the story and characters of the play. The second, how the development of this script can enhance an understanding of what it is to be an emerging playwright, grounding the piece in personal experiences and contributing discoveries for young Pacific Playwrights. The practical elements of the project will be evaluated through the submission of two scripts, the first draft and the final working script, the reflection of this process in the thesis including facets of a workbook and in the presentation of the final performance itself, a copy of which will be made available to all markers.
\end{abstract}

What drives the project is a desire to see how the experiences of young, male, Samoans might be represented theatrically and how this might be an effective way of connecting with community. This process has opened up two further questions, being:

- What is the role of the writer in the rehearsal room?

- What are the dramaturgical challenges of developing a script in-progress? 


\section{Acknowledgments}

This thesis could not have been realized without a great deal of guidance and both mental and practical support. I would like to deeply thank those who throughout the two years this MA lasted, helped provide me with all that I needed.

I would like to express my gratitude to my Primary Supervisor, Dr. Nicola Hyland for her continuing guidance, encouragement and patience. You never once hesitated to offer support or a word of advice and were always there to help me through any difficulties, thank you.

I would like to thank my secondary supervisor, David O'Donnell, for providing invaluable advice and guidance at times when I needed it.

I would also like to express my gratitude to Paul Edwards and Stuart Brock for trusting in me and supporting me throughout the final months.

To my Director, friend and Uso, Ian Lesa, thank you for your vision and patience. Thank you for trusting in Blackout and believing in it's potential.

E'e ia i lagi tapu ou pa'ia sautuafafafa Samoa o le ao mamala, e le toe tau'aufagaina le niu loa pe toe tau faafuluina le maaosofia, aua o Samoa ua uma ona totofi. Ae avea lenei avanoa ou te momoli atu ai la'u FAAFETAI TELE i le tapua'iga a nai o’u aiga, uo ma a'u pa'aga uma sa tatalo ma tapua'ia lo'u alo faiva, lenei ua tinitauao ai lo’u faamoemoe, e ala i lenei su'esu'ega.

O upu a le atunu'u, e le sili le ta'i i lo le tapua'i, ona ou manatua lea o le tatalo faifaipea a nai ou tama ma tina ua fai i lagi le folauga, Muaau Ululu o Levi Saleimoa, Nanai Taulia ma Tamasa'ilau o Matautu Falelatai, ae faapitoa la'u faafetai ia Grandma Sa'ele Muaau, sa le tunoa ana tatalo i le ao ma le po, ina ia tau lau o lo’u faamoemoe.

O ou aiga uma i Ueligitone ma isi vaega o Niu Sila, faapea Ausetalia ma Samoa, faamalo mo le tapua'iga aemaise a outou talosaga, sa fai ma punavai o faamalosi'aga, a'o taumafai i le mea e gata mai ai le mafai. Ia toe faafo'i atu sautualasi manuia o le Atua, e pei ona ia faamanuia mai ai ia te a'u ma lo'u taumafai.

To my Mum and Dad, Talafulu and Nanai Pati, thank you for being there for me when I needed it most, financially, mentally, emotionally and most importantly spiritually.

To my rock, Olivia Dunn, thank you. For your patience and your love, your advice and your company. I cannot thank you enough for being there for me.

This thesis is dedicated to my Father in-law, Peter Martin Dunn, whose wisdom and guidance helped me through tough times and whose warmth lives on through all those fortunate enough to cross paths. 


\section{Table of Contents}

Acknowledgements 3

List of Illustrations

$\begin{array}{ll}\text { Introduction } & 7\end{array}$

Corned-beef with a side of No. 8 wiring

$\begin{array}{ll}\text { Chapter One } & 21\end{array}$

The Trope of the Pasifika Rugby player:

Exploring Samoan Masculinity and Rugby in New Zealand

\section{Chapter Two}

The Spirit realm in Blackout

Discussions on the unseen and the internal

Chapter Three

From Page to Stage

Mapping the developing journey of Blackout from the first to final drafts

$\begin{array}{ll}\text { Conclusion } & 116\end{array}$

References 122 


\section{List of Illustrations}

Figure

1. ..... Excerpt from THEA 405: Week 2 Exercise. These words represented the pressures players faced both externally and internally when dealing with concussions.

2. ..... Excerpt from THEA 405: Week 2 Exercise. These were direct quotes from those affected directly from concussions or from family or friends of those dealing with concussions.

3. ..... Excerpt from THEA 405: Week 3 Exercise. This scene closely resembles 2 . LIFE in the first draft of Blackout.

4. ..... Excerpt from THEA 405: Week 2 Exercise. This excerpt closely resembles 7 . HARDEN in the first draft of Blackout.

5. ..... Early concepts of costume for the Spirits: detailing including patterns of the Siapo and traditional Samoa tatau concepts (photo by: Johanna Friederike Otto).

6. ...... Final concept for Spirits Costume design: detailing included aspects of Samoan Lavalava with detailing above included (costume design by Johanna Friederike Otto).

7. ..... Spirits, Technical Direction Project Poster (photo by Leigh Minarapa)

8. ..... Presign meeting notes: Exploring three worlds of the play; changing room, spirit world and home (notes by Kirsten Lee; taken 26 March, 2015).

9. ...... Blackout Development Season Poster (photo by Bridie Collins).

10. ..... Blackout Development Season feedback response sheets.

11...... Movement exploration: shifting of weight from arms and body onto your feet whilst supporting your entire body (photo by Sepelini Mua'au)

12. ..... Choreography exploration: exploration of traditional Pacific Island dance practices: specifically, Samoan (photo by Leigh Minarapa).

13. ...... Choreography exploration: incorporation of Māori Haka practices including a sequence used in 'Kapa $\mathrm{O}$ Pango', a haka used by The All Blacks (photo by Leigh Minarapa).

14. ..... Choreography exploration: integration of 'vogue-esque' style dance movements: running commentary on popular culture today (photo by Leigh Minarapa).

15...... Choreography exploration: combining traditional aspects of Siva Samoa with contemporary dances. 
(photo by Leigh Minarapa).

16. ..... Light exploration: playing with dark hues, casting shadows and integrating a black-light to enhance the spirit world (photo by Leigh Minarapa).

17. ..... Light and powder exploration: casting different lights, strengths and from different angles onto scenes of spirit and powder movements to explore the relationship between light and powder (photo by Ian Lesa).

18. ...... Set and space exploration: Hanging panels for the set, incorporated in are the lighting hues. Far right panel has tatau patterns laser cut into it (photo by Leigh Minarapa).

19. ..... Set exploration: another view of the tatau design on the panel: coupled with a light shining from behind, evoking a discussion into the shadows and relationships with panels themselves (photo by Leigh Minarapa).

20. ..... Powder and light exploration: distinguishing the characteristics of the powder interacting with the light and how the light reveals the individual particles of powder (photo by Sonny Tupu).

21...... Excerpt from Blackout first draft, Scene 3-NAMES. NAMES. This draft was the cut draft that was used for all the projects.

23. ...... Audience feedback response sheets for Development Season of Blackout.

24. ...... Audience feedback response sheets for Development Season of Blackout. 


\section{INTRODUCTION}

Corned beef with a side of No. 8 Wiring.

I grew up in New Zealand. Raised on Weet-bix, nurtured with fish n' chips, and bred with pavlova. I was brought up in a Samoan family. Fed corned-beef sandwiches, educated with weeknight $l o t u ' s,{ }^{1}$ nourished with raw fish and embarrassed with White Sunday ${ }^{2}$ speeches. I took flight on the rugby paddock, served taro and sapasui ${ }^{3}$ for dinner and all but survived off 'ghost chips't whilst watching the All Blacks win back to back Rugby World Cups. ${ }^{5}$ I had a distinctly New Zealand Samoan upbringing and one not all that dissimilar to many young Pacific Island boys and girls living in New Zealand, and abroad, from their homeland today. I learnt how to throw a rugby ball before I could walk, how to act in front of my elders before I could speak, and how to fix a broken anything with a piece of sellotape and No. 8 wiring because, frankly, 'DIY is in our DNA.'6 My parents grew up on the island of Upolu, Samoa. My father and his father made a living for their family by fishing in the early hours of every morning and selling their catch on the

\footnotetext{
${ }^{1}$ Lotu translates to either Church Service or Prayer.

${ }^{2}$ White Sunday is a Samoan church event celebrated across multiple denominations and is a celebration for kids and by kids.

${ }^{3}$ Sapasui is the Samoan version of Chop Suey, a vermicelli noodle dish.

${ }^{4}$ Ghost chips is a phrase from an anti-drink driving advertisement aired in 2011 by the New Zealand Transport Agency.

5 The first World Cup win was in 1987, but it was not until 2011 and 2015 that this was repeated. 6 'DIY is in our DNA' is a catch phrase for the hardware franchise Mitre 10, featured at the end of their advertisements.
} 
roadside. My grandparents raised families who lived off and made a living off the land in community-based environments that thrived on building and maintaining relationships and culture. They moved abroad for prosperity and opportunity for themselves and their future generations. My father passed an exam in Samoa to enter this country on a scholarship in the 1970 s. Once here, my parents found comfort and familiarity in their church community which represented the village life back home in Samoa, an environment that is to this day a key part of Samoan society. My parents worked multiple jobs, provided for their kids and never made them feel any less privileged than the next. My father fought on unions for workers while his family endured the dawn raids ${ }^{7}$ of the mid 1970's, even so, he always found ways to support the Samoan community here in New Zealand.

My family's story is a unique one, however, not dissimilar to that of many Pacific diasporic migrants who made their way into new lands in search of a better life for themselves and their families. Their worlds were reflected through the stories that permeated the plays of Oscar Kightley, ${ }^{8}$ one of the first people to present issues faced by Pacific Island migrant communities on stage and more importantly, from a Samoan perspective. Kightley's stories were those of my parents, the ones that challenged negative stereotypes of the people from the smaller island nations and served as an observation and examination of a culture in a specific time. Their stories were distinct and contemporary and enabled the rise of what is now known as a Pacific Theatre tradition in New Zealand. What waves of theatre did this

\footnotetext{
${ }^{7}$ The dawn raids were raids by the New Zealand Police in the early hours of the morning on the homes and workplaces of suspected over-stayers in New Zealand.

${ }^{8}$ Oscar Kightley is a Samoan New Zealand playwright and co-founder of Christchurch's Pacific Underground theatre company in 1992.
} 
multicultural generation promote? What theatre existed in New Zealand previous to their arrival as New Zealanders? Indigenous Māori share a relationship with the land as Tangata Whenua ${ }^{9}$ resulting in themes in contemporary Māori Theatre focusing on the loss of culture due to the negative aspects of colonisation or the subsequent fight to recover their culture and land. Those who migrated from the South Pacific Islands, such as Samoa, Tonga and Fiji, however, do not share this indigenous status, therefore, the themes of the first contemporary Pacific Island Theatre in New Zealand focus on the migrant or diasporic experience and the subsequent issues that arise, the clash of cultural values and juggling of two cultures in one home; these are the stories of my parents' struggles.

Pacific Underground ${ }^{10}$ - drawing heavily on the tradition of the Samoan Clowning form Fale Aitu ${ }^{11}$ - was one of the few Pacific Island theatre groups touring New Zealand in the 1990s. Led by Kightley, David Fane ${ }^{12}$ and Erolia Ifopo ${ }^{13}$, productions such as Romeo and Tusi (1996/2000) and Fresh Off the Boat (1993) saw these Pacific Island practitioners emerging, alongside artists such as Nina

\footnotetext{
${ }^{9}$ Tangata Whenua is a Māori term for the indigenous people of New Zealand and literally translates to English as "people of the land".

${ }^{10}$ Pacific Underground is a community based Pacific performing arts group interested in telling the stories of Pacific peoples in Aotearoa through mediums such as music, events and drama.

${ }^{11}$ Fale Aitu is translated from Samoan as the "house of spirits" and is a form of traditional Samoan clowning and storytelling.

${ }^{12}$ David Fane graduated from the New Zealand Drama School Toi Whakaari in 1991, he has enjoyed success in performing arts, stage and screen and is an established writer and comedian.

${ }^{13}$ Erolia Ifopo is a New Zealand actress and playwright, working together with Oscar Kightley in 1996 to co-write Romeo and Tusi.
} 
Nawalowalo ${ }^{14}$ and Nathaniel Lees ${ }^{15}$ to become household names in works characterised by boundary-pushing humour and challenging negative stereotypes of Samoan families, religion and poverty through satire. Pasifika artists such as Victor Rodger $^{16}$ and Lemi Ponifasio ${ }^{17}$, and a new generation including Courtney Sina Meredith ${ }^{18}$ and Moana $E_{t e}{ }^{19}$, have created new work which explores specific stories informed by very particular diasporic experiences and family histories. I live as a part of the second-generation New Zealand born Pacific Islanders and our experience, whilst similar in aspects to those of our parents, I believe, deserves its own stories and its own generation of Pasifika writers. For me, this meant a journey into the lives of young Pacific Islanders, specifically Samoan, in today's society and it is where my play, Blackout forms its narrative.

${ }^{14}$ Nina Nawalowalo is an established Pacific theatre director and maker, creating pieces with wellknown theatre collective, The Conch.

${ }^{15}$ Nathaniel Lees is an accomplished Samoan actor in both stage and screen, as well as an award winning theatre maker and director.

${ }^{16}$ Victor Roger is an award winning screenplay writer and playwright; his notable works include his play My Name is Gary Cooper as well as writing credits for New Zealand's long running television drama Shortland Street.

${ }^{17}$ Lemi Ponifasio is a Samoan and New Zealand director, dancer, designer, choreographer and artist. He founded MAU in 1995, a theatre company working with artists and communities worldwide. ${ }^{18}$ Courtney Sina Meredith is a pacific playwright, fiction writer and musician known for her awardwinning play Rushing Dolls (2010).

${ }^{19}$ Moana Ete is an established theatre practitioner, both stage and screen actor, musician and graduate of The New Zealand Drama School Toi Whakaari. 


\section{Synopsis of Blackout}

In 2014, as part of an Honours script-writing course, I wrote a draft for my first full-length play. Inspired by the work of Samoan playwright Oscar Kightley, Blackout is a play that intersects the story of four young Pacific Island boys in their last year of College with the journey of a talented young Pacific Islander in his mid20s trying to make his way in the Professional Rugby world. Interspersed with this story is a spirit realm that not only lives and breathes its own life, but carries on into the real world of the play and reacts to the characters and their stories. The spirits create imagery, offer words and inform the audience of internal battles as well as presenting the social and cultural struggles for the characters.

This work fuses realist with non-realist forms drawing from elements of postdramatic theatre ${ }^{20}$ in the spirit world (structure of time, characters and plot) and combining it with a very real Pacific Island story. This experimental form is a part of a recent shift towards a more diverse Pasifika theatre, one that not only envisions the unique journey of young Samoans today but depicts their struggles. The narrative considers the lives of young Pacific Island boys and the cultural and social struggles they face in everyday life. The accounts in the play are somewhat autobiographical but also touch on a subject that is prominent in the lives of not only young Pacific Island athletes today, but athletes worldwide and across multiple sports; the stigma surrounding injuries, particularly concussions or head injuries.

\footnotetext{
${ }^{20}$ The concept of Postdramatic theatre was recognized by Hans-Thies Lehmann, a German theatre researcher, in his book Postdramatic Theatre. In it he established certain trends and aesthetics arising towards the end of the 1960s in avant-garde theatre.
} 
Compounding these issues are the cultural dilemmas young second generation New Zealand born Samoans experience, particularly in the search for prosperity, but more importantly, social and cultural identity between the two worlds. The issues are examined and portrayed through the title characters Jacob and Sua, both dealing with symptoms of repeated concussions. Their lives highlight the ways in which young Pacific Island athletes deal with these types of injuries, more importantly, their stories reflect the very real pressures these athletes face in today's society. In regards to this thesis, it is part of a practice-based research project, comprising a $60 \%$ theory-based thesis (30,000 words) and 40\% practical component, developing the script through three workshop productions.

\section{New Zealand Plays about Rugby}

A play dealing about rugby or rugby players is not new territory in New Zealand theatre. When it comes to rugby and theatre, it is important to mention New Zealand's most famous rugby play, Greg McGee's, Foreskin's Lament, a landmark in the history of New Zealand theatre. This story, set in the changing room of a rugby union team presents New Zealand rugby attitudes during the mid-1970's, against the backdrop of the 1981 Springboks Tour. The political commentary underpinning the play hit a nerve with the New Zealand public along with the relatable characters and story. Whilst this play remains a staple of New Zealand theatre, it doesn't fulfil a contemporary rugby experience or a Pacific one. Foreskin's Lament is a critical text that considers the formation of a national identity through the metaphor of a predominantly palagi rugby team. To an extent, Blackout responds to this homogenous view of 'New Zealand' through making palagi who dominate McGee's play, entirely absent. What also differentiates my script from this text is the 
contemporary, singularly ‘second-gen Samoan’ focus and hybrid of realist and postdramatic elements.

Whilst most of the early Pasifika plays centre around the migrant experience, some do touch on the influence of sport, mainly rugby. For example, the second half of the Naked Samoans fifth show, Naked Samoans Go Home follows the journey of Sione, a young Samoan immigrant flown to Auckland and offered the chance to play for a professional rugby team. Sione fails to make the team but continues to lie to his brothers back home saying he is studying medicine when in fact he is a labourer. Plagued by his failure to become successful in New Zealand and too afraid to face the shame from his brothers back home, Sione decides to end his own life. This powerful story does have links with Blackout in that it presents the pressures Samoans face in today's society, however it is still a story of the Pacific migrant experience and less so about the journey of young Pasifika athletes living here in New Zealand. Other notable plays that deal with rugby are Pack of Girls by David Geary which explores the exploits of Pam Hooper, a women who starts her own women's rugby team to spite her husband for ignoring her due to his rugby recovery and C'mon Black by Roger Hall, a one man show based in and around the 1995 Rugby World Cup.

\section{Contextualising the journey of Blackout}

As mentioned earlier, the first draft of Blackout was completed in 2014, however, in order to contextualise the piece, it is important to note the origins of the play were from provocations completed throughout my Honours Scriptwriting course. The first provocation of major influence to the writing of Blackout came in the week 2 exercise: 
Consider what qualities make a text 'post-dramatic' (refer to Hans-Thies Lehmann: Postdramatic Theatre or read 4:48 Psychosis by Sarah Kane as an example) and create a post-dramatic micro-play in no more than 7 pages. (THEA 405, 2015).

This exercise became a structural basis for the spirit scenes: 7. HARDEN, 10. CHAOS, and had influences in 14. HOSPITAL. [Please note these spirit scenes as well as discussions on the post-dramatic will be discussed in depth in later chapters]. The excerpt (see Fig. 1), reveals the impact of what is categorized as post-dramatic qualities on the script, no aspects of time, characters or plot. I presented a series of episodes concerning concussions, either of the concussions themselves, the effect it has on the person involved and the people surrounding them. What is offered are a series of quotations where the speaker is not suggested as the originator, episodes that are not structured to progress ideas or themes and no characters, only text bearers.

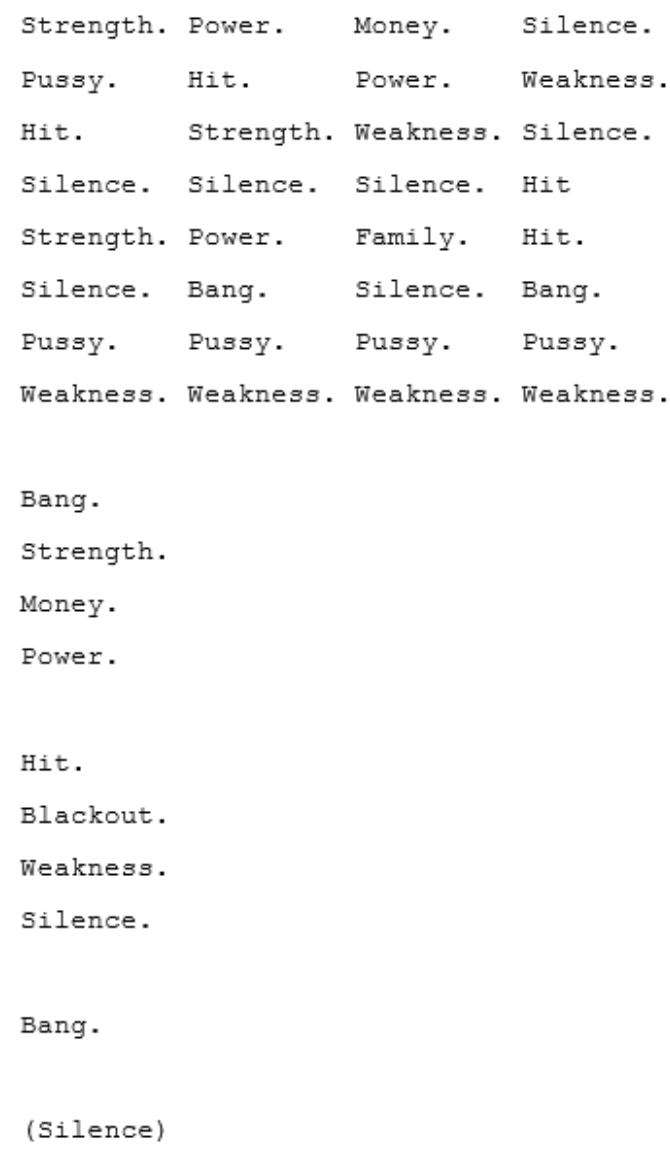


Fig. 1: Excerpt from THEA 405: Week 2 Exercise. These words represented the pressures players faced both externally and internally when dealing with concussions.

What is also important to note is that this exercise is the first time I delve into the issue of concussions and the stigma surrounding such injuries. My interest peaked during this time after an article published on the New Zealand Herald website in early July concerning the death of a young rugby player in Whangarei from a brain bleed resulting from a head clash on the rugby field (in Tait, 2014). I took inspiration for the exercise from stories and articles of people or families affected by concussions, often directly quoting them (see Fig. 2).

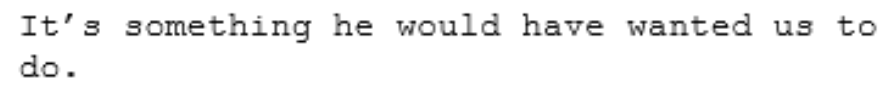

Fig. 2: Excerpt from THEA 405: Week 2 Exercise. These were direct quotes from those affected directly from concussions or from family or friends of those dealing with concussions. 
of the exercises into a semi auto-biographical story, involving traditional Samoan aspects of a spirit world. The stories of the four boys in school were daily accounts of what went on during my time at school and the struggles represented, including Elle and Sua's storyline, were triggered from the articles on concussions I came across, articles that will be discussed in the thesis. Towards the end of the first draft, I found common ground to combine the two worlds. However, at the end of the final draft, it felt unfinished, there were still a lot of things I did not know. While I knew the pressures existed for young Pacific Island people today, I was unaware of the exact nature of these pressures; the social and cultural factors plaguing the boys were present but vague and needed to be given a full working over.

This led me to an MA and gave me the opportunity to research and develop the script further, to enhance and illuminate ideas and themes circling throughout Blackout and make them stronger and heightened for its audience. For the story to express the real implications it had in the real world, I felt that it needed time to be worked on, the characters needed exploring, reworking and the script as a whole needed to be developed. Blackout was invited to its first reading as part of the annual Pūtahi Festival of Māori and Pasifika performance in development (Studio 77, Wellington) in February 2015, offering me the chance to hear these characters come to life for the first time and it was after this reading my connection and collaboration with director Ian Lesa was established for the MA.

\section{Collaboration}

This thesis and project are linked to a practical component undertaken by MTA (Part II) student Ian Lesa who directed the realised script in two workshop seasons. Collaborating together allowed us to complete our respective programs, but 
more importantly offered us the chance to work on a community piece, specific to our culture and upbringing and at the same time make work for and regarding issues pertinent to those communities. The first workshop season was the 20 minute Spirits 'Technical Piece', staged in May 2015, which took elements of the spirit world and explored how it would come to life; which will be discussed further in chapter two. The second workshop season was the 20 minute 'Actors Piece' in October 2015, which explored the relationship between Elle and Sua and their journey in the play. I was the recipient of Playmarket's ${ }^{21}$ annual Brown Ink ${ }^{22}$ competition workshops that provided the cast, director and myself three workshops in November 2015 to help develop the script further, led by Nathaniel Lees. The next and final component to the development was the 'Major Production', [The Development Season of $₫$ Blackout which ran in December 2015 and took the script to a fully realised production. Throughout the year, the rehearsals offered a space for further research, development and exploration into the characters.

Ian and I pursued a 'Tuakana-Teina' approach to our roles which works as peer support collaboration where the roles shift accordingly; for the most part as writer and director, our influence and input were present in all aspects of production including important rehearsal discoveries. Ian applied the script 'practically', investigating how different elements of the script could further his work as a director

\footnotetext{
${ }^{21}$ Playmarket is noted as New Zealand Playwrights' agent, advisor and bookshop. As agents they represent the rights and interests of playwrights, as advisors they offer support and advice to those in the business of writing plays and as a bookshop they host a comprehensive selection of published and unpublished New Zealand plays, for anyone and everyone.

${ }^{22}$ Brown Ink is an annual playwriting competition run by Playmarket for all Māori and Pasifika writers. They take new scripts and run clinics to workshop and develop the scripts further.
} 
through the two workshop seasons before culminating in the development season. For myself, this was an opportunity to use not only the discoveries made in rehearsals and performance to develop a working script, but also through the responses to the performances themselves to find new ways to further define the play and the work of young emerging Pacific Playwrights in the future. What unites the projects is our desire to see how the experiences of young, male, Samoans might be represented theatrically and how this might be an effective way of connecting with community. Significantly, however, these were two separate projects with two separate objectives; while collaboration was useful in many respects, it also presented challenges that will be discussed in chapter three, such as the need to mark the parameters of the project for both writer and director as well as the boundaries. In chapter three, I delve further into clarifying what the projects were, their aims and outcomes.

\section{Focus}

This thesis examines key ideas concerning masculinity and Samoan identity, focusing on the external and internal pressures placed on Pacific Island athletes in New Zealand and abroad to inform the development of an original script, Blackout. The two working questions the thesis and production process centre on are, firstly how the experiences of young second generation Samoan males can be explored through a contemporary theatre text; enabling the research to develop the story and characters of the play. The second; how the development of this script can enhance an understanding of what it is to be an emerging playwright; grounding the piece in personal experiences and contributing discoveries for young Pacific Playwrights. 


\section{Chapter structure}

Chapter One explores the journey of rugby in New Zealand, the construction of the trope of the rugby player and how masculinity and rugby impact on Samoan players trying to fit this mould. The chapter then turns its focus to the journey of young Pacific Island athletes along with the specifically Samoan pressures they face in their lives. Chapter Two deals with the Spirit World of Blackout; reflections on the Samoan notion of $v a$, a liminal realm drawn from Samoan cosmology, and how va can operate as a dramaturgical but also thematic and spiritual element to the play. Also considered are traditional Samoan cultural customs of fa'aSamoa including dance practices versus contemporary performance. Finally, Chapter Three will focus on the script, mapping its developing journey from original draft to the stage to the final draft. The chapter will note the continual development of the work through practice and review and the search for a dramaturgical link for the play itself; delineating the roles between writer, playwright and dramaturg.

\section{How to read this thesis}

For the full impact of the script development to be realised, it is important to read Blackout First Draft, followed by the Thesis, and finally; Blackout Final Draft. The aim is that the reader will be able to see how decisions were made during the process that affected the final script. 


\section{CHAPTER ONE}

The Trope of the Pasifika Rugby player:

Exploring Samoan Masculinity and Rugby in New Zealand

Late February, 2013. In sweltering heat, on a sticky Sydney day at the West Tigers' Rugby League Club headquarters, a young twenty-year-old, New Zealandborn Pacific Island boy sweats through his final training before the start of the National Rugby League ${ }^{23}$ competition. A soon-to-be father, Mosese Fotuaika pushes himself wholeheartedly to become the professional football player he has worked so hard to be and the competitor and provider he wants his parents and family to see him as. He spends more time in the gym and more time training off it than anyone else in the club (Cadzow, 2013), and his reward? A first grade debut, the supreme objective of every young rugby league star. And with this, the opportunity to fulfil a dream for young Pacific Island athletes alike, to provide, repay and honour those who made it possible for their success:

When I debut, it's not my debut. It's my mother's, my father's, my grandparents', my great-great-grandparents', who are watching over me now. It's their debut (cited in Cadzow, 2013).

This chapter explores the growth of rugby in New Zealand, its effect on the migrant Pacific Island (PI) Communities in New Zealand and vice versa, the effect the PI Community has had on the New Zealand rugby scene. The chapter will

\footnotetext{
${ }^{23}$ The National Rugby League (NRL) competition is the Premiere league competition of professional rugby league clubs in Australasia.
} 
investigate the role rugby plays in today's society, particularly from a Pacific Island perspective, in order to gain insight into the lives of young second-generation PI, predominantly Samoan, boys.

\section{Origins of Rugby in New Zealand}

In The Browning of the All Blacks, Andrew Grainger ${ }^{24}$ traces the origins of rugby, its shift to and ensuing popularity in New Zealand thereafter, and the relationship to notions of masculinity resulting from, or coinciding with the sport. Grainger notes the growth of a rugby 'culture' in New Zealand and considers its influence on masculinity and the key role this sport has on the development of New Zealand masculine identity. The roots of the rugby game date back to the early $1800 \mathrm{~s}$ in the English Public School System, coinciding with the idea of 'manliness' surfacing as an ideal towards which young men strived. This is an ideal further reinforced by values of the Protestant elite (Dunning \& Sheard, 2013) which highlights the close relationship between morality, sport, religion and masculinity in rugby's earliest days, where a "belief that strength of character could be achieved through sturdiness of the body," (cited in Grainger, 2008: 64) so that sport could aid in the development of not only physical characteristics but also Christian values. Sports such as rugby became synonymous with the British upper class schooling system and it is in this vein that rugby arrived in New Zealand, providing an ideal way for "a 'manly' education tempered by civilizing restraints" (cited in Dunning and Sheard, 2013: 74).

\footnotetext{
${ }^{24}$ Andrew Grainger is the author of The Browning of the All Blacks: Pacific peoples, rugby, and the cultural politics of identity in New Zealand. A dissertation examining how the multifaceted, and repeatedly inconsistent, discourses of being a 'Pacific person' are played out in, and through, New Zealand rugby. University of Maryland, College Park. Kinesiology.
} 
As Palenski notes: "One of the schools to adopt rugby was Christ's College in North London” (2013: 2). It was there, a young New Zealander, Charles John Monro, learnt to play the game of rugby after being sent there for his schooling. When he returned to Nelson in 1870, he convinced the then Headmaster of Nelson College to modify their varied football game to rugby rules thereby initiating the very first rugby game in New Zealand on 14 May 1870 (Palenski, 2013: 2).

Although it began among the elite, rugby soon "spread quickly through other social classes" (in Phillips, 1996: 90). Grainger identifies a number of reasons for the rapid spread of rugby's popularity:

What in England was mainly an upper class game...became in New Zealand a symbol of mateship, intrepidness [and] coloniser-colonised reconciliation (citing During, 1998: 35).

A view that the 'roughness' of the sport may have been more appealing to early New Zealanders is further supported by the assertion that it was because it perpetuated traditional notions of masculinity, concluding that rugby was the "epitome of rural, colonial masculinity” (in Ryan, 2004: 157). Furthermore;

The effort, cooperation and egalitarianism required of pioneers in taming a rugged landscape supposedly produced an especially tough New Zealand male 'type' ideally suited to the combative demands of the rugby field (Ryan, 2003: 167).

It can be asserted the importance of rugby's role was, moreover, an answer to the rapid urbanisation of cities and towns across the country and utilised in the social integration of the communities themselves. The use of rugby to operate in aiding social integration can also be found in early communities of the diasporic Pacific 
Island migration, post-World War II. Significantly, the most popular "myth" as to the rise of rugby in New Zealand stems from the country's purported classlessness. While this classlessness remains in contention, for the purposes of this study, discussions on race-relations and the egalitarian classlessness myth, while duly noted, will not serve as a main point of analysis.

\section{The role of rugby today}

Since its arrival and subsequent popularity, rugby is, without a doubt, an icon of New Zealand culture and society and to an extent a part of its national identity:

As rugby came to form a tight embrace with New Zealand identity, it suggested the nation as decidedly masculine (Grainger, 2008: 170).

As Julie Park ${ }^{25}$ notes, however, it also "stands for a dominant, if not hegemonic, New Zealand masculinity..." (cited in Park, 2000: 540). Rugby patterns the lives of young boys growing up in Aotearoa, regardless of culture or ethnicity. While it is now a ubiquitous game across the country, being played out wherever the ground is flat enough, it is likewise a yardstick with which to establish one's identity and to an extent, measure their worth. Park considers aspects of rugby identity in New Zealand and how versions of masculinity stemmed from this history:

...the popular equation of the national rugby team, the All Blacks, with the nation was accomplished as early as 1905 , along with the equation of rugby-playing with

25 Julie Park is the author of "The Worst Hassle Is You Can't Play Rugby": Haemophilia and Masculinity in New Zealand. Her work explores rugby in New Zealand and its symbol for and practice of a hegemonic form of masculinity in NZ. Department of Anthropology, University of Auckland. 
"the kiwi bloke": heterosexual, aggressive, stoic, physically strong and skilled, and a good (homosocial) mate (Park, 2000: 446).

This specific form of masculinity, whilst one of many, became hegemonic in New Zealand society. Park notes that hegemonic masculinity is only a fragment of an overall system of a gender order and social practice, which "consists of relations of alliance, subordination, and dominance between masculinities and femininities" (cited in Park, 2000: 446). As New Zealand emerges a heteronormative, patriarchal society that relates and values physical ability over intellectual achievements, male status and masculinity dictates society. This order is part and parcel of growing up in New Zealand and Pacific Island boys are not immune to this.

In Tackling Māori Masculinity: A Colonial Genealogy of Savagery and Sport, Brendan Hokowhitu²6 examines Māori masculinity and its changing forms through the lens of his upbringing in the rural town of Opotiki, New Zealand. In many ways Hokowhitu's upbringing is not all that dissimilar to mine, a specifically New Zealand Samoan one, or to many other Pacific Island boys that I grew up with. Particularly, the Māori masculinity in the twenty-first century Hokowhitu alludes to as becoming “a spectacle played out by the overachievement of täne (Māori men) on the sports field" (cited in Hokowhitu, 2004: 259).

${ }^{26}$ Brendan Hokowhitu is the current Dean of the School of Māori and Pacific Development at The University of Waikato. He is the author of numerous publications across a number of disciplines including masculinity, indigenous critical theory, media and sport. 
Furthermore, Hokowhitu describes the journey of young men raised in a masculine culture where it was essential for both Māori and Pākehā males to exhibit their physical capabilities. Similarly, these ideas correlate with the journey of young Pacific Island men conforming to the notion that it is easier to fit in when playing sport with the other boys and fostering this masculine culture as a way of being socially accepted into the norm (Hokowhitu, 2004: 259). As with myself, many young Pacific Island boys unknowingly fall into this mould and it is not their fault, they fit in, they feel validated by playing sport and moreover, they're admired by younger boys and afforded great status in school. As Hokowhitu suggests, they are the Kiwi version of the "jocks" in United States schools. Park further emphasizes the role rugby plays for young boys growing up in New Zealand:

Playing rugby is a part of a "normal" boyhood to the point where masculinity and citizenship may be suspect if a boy does not play (Park, 2000: 449).

With the rise of rugby during its early years in New Zealand, schools across the country accordingly made it obligatory to play, claiming active participation in the sport was "a core experience of the school curriculum for young New Zealand males" (Phillips, 1996: 107). Partaking in rugby confirmed the boy's capability to both endure and exact pain and if the "boy of character had to take it like a man" (cited in Phillips, 1996: 105), then as a result rugby would transform the boy into a man. As Grainger notes, the physical hurdles these young boys faced "cemented the equation between masculinity and physical toughness" (in Grainger, 2008: 168).

Hokowhitu implies that it is hard to look at Māori masculinity through a contemporary lens when indeed it comes as a constituent of genealogical constructs through history. This history highlights the relationships between the Māori body 
and the colonisation of the land and the subsequent representation of Māori constructed from that over the years:

Whether intentionally or not, early European travellers and missionaries sowed the seeds of a genealogy of representations in which Māori and tikanga Māori were depicted as inherently inferior (Hokowhitu, 2004:265).

His paper further delves into two main focuses of the "physical savage" discourse. The first was the representation of Māori being inherently inferior then evolved to Māori being "practical-minded" (cited in Hokowhitu, 2004:266). He talks of the need for boys to progress into the manual, technical and agricultural work force leading to schools having a narrow and limited view of Māori potential. Hokowhitu goes on to state:

Confinement to manual labor, combined with a general discourse that described täne as inherently physical, led to generations of täne thinking of themselves as "practicalminded" and unable to relate to abstract thinking (Hokowhitu, 2004: 268).

This discourse offers insight that the privileging of the physical is an inherently racist system in education and government. This notion decreases the capacity of Pacific Island men in positions of power, in sport/physical labour, they are putting their 'savage instincts' to a practical purpose that renders them less dangerous. Moreover, they are encouraged not to strive for roles of actual power [i.e. politics] but that the best they can do is run/jump/box etc. This directly speaks to certain aspects of not only my life but many young Pacific Islanders today. Not just the fact that they only see themselves playing sport, but they believe they can succeed because they see it in other PI/Māori sports stars: the "Māori sportsman as spectacle; 
an exemplar that reinforces Māori boys' aspirations to make it in the sports arena.” (cited in Hokowhitu, 2004: 274).

These limitations Hokowhitu places on himself and others placed on him, are the same ones placed on young Māori and Pacific Islanders today. More importantly, they are not just lazy definitions they're confined to but are, in fact, as Hokowhitu describes, historically-framed genealogical constructions (2004: 284). As Hokowhitu notes:

[The] dominant discourse through many institutions, pervasively limits Māori men, and many Māori men swallow these constructions... a discourse that was constructed to limit, homogenize, and reproduce an acceptable and imagined Māori masculinity, and that has also gained hegemonic consent from many tane. (2004: 284).

Hokowhitu accurately describes the attitude of many young Pacific Island boys growing up in New Zealand. They conform to the ideas that they are either sports stars or otherwise work in the manual labour industry. Despite the study focussing on the influence of colonisation and the effects it had on Māori, it also mentions their Pacific Island counterparts and makes note that during the late twentieth-century there came a new discourse to the discussion;

...the talents of Polynesian male athletes (being) seen as raw materials to be captured, brought under Pākehā control, and molded into a commodity (Hokowhitu, 2004: 272).

This concept of athletes as a 'commodity' correlates with the professionalization of rugby in the mid-1990s and the subsequent "poaching" of Pacific Island players to clubs around the world which is discussed later in the chapter. 


\section{Influence of Pasifika rugby stars on the PI Community}

Pacific peoples have an illustrious history in New Zealand rugby. Whilst their origins do not hark from the beginning of rugby in New Zealand, they have been a mark of the All Blacks since Frank Solomon, of American Samoan descent, played his first test at Eden Park, Auckland in 1931. With the arrival of Pacific migrants throughout the 1960s, the formation of Pacific Island communities became established in and around church affiliations. The different denominations became a means for social support, congregation and a tool to cultivate a similarly integrated 'village life' as back home. For many of these communities, rugby became a second method for which to foster this unity.

The church and rugby served to create what Cluny Macpherson (2002) notes as 'moral communities': a place to aid in upholding traditional practices and values. One of the more prestigious rugby clubs out of Ponsonby Auckland became a source of pride for its Pacific Community and it's hard not to see why with the emergence of one of the very first Pacific Island sports stars, Bryan "Bee Gee" Williams; Williams was one of the few Pacific Island, let alone, Samoan players, to wear the All Black jersey at the time and undoubtedly the first Samoan rugby superstar. ${ }^{27}$ His rise to rugby notoriety in the 1970 s came at a time when the Samoan Community, as a whole, was still finding its place in New Zealand society. Williams notes it was not until after his playing years that he acknowledged the importance of his journey, the

\footnotetext{
${ }^{27}$ Bryan Williams played for the Ponsonby Rugby Club from 1968-1982, he was also an Auckland NPC Representative from 1969-1982 and also an All Black Representative from 1970-1978 earning 38 caps for the National team. Williams also coached the Samoa National Rugby Team as well as Assistant Coach of the Hurricanes 2000-2001.
} 
role of sport in his life and the impact he had on the Samoan community in New Zealand (Cleaver, 2011). Williams' popularity in the 1970 s reinvigorated pride among Pacific Island communities in New Zealand:

Bryan "Beegee" Williams was more than a wonder winger, he was a pioneer (cited in Cleaver, 2011).

Williams gave Pacific peoples a small sense of belonging in an era of "dawn raids, hostility from the police, and the 'overstayer' deportations of the same period" (cited in Teaiwa and Mallon, 2006: 213). Williams explains how openly showing one's "culture" was not encouraged in those days and similarly these themes are reflected in Oscar Kightley's play Dawn Raids (1997) where living the 'Niu Sila/New Zealand' way was the only way to live. Williams' success, however, represented what could be achieved "against the economic and social odds in New Zealand society" (cited in Te'evale, 2001: 220). It was during these divisive years that rugby and the success of Williams helped Pacific Islanders overcome the hurdles and find a sense of respect and acceptance.

However, this idea of overtly showing one's culture changed over time and being proud of Pacific Island heritage in New Zealand became widely accepted. Williams attributes this to the pride generated by those who had made it to the top of the sporting tree, he being the pioneer of it all. These PI rugby players were the next stars and Williams himself had a hand in a number of these All Black legends, including Michael Jones ${ }^{28}$ who spoke on Williams' contribution to his early playing days:

${ }^{28}$ Michael Jones had a prestigious rugby career starting out for the Auckland NPC team from 19851999, he furthered his career with the Auckland Blues from 1996-1999 and played International for 
As a young Polynesian kid growing up in Auckland, I had my heroes growing up and my hero was BG and I wanted to be like BG. He was my inspiration and he was my role model. He was the person we could relate to and identify with (cited in Clark, 2013).

Former All Black and Auckland Coach Pat Lam ${ }^{29}$ also talks of Williams' career and the effect it had on him growing up:

It meant a lot to my dad and uncles to see Bryan Williams become an All Black. Even now when Samoans do well it gives my family a sense of pride. Parents had an example of someone they could highlight. They could hold up guys like Bryan... as people from a similar background who had been successful (cited in Paul, 2007).

From the mid-1970s, the door had truly been opened to the prospect of 'New Zealand's Game' featuring a broad range of people and cultures. A new wave of Pacific Island All Blacks followed in the steps of Williams such as Joe Stanley ${ }^{30}$, John Schuster $^{31}$ and 'The Iceman’ himself, Michael Jones. By the late 1980s, Williams, along with Morris Trap, took the helm of the Auckland Blues to help shape not only

Samoa in 1986 before changing his allegiance to the All Blacks where he built his reputation as a hard hitting, no-nonsense ball runner from 1987-1998.

${ }^{29}$ Pat Lam was an International rugby representative, playing for both New Zealand and Samoa's National teams from 1991-1999, he went on to captain the Samoan National team, representing them in three world cups.

${ }^{30}$ Joe Stanley is member of the Ponsonby Rugby Club and was an Auckland and New Zealand Representative playing from 1984-1991.

${ }^{31}$ John Schuster was one of the first dual code International stars. He came from a long sporting line of Schusters based in Wellington and represented New Zealand and Samoa on rugby's International stage. He made a switch to Rugby League playing in the NRL for 3 years and represented the Samoa National Rugby League team. 
future Pacific Island stars in Eric Rush ${ }^{32}$ and Peter Fatialofa ${ }^{33}$ but also future All Blacks in Sean Fitzpatrick ${ }^{34}$, Zinzan Brooke ${ }^{35}$ \& David Kirk ${ }^{36}$ (to name a few). In 1991, Williams joined as Technical Director to the Manu Samoa National Rugby team at the Rugby World Cup that year. In talking with Tagata Pasifika (television show) he says it was an easy decision and that he felt that he had a contribution to make to Samoan Rugby as he had already had a successful playing and coaching career in New Zealand:

Williams admits the greatest reward as an All Black was being put on a pedestal. It's a pedestal that, in the eyes of the Samoan community in particular, he's never left (in Cleaver, 2011).

${ }^{32}$ Eric Rush was a North Harbour and New Zealand rugby representative. He played for The All Blacks from 1992-1996; however, he made a name for himself on the Rugby Sevens circuit winning two Commonwealth Gold Medals and one World Cup Sevens medal for New Zealand.

${ }^{33}$ Peter Fatialofa played 72 representative games for the Auckland Provincial side and was one of the first New Zealand-based players to represent Samoa on the International stage from 1988-1996. In the 1996 Queen's Birthday Honours, Fatialofa was made a Member of the New Zealand Order of Merit, for services to rugby.

${ }^{34}$ Sean Fitzpatrick is one of the most highly regarded All Blacks of all time. He earned 92 caps for the All Blacks over an eleven-year career from 1986-1997 and was made an Officer of the New Zealand Order of Merit in the 1997 New Year Honours.

${ }^{35}$ Over the course of his career, Zinzan Brooke represented New Zealand in 100 games, 52 of those were test matches, he captained the Auckland Blues to back to back Super 12 championships in 1996 and 1997.

${ }^{36}$ David Kirk captained the Champion All Blacks at the inaugural 1987 Rugby World Cup in New Zealand. His career spanned from 1982-1987 and he was appointed a Member of the Order of the British Empire in the 1988 New Year Honours for services to rugby. 
Similarly, Michael Jones says the greatest thing he has gained from being an All Black is using his reputation as a platform to work with young people and the community: to give back. In an interview with Pacific Beat Street ${ }^{37}$, Michael Jones speaks of the kaupapa $a^{38}$ or belief that it takes a village to raise a child. Jones adds he grew up without a father and that he was raised by his mother, aunties, uncles, cousins, neighbours so that it was a whole community that raised him and who consequently, he owes his success to (in Pacific Beat St, 2010).

This idea of "giving back" is central to many a Pacific Island athlete's ethos: the praise they receive is ultimately owed to those who helped form who they are. This translates to Samoan athletes who feel that when given the opportunity to succeed at a high level they not only represent themselves, but their family and their village as a whole. Their success is shared between them all and showing respect to one's roots is important to these athletes, especially for those born and raised in New Zealand with Samoan or PI background. A specific and common way of paying your respects to your Samoan heritage is by giving back to those that made you. ${ }^{39}$

However, it is this act of putting one on a pedestal that I believe creates tension and pressure with young Samoans today; the constant burden of failure that lurks behind the success. In the same way success is shared between the family and

\footnotetext{
37 'Pacific Beat Street' was a NZ Television programme run by young Pacific Islanders showcasing PI talent and current events across NZ and the World.

${ }^{38}$ Kaupapa in the context of this discussion refers to the topic or purpose. It is said to have translated from the kaupapa of the main body of a Māori cloak, referring to the main points or parts.

39 This idea of giving back to those who aided your success is found in other Pacific Island cultures such as the concept of whanaungatanga in Māori culture.
} 
village, failure and the embarrassment associated with it is also shared with all. In his autobiography, Living the Dream, Mils Muliaina ${ }^{40}$ recounts his early playing years for the Auckland NPC team. Along with the rugby was the alcohol which back then it seemed came hand in hand with being a professional rugby player (Muliaina, 2009). He felt part of the team because of it - this culture of fitting in through alcohol, socialising and having the older guys looking after the younger is still a large part of club rugby culture today. Muliaina details an evening getting intoxicated and urinating in a public bar. The media got wind of it and Muliaina made front page headlines the next day for all the wrong reasons. He received a fine and suspension from the Auckland Rugby Union. Two revelations stood out from this incident for Muliaina, the first and hardest part of it all was for him to tell his mother:

I could hear the disappointment in her voice $[\ldots]$

I think she felt let down because she hadn't brought her son up like that, and certainly not to do dumb things like that (Muliaina, 2009: 61).

Muliaina speaks to a generation of Samoans born and living in New Zealand; disappointment and embarrassment that is shared not only by you but your mother and your family is a tough pill to swallow. The incident was a turning point for Muliaina, he resolved to never embarrass or disappoint his mother again. In this same vein, when asked the one thing his mum would be proud of, Jones is quick to answer that he always put God first in his life which was his mum's life motto. His Christian

\footnotetext{
${ }^{40}$ Malili "Mils" Muliaina is a current professional rugby union player for San Francisco in the US PRO Rugby competition, he most recently played for Zebre in the European Pro 12 competition. He carved an illustrious career in New Zealand Rugby over 25 years and was only the second player to earn 100 caps for the All Blacks.
} 
beliefs were well known in that he refused to play on Sundays. You represent your family in everything you do, on and off the field.

\section{Bridging the gap between the professional and "semi-pro" eras}

The second revelation, stemmed from the fact that Muliaina had to take counselling sessions. This gave him an opportunity to talk to someone about his life, his struggles and not just about rugby:

There were a lot of guys who had been in the semi-pro era when I made the Auckland team. Those older players grew up when the game wasn't pro, so there were two different environments. You had to develop the attitude of those guys who'd been there the longest and that's probably where I got caught out a bit. You played hard, you trained hard, you drank hard. And if you had any problems you had to go away and fix them yourself (Muliaina, 2009: 62).

Seeing a counsellor gave Muliaina someone to confide in. To help confront his actions, accept that it came down to this rugby lifestyle and being aware of the things that not only were causing him to act that way but weren't helping his cause (Muliaina, 2009). This dilemma of not having someone to confide in contributes to the negative aspects of rugby culture, issues of masculinity that real men don't need help and the stigma of needing help itself.

With the professionalization of rugby in 1995, an interesting aspect to consider is the fact that if Williams played in today's era, he would have been a rich young man. Professionalism brought a much-needed injection of funds into areas such as the Manu Samoa National Team, to keep them from switching codes to Rugby League where their Pacific counterparts were already earning pay. However, it also brought rules and regulations which for Pacific Island players meant they 
could not ply their trade in the 'Super Rugby' competition, arguably the best rugby competition in the World. New Zealand Super Rugby teams are only allowed to contract two non-eligible All Blacks in their squads. The dual-nationality players who want to make the All Blacks but also qualify to play for a Pacific Island nation are caught in a tough spot. Those who do not make the All Blacks who then want to play for their Pacific heritage run the risk of losing out on a Super Rugby contract due to the tight restrictions on non-eligible All Blacks, which they will become if they commit to another country. Not only this but non-eligible All Black super rugby players are on restricted pay too.

Rugby journeyed from a perspective of integration and assimilation to becoming a central part of Pasifika families and communities. The professionalism of rugby developed the sport into an avenue of financial success and, in turn, family success for Pasifika families; in the dreams of young Pacific hopefuls now lay a very real financial benefit. Unfortunately, it is on this note that the discourse surrounding the Pacific Body is brought to the fore; the subsequent examination that it is a commodity to be taken advantage of and discarded once used. As Peter Horton ${ }^{41}$ notes, Pacific Islanders are now one of the most "prodigious" and "predominant" ethnic groups to migrate globally for rugby:

They've become 'exquisite products' and prime commodities, as they are now a major force in the leading competitions worldwide (cited in Horton, 2012).

\footnotetext{
${ }^{41}$ Peter Horton is the author of Pacific Islanders in Global Rugby: The Changing Currents of Sports Migration. His work illustrates the role rugby plays in Pasifika communities focussing on how and why it has become an avenue for potential success, aspiration and social advancement for Pasifika people.
} 
These include the top French, English, Italian and even Japanese competitions. The result of this is evident in the findings of Adam Perrin" ${ }^{42}$ who states that "a third of the players involved at next week's (2015) Rugby World Cup can trace some of their ancestry back to the Pacific Islands" with the World Champion All Blacks alone contributing nine players with Pacific Island roots (cited in Rees, 2015). Not only is the impact and presence of Pacific Islanders felt in the top teams of rugby union and rugby league, but they're similarly prominent in the sporting arena of the National Football League $^{43}$ (NFL) in the USA:

Over 70 players in the NFL are of Polynesian descent. There are 30 players from American Samoa in the NFL and more than 200 play Division I NCAA Football. A Samoan male is 56 times more likely to play in the NFL than an American NonSamoan (cited in Steinberg, 2015).

Their impact is global, but for every success story the question lingers of how many failures are on the other end of the spectrum. How many hopes and dreams are shattered by clubs and organisations doing their part to create a successful business? Every season, clubs from all over the world snap up young up and coming talents from Pacific Island such as Samoa, Tonga and Fiji. Dan Leo ${ }^{44}$ speaks on the subject from a former player's and Pacific Island, (specifically Samoan) perspective and his

\footnotetext{
${ }^{42}$ Adam Perrin is documentary film-maker whose film "Pacific Warriors" explores the impact and influence of Pacific Island rugby players on the rugby world.

${ }^{43}$ The National Football League (NFL) is the premiere American Football league in the world. Consisting of 32 teams spread across the United States of America, it is the highest level of American football in the world.

${ }^{44}$ Dan Leo is a retired rugby professional. He carved a name for himself representatively for the Manu Samoa as captain playing 39 tests from 2005-2015.
} 
voice has emerged as a voice for the PI community. His cause remains that the poaching of these players impacts the young players negatively, while clubs would argue it is in fact good business (cited in Keane, 2015). Allegations of "crooked" agents, player poaching and concerns over the release of players for important tournaments have damaged the global game and its reputation. Leo sheds light on the fact that while the big contract Pacific Island players are the lucky few whose cases do get recognised, there are "just as many who are on less than no money in places such as Romania” (cited in Keane, 2015), nevertheless:

Teams are catching on and they realise the benefit Pacific Island guys in their sides will bring but there's no protection for some of these young players. [ ...]

These guys are being taken advantage of big time, by some of these smaller unions for next to no money (cited in Keane, 2015)

To help counter this "poaching", a rugby academy has been set up in Samoa by former players Mahonri Schwalger ${ }^{45}$ and George Stowers. ${ }^{46}$ This academy acts as a platform for young, up-and-coming Samoans to showcase their abilities to hopefully achieve scholarships to schools and clubs abroad. However, a worrying trend is the formation of two academies in Fiji by major French rugby clubs 'Clermont' and 'Brive' in an effort to secure a steady flow of young and local talent (Keane, 2015). While these academies are based in the islands, the reality is that to earn money these players eventually have to take their game overseas and the positives of these French

\footnotetext{
${ }^{45}$ Mahonri Schwalger is a Samoan International, Provincial and Super Rugby Representative whose career spans 15 years in both the Southern and Northern Hemispheres.

${ }^{46}$ George Stowers is another Samoan International rugby union player who currently plies his trade for Ospreys in the RaboDirect Pro 12 Competition.
} 
academies become evident. The players exposed to the academies are already a step ahead in that they can speak decent French and are "dual-qualified so they can either play with Fiji or they have the choice of playing with France" (cited in Keane, 2015). The professional landscape of rugby is rugged to say the least; players are expected to be equipped with an understanding of the business from a young age and in reality they are not. They are, however, conscious of the pressures of family and providing a level of comfort and support for them and ultimately, the necessity to forge a living playing rugby. Williams, a product of the amateur era of rugby quips on the reality of playing professionally:

Professional rugby can be over in a flash, you know, you get a serious injury and suddenly your career's over and if you've got no training for anything else, you've really got nowhere to go (cited in Clark, 2013).

The potential of failing as a professional athlete is one of the many fears and realities that many young up-and-coming stars face today. There are two fronts on this issue; the first correlates with the fear of being injured or showing pain and losing the image of the 'hard man', and the second is the actuality of being injured itself and rendering yourself unable to perform. Parks notes that rugby uses the values of courage, strength and "mateship" to embody the best of New Zealand male characters. Rugby was "about suppressing emotions, overcoming pain, taking terrible risks and taking them like a man" (in Park, 2000: 448). With the professionalism of Rugby League and Union, the capital injected into different clubs, infrastructures, facilities and programmes has significantly upgraded not only in the development of young sports stars but also advanced the prevention and management of injuries. Nonetheless, the fact remains with these heavy contact sports, injury is exceedingly common, almost inevitable. 


\section{The Injury Dilemma in Contact Sports}

The focus turns now to Mosese Fotuaika, the aforementioned athlete and a hard-working young man whose journey not only embodies the reality of being a rising rugby league star but reflects the many stories of young Pacific Island boys struggling to make it to the big time. Fotuaika and his family moved to Australia from Gisborne when he was fifteen, partly for him to pursue his career in the sport. At nineteen, Fotuaika signed a contract with the West Tigers and after two successful years playing for the juniors it became just a matter of time before his selection into the first grade was made a reality: "That was the ultimate thing for Mosese, to debut in the NRL” (cited in Cadzow, 2013).

In his final training before the start of the season, Fotuaika plugged through his round of exercises on the bench press. He routinely benched up to $160 \mathrm{~kg}$, that day only 90. In an instant he gasped and as his partner during the exercise notes, "it was a split-second thing... he went to lift and then he couldn't" (cited in Cadzow, 2013). The physiotherapist later attempted to comfort Fotuaika as he confirmed he had torn a pectoral muscle and faced up to several months on the side-lines. Fotuaika's body was found later that evening in his garage by his partner when she got home from work.

A promising young hooker, Alex Elisala, played sixty-nine games for the North Queensland Cowboys' U20s ${ }^{47}$ team over the course of two years. In 2013, he

\footnotetext{
${ }^{47}$ The National Youth Competition (NYC) is the Under 20's NRL premiere competition that runs together with the Senior club teams. Alex Elisala played for the U2os North Queensland Cowboys team, a junior team to the NRL North Queensland Cowboys.
} 
got the call up as a full-time member of the senior squad, giving him the chance to make a name for himself as a professional. Two months after the passing of Fotuaika, Elisala made his international debut for the Toa Samoa International League team alongside good mates Antonio Winterstein and Kalifa Fafai Loa. A week later, Elisala was found on the balcony of his hotel after attempting to take his own life. His family made the decision to turn off his life support in the days following (McDonald, 2014). Fast-forward to early 2015, the suicides of Regan Grieve and Hayden Butler, two rising rugby league stars on Australia Day shocked the country (Lutton, 2015). A third occurred a couple of months after, nineteen-year-old Francis Winterstein, whose brother plays for the North Queensland Cowboys, winger Antonio Winterstein.

These players, along with many young Pacific Island sportspersons, unknowingly fall into the perception that their one avenue for success is on the sports field, they are nurtured their whole lives to fulfil that dream, and take on the added pressures of providing for and representing their family on their own. Compounding this are the idealistic prospects about their futures, once they've entered the semiprofessional arena. For young rugby league players, the U20s competition represents a stepping stone to the top grades. At a young age they are exposed to the life and environment of a professional athlete and there is a very real fear that:

... a generation of talented young Islanders may have unrealistic expectations about their futures because of the high profile of the NRL's under-20s competition which has featured matches twice a week on pay television (cited in Barton, 2013).

The players put their time and effort into their chosen sport and before they have even made any team the pressures have already mounted on them. These pressures 
often go unnoticed and affect a player more than any physical injury could. As in the case of many young Pacific Island athletes, their first and only choice is sport:

Fotuaika had focused so single-mindedly on becoming a professional footballer that he had acquired no other qualifications (cited in Cadzow, 2013).

These suicides highlight the need for a shift from solely focussing on the development of player's talents and abilities to an emphasis on the overall welfare of players. A close friend of Mosese Fotuaika, Ben Murdoch-Masila, adds to the discussion on Pacific Island athletes and their struggle with opening up on their "fears and problems":

When I first came into NRL and first grade training, I held back a bit. I didn't really talk to anyone for the first six months... Some Polynesians tend to hide their feelings a little bit. They hold back... A lot of pressure is building up in their own minds... With my mate Mosese, he had a lot of pressure ... feeling as though he had to give back to his family. There's a lot of things probably running through his head and I think it just got the best of him... (cited in Barton, 2013).

Such a shift would reduce the stigma of being injured and losing the "hard man" image. However, it is these unseen pressures, particularly in Pacific Island players, that are now the primary concern for clubs and sports organisations. These are young players, leaving school and being thrust into the professional sports environment where their every move is monitored and scrutinized by the media. To add to that, they are held up as role models for kids growing up in New Zealand, Australia and the Pacific. Horton adds to the discussion on the welfare of young players: 
... in the big business that is modern rugby, young Islanders are sometimes regarded as commodities rather than as vulnerable human beings (in Cadzow, 2013).

In contrast to this:

If you're making a lot of money out of these kids, you've got to develop them holistically... You can't just think about their side-step techniques (in Cadzow, 2013).

Part of this problem comes down to the nature of the professional realm in the sport and the specific pressures it places on the players, particularly the financial side. Joel Luani, whom Fotuaika partnered with during his last training session, talks of Fotuaika's distress about the injury and how he believes this is what added to his final predicament. Luani notes that not only would Fotuaika lose the opportunity to add match fees on top of his contracted salary, more importantly it would be less likely that his club or any other club for that matter, would be interested in re-signing or signing him if he wasn't actively playing and proving himself (Cadzow, 2013). Unfortunately, that is the nature and reality of professional sports.

\section{Concussion discussion: The one no one wants to have}

Rugby is a tough sport, whether Union or League, men are afforded great status if they play and even more so if they play on through injury. Headlines will read "How I beat the pain to play in the World Cup final" (in McCaw, 2012), if a player is lucky they might make a top list, "14 most ridiculous injuries players have played through" (in Russo, 2015) and if they are fortunate enough, they can score a full front page article the next time they play through an injury: "Broken foot nothing on fractured rib - McCaw" (in Knowler, 2014). Legends are born, stories live on forever and articles will read: 
Rugged Englishman Sam Burgess will go down in rugby league folklore after playing the NRL final with a fractured cheekbone and helping Souths to a treasured title (cited in Johnston, 2014).

There are many examples to date of sporting "heroes" who pushed their body to its limits on sporting fields across the world. Wayne "Buck" Shelford, in a story most Kiwi kids grew up with, got caught in a ruck twenty minutes in and "had his scrotum ripped open, exposing his testicles" (cited in Johnston, 2014). Shelford then ordered the team physiotherapist to stitch him up and promptly returned to the field. In a harrowing turn of events, it took a knockout blow further down the match for Shelford to be taken off the field as he recounts:

I was knocked out cold, lost a few teeth and had a few stitches down below. It's a game I still can't remember... I don't really want to, either (in Johnston, 2014).

Words used in these articles to describe these men include "champion", "bravest", "hard-as-nails" and "hero". In Rugby League, nothing compares to "quite possibly the bravest performance in the history of the game" (cited in Russo, 2015). It was only a couple of minutes into the 1970 National Rugby League Competition Grand Final when South Sydney captain John Sattler endured a broken jaw after a vicious punch from one of the opposing forwards. Disregarding the appeals of his team to leave the field, he carried on to lead South Sydney to victory. Sattler embedded himself in Rugby League lore when he, barely able to stand, famously uttered to Mike Clearly "hold me up, don't let the bastards know I'm hurt" (cited in Russo, 2015). 
Children all over the world in rugby circles grew up with these stories including, Shontayne Hape ${ }^{48}$ whose stance on concussions growing up in New Zealand, is no different to many young players today:

Growing up playing league in New Zealand, everyone got knocked out at some point. Everyone got concussed. I can't think of a single guy I played with who didn't. You just got up and played on. We were told to be Warriors. It's the nature of the sport. Harden up. That was the mentality. I was brought up with that (cited in Deane, 2014).

In January, 2014, at the age of 33, Hape retired from Rugby Union after it was revealed he had suffered around twenty concussions and black-outs before he had even started his final campaign with London-Irish in 2011. Those twenty or so concussions were nothing to what was to come in the latter stages of his career. This "harden up" attitude is part of the overall issue with what 'masculinity' represents in rugby culture which in turn is aligned with New Zealand society. There have been many parallels running throughout this chapter discussing the impact injury concerns have had on young athletes and their professional careers. The major difference and most damaging is the fact that concussions can be hidden from team mates, family and even coaches. The internal pressures that young players face when coming to terms with concussions are exacerbated further by two major external factors. The pressures of the professional world; the coaches needing to provide a

${ }^{48}$ Shontayne Hape is a retired dual-code rugby superstar. He played rugby league for the New Zealand Warriors and the New Zealand International team before moving overseas to play for the Bradford Bulls where he forged his name in the English competition for six seasons. Hape made the switch to Rugby Union playing for Bath Rugby Club and successfully made his debut for the England Rugby International side in 2010. 
successful team for their fan base and players needing to play to make bonuses to provide for family. Compounding these pressures are the physical effects of repeated concussions; the headaches, memory loss not to mention the long-term effects. Shontayne Hape lived this life, he pushed through his whole career brushing aside these head knocks, unfortunately, as any young star would, attempting to make a name for themselves in the professional sporting arenas.

The facts are steadily coming in, regrettably, without much of a receptive audience from the people who really need it. Concussions can occur in any sport however rugby athletes are eighteen times more likely to sustain a concussion than the average athlete across all sports. Furthermore, the concussion rate for every minute of athletic exposure (AE) for rugby is alarmingly higher than any other sport including American Football (Rappaport, 2015). Notwithstanding, the short-term impacts of concussions on players' every day ability, the long-term effects are the ones many players are not aware of. In the Coroner's Court in Dublin, an amateur rugby player, whose family donated his brain for research, found that his premature death was directly related to repeated head blows sustained during his years on the rugby field (cited in Fanning, 2014). Two neuropathology experts cited that Kenny Nuzum, a prop forward with a rugby club in Dublin, passed away in March 2014 due to chronic traumatic encephalopathy (CTE), the disease which is the focus of the 2015 film, Concussion and that to some extent is alluded to in the Television programme Ballers. The film Concussion, based on true events, is set in 2002 and stars Will Smith as Dr. Bennet Omalu, a Nigerian forensic pathologist who in his research on the brain 
of a deceased American Football Player, Mike Webster, ${ }^{49}$ discovers the brain degeneration disease linked to repeated head knocks in the sport. The disease was commonly associated with NFL players until the death and coroner's report of rugby player Kenny Nuzum and revelation of chronic traumatic encephalopathy (CTE) linked to his brain. Ballers is a considered from the perspective of current and former NFL players, starring Dwayne “The Rock” Johnson ${ }^{50}$ as Spencer, a retired player turned financial manager for young up and coming players. Through the use of flashbacks, it becomes apparent that Spencer has concerns over his own wellbeing showing symptoms of a brain injury from repeated blows to the head during his years as a player. This is explored further in the episode "Heads Will Roll" (Ballers, 2015: ep. 4). The international exposure of these issues reinforces how sports injuries of this nature, in becoming part of popular culture mediums, are now relevant to broader audiences but more importantly mainstream audiences. Not necessarily impacting change upfront but at the very least creating a forum for discussion in the everyday lives of young people and crucially in the circles of the sportspeople themselves.

As mentioned with Mike Webster, the devastating disease that is CTE has subsequently been linked to the brains of a number of deceased American football players (cited in Schofield, 2015). CTE was once well known as dementia pugilistica,

\footnotetext{
${ }^{49}$ Mike Webster was a four time Superbowl winner and a sixteen-year veteran of the National Football League playing a total of 245 games for two franchises. His death in 2002 and subsequent research on his brain helped the NFL take responsibility for their role in not providing adequate information on the risk of brain injuries.

${ }^{50}$ Dwayne "The Rock" Johnson is an international celebrity who made a name for himself in the Professional Wrestling arena before taking the leap into Hollywood;
} 
the boxer's disease, however, Dr Willie Stewart ${ }^{51}$ notes that while it used to be common in boxers exposed to high levels of head injuries; he has now seen this type of exposure in rugby players. One of the biggest developments in the concussion discussion came in 2015 when the National Football League (NFL) finalised a settlement worth $\$ 1$ Billion USD to more than 4,500 players for not disclosing the dangers of concussion related head trauma (Schofield, 2015). Whilst there remain systems in place to measure concussion symptoms and stand down periods in rugby, the fact remains these tests are either run by rugby clubs themselves or at the discretion of the players themselves. Questions arise about the welfare of players facing life-threatening concussion injuries, questions pertinent to the lives of young Pacific Island athletes and athletes in general in contact sports. The onset of dementia and other effects of concussions such as memory loss, short tempers leading to isolation and depression are the consequences of repeated concussions rarely heard about by young players. What drives a young athlete to hide repeated concussions? The overall attitude towards concussions from the players themselves is a determining factor in the future of this discussion. As Wales winger George North explains, this is still a game for hard men:

At the end of the day, it is rugby, isn't it? ... It's not table tennis, or tiddlywinks. It is a contact sport and you are going to get some bangs (cited in Kitamura \& Rossingh, 2015).

\section{Conclusion}

Fa'a Samoa a pillar of Samoan upbringing: Spiritual more than the physical.

${ }^{51} \mathrm{Dr}$. Willie Stewart is a neuropathologist who has done extensive research into the links between rugby and long-term brain damage. 
Pacific Island people take with them a certain understanding concerning their cultural practices and discourses not only in their career decisions but in their daily lives. For athletes of Samoan descent, their cultural discourse is fa'aSamoa, which has "elements of spiritual significance and connection with birth place, family, tribe and cultural wellbeing" (Panapa \& Phillips, 2014: 1379). The central elements of fa'aSamoa are formed around cultural ideas of aiga (kin group), made up of tino tasi (one body) and toto e tasi (one blood), and the values of alofa (love and compassion), fa'alavelave (obligations), fa'aloalo (respect) and tautua (service). These tenets form the social structure of Samoan society itself (cited in Panapa \& Phillips, 2014). It is important to understand this particular cultural discourse because it informs and shapes the way these young players think and make choices and provides a certain understanding of Pacific Island, particularly Samoan, experiences in today's society:

... the goal of aiga or kin group through the division of power, status, labour and expectations is a motivational force to uphold family status. For Samoan people, members of an aiga inherit and identify from birth. Learning appropriate behaviours is of primary concern to the aiga because failure to understand these social mores implies that one does not know who one is and will consequently bring shame on the family (Panapa \& Phillips, 2014).

It is important, however, to distinguish that Samoan families migrate and integrate with many cultures and ethnic identities. Nonetheless, the focus of this thesis will remain with the Pacific Island athletes whose discourse of fa'aSamoa is still central to their identity. For many young Samoans living or born away from their home nation, while they may not have a complete understanding of fa'aSamoa because of their different upbringing and life experiences, they still exhibit tenets of fa'aSamoa and its values. In a similar vein with an earlier quote, an NRL player with the pseudonym Lisone, acknowledges aiga when he joined the NRL and laments: 
When I sign a contract I'm signing not just my name ... ['This Samoan name’] is my family so like I need it and that's really important ... I need to get that right ... I want to be able to help my family out ... it will help my brothers and sisters go to school and stuff, helping my parents with their business ... that's what this environment has done for me (cited in Panapa \& Phillips, 2014).

He frames his decision of playing rugby league in the context of the "aiga" as defined by Samoan culture. In the same way, he exhibits the beliefs and duties of fa'aSamoa that give him a reason to play. Many young Samoans, athletes or not, are mentored by their parents, who pass down knowledge of fa'aSamoa both formally and informally throughout their lives so that they may uphold levels of fa'aSamoa in every respect of their own lives in future. To do so is to give back that respect and honour to one's parents. Samoan athletes find they can achieve levels of fa'aSamoa that their parents can be proud of when they attain professional status. Not just the financial significance of bringing prosperity to the whole aiga, but even more the spiritual and emotional, as "Ateli” another NRL player admits:

I'm the oldest so I've got to set a good example for my brothers and sisters ... my little cousins as well so just trying to lead the right path. Trying not to put myself in bad situations and definitely my family I've got to put them first now, so I'm just trying to maintain that . . because I've made it to that level. It's been good my dad really put that responsibility on me, so I took it with both hands (cited in Panapa \& Phillips, 2014).

The ideals and attitudes placed on and practiced by men and society are the constructs of years of ideas of masculinity in New Zealand which are further compounded with a search for culture, acceptance and identity for young Samoan males today. The complexity of this issue goes beyond just the physical; to lose a 
contract, to get injured, to be physically unable to perform, succeed, or even make it on the professional stage is not only a financial loss; but moreover a mental concern and a spiritual loss. These Samoan players do not just feel the loss and disappointment of their parents, they lose a sense of fa'aSamoa, something they are taught sits at the core of every Samoan and their aiga. 


\section{CHAPTER TWO}

The Spirit realm in Blackout:

\section{Discussions on the unseen and the internal}

[Va is $]$ the space that appears and disappears - and that's the whole space that holds us together as a group and gives meaning to all of us as individuals.... What we think of the empty space between us is what links us (Sharrad, 2003: 19).

This chapter will focus on the initial constructions of the non-realist elements of Blackout which dramatically express the internal and psychological realm of characters, directly or indirectly, affected by concussions. These interpretations are a product of previous provocations mentioned in the Introduction, influenced by Postdramatic theatre. The emphasis of the thesis will turn to considerations of the Samoan notion of $V a$, a liminal realm drawn from Samoan cosmology and how the Va can operate as a dramaturgical but also thematic and spiritual element to the play. The discussions around the va and the Postdramatic will inform the development of the spirit world and help answer a key question surrounding what the 'Spirit' realm of Blackout represents. The spirit realm in Blackout encompasses spirits that inhabit both the spiritual and real world. They speak through actions and words, however their form is inhuman. This chapter is largely a development of the spirit world expanded from the rehearsal, research and production and reflection processes which serves to define the world and offer new meanings and possibilities for the spirit world and, in doing so, align the play with my central thesis questions. 


\section{Clarifying the projects: The Technical Direction Project}

As mentioned in the introduction, over the course of 2015 and in collaboration with Ian Lesa, a Master of Theatre Arts Part II student, Blackout was put through two 20-minute workshop seasons, one in May and the other in October of 2015, each with their own focus and objectives. It was then a part of Playmarket's Brown Ink clinics, going through three workshops before finally being fully realised in the Development season of Blackout staged in December, 2015.

The first workshop stage was the Technical Direction Project. This aspect of development focused on the devising of the 'Spirits scenes in Blackout, specifically to realise the potential of the physical movement and aesthetic form of the spirits and the world they inhabit. These aspects were explored to identify the spirit worlds relationship to the real world in the narrative. The Project had four showings in May, 2015 at the Whitireia Performance Centre on Vivian Street, Wellington City (see fig.

7). The areas of focus for this project were on the non-human theatrical elements as primary conveyors of meaning, these were aspects of lighting, scenography and costume. Consequently, some of the aspects considered were technical in nature and did not directly affect the script. It is important to clarify the projects chronologically in order to understand the journey of Blackout. More of the rehearsal and performance discoveries will be discussed in the third chapter.

\section{The physical and spiritual nature of the Samoan person}

In Samoan culture, the Samoan individual is understood to be itu lua, translated to be both spiritually and physically natured. The expression itu fa'aletino is rendered the physical realm of the human, whereas, itu fa'aleagaga refers to the spiritual (Tamasese et al., 2005). This notion has a significant impact on the spiritual 
beliefs of Samoan people. Notably, the spiritual and physical realms are interdependent; it is essential to consider them together when concentrating on the whole person. What binds the two worlds can be seen as the va, a notion from Samoan traditional culture that will be expanded on later in the chapter. This discourse of the spiritual versus the physical realm offers a possibility for the spirit world of the play to have a real impact on the real world, and vice versa. In times of distress, confusion or content, the spirit world has the opportunity to not only reflect but to act upon the real world to enact change. Interestingly, in part due to the feedback process, this analysis was already considered when an audience member questioned the bearing the physical realm having on the spirit.

As mentioned in the Introduction, the exploration of a spirit world began in 2014 in an Honours paper (THEA 406: Scriptwriting) during an exercise in which we were challenged to write a short piece that reflected themes of the Postdramatic. The notion of Postdramatic theatre was coined by Hans-Thies Lehmann, author of Postdramatisches Theater. The translation of this book into English gives the best understanding of the Postdramatic. Moving writing away from ideas surrounding the dramatic and all the elements traditionally used to create dramatic writings, and into a world bearing no characters, no time, no plot. The question asked was, what is drama? In short, it can be defined by two prominent processes, "it represents and it structures time” (cited in Barnett, 2008: 14):

Representation corresponds to Aristotle's definition of mimesis, the imitation of an action. Actors represent characters, props represent objects, sets represent locations and so forth (Barnett, 2008: 14) 
Problems arise in that representations in drama are both biased and selective which reduces that which is being represented because it is far more complex. This complication is present in my depiction of the real world of Blackout. The Postdramatic proposes theatre moving past dramatic representation, whereby performance practices attempt to present matter rather than "posit a direct, representational relationship between the stage and the outside world" (cited in Barnett, 2008: 15). This definition is key in the development of Blackout because of its use in the spirit world. While the real world narrative of Blackout is a representation of the world we live in, the Postdramatic influence in the spirit world offers words and movements that evoke their own meanings of the world and not meaning assumed or assigned by the writer. This definition of the Postdramatic also finds ties to the discourse of the Va in Samoan traditional and contemporary culture. This connection will be examined later in the chapter. Another aspect of the Postdramatic is the unstructured nature of the text:

The textual basis of Postdramatic theatre is only a small part of the phenomenon. The words themselves, one of the dominant elements of the dramatic theatre, become just another element in a theatrical mode that militates against hierarchies in performance (Barnett, 2008:16)

Reflected in my earlier work (see Fig. 4) in week 2 exercise, many Postdramatic texts aim to suspend linearity or at least present material that is not disturbed by action but deals with circumstances or conditions. It is important to acknowledge that Blackout fuses the work of dramatic writing with the Postdramatic and that the discoveries in this chapter reflect only a certain aspect of the writing, specifically the spirit world scenes and not the whole. My writings centred on a subject I felt strongly about, that of concussions, the stigma surrounding head injuries and the 
fact that rugby culture in New Zealand and contact sports such as rugby union, rugby league and American football, give little or no attention to this dilemma.

\section{harden (här'dn)}

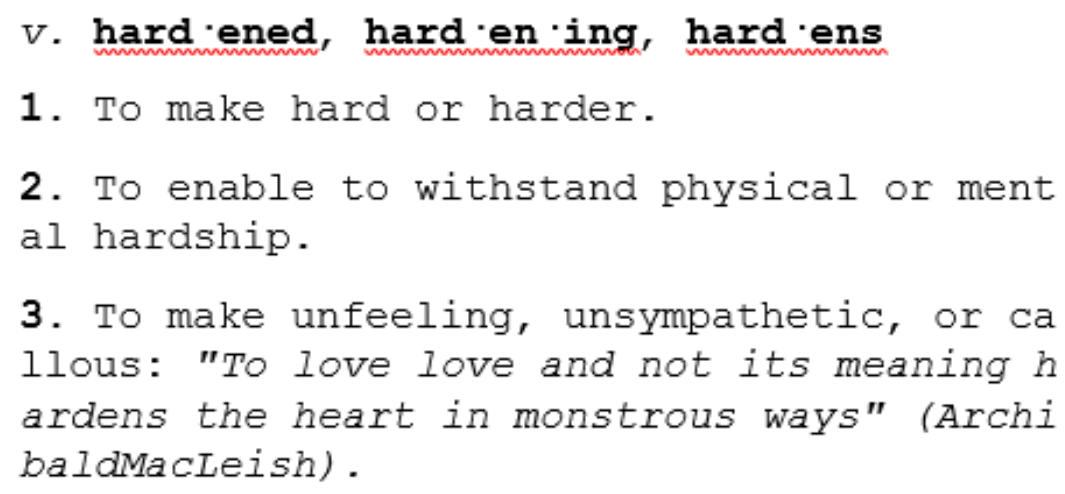

4. To make sharp, as in outline.

5. To protect (nuclear weapons) by surroun ding with earth or concrete.

v. intr.

1. To become hard or harder.

2. To rise and become stable. Used of pric es.

3. To become inured.

Fig. 4: Excerpt from THEA 405: Week 2 Exercise.

The early draft illustrated the effects of the injury and the stigma of head injuries in rugby culture from perspectives of the affected. In the excerpt from the week 2 exercises we see deliberately placed words, feelings, definitions of rugby terms (see fig. 4), short dialogues and internal thoughts all together to not explain or create narrative but to simply express and present the circumstances. When delved into further, the aims of the scenes reflect on feelings of hopelessness and loss that relate to concussions and the stigma surrounding them. In these early writings the 
intentions and results formed the basis of the world, assuming no meaning but simply presenting. As the term progressed these ideas were put through further development in the week 3 provocation alluded to in the introduction: to create another short piece using the stage as a metaphor. The challenge was to remove myself from literal mindedness, using distinct theatrical expressions and metaphors to convey certain ideas and events. Again, shifting away from standard dramatic text, the key progression here was to use the stage to portray a certain psychological dimension beyond just displaying human behaviour; an actor showing sorrow, hurt or pain. The stage therefore became a cosmos for expression and the idea for the spirit world was to help inform the audience firstly of the internal and unseen battles and secondly, how these influence people and communities they inhabit. The purpose of Blackout was to generate a commentary on these social and cultural issues within the communities they effect.

The spirit world transformed from a commentary on rugby culture into the exploration of the psyche of a character dealing with loss. Creating a theatrical expression of loss or losing someone narrowed down to an emotional state of loneliness; a sense of 'what if for themselves, whether they could have helped; a longing to see or hear a lost loved one again; feelings that nothing will be the same again and finally, a feeling of helplessness encompassing sadness and anger. I needed the spirits to convey these feelings using the stage as their tool for carving and eventually these feelings would become markers for each character; at one point in the play they feel these emotions. The idea of the Spirit World enacting the Postdramatic text during one scene and portraying the stage as a metaphor the next informed the final piece of the puzzle: the dramatic story. Blackout became a story that presented a world held up for ridicule and commentary on rugby, New Zealand and Samoan culture. As the story and characters began to unfold, so too the spirit 
world found room to unfold, physicalizing the psyche of the characters affected in that world. Aspects of the play would cover concussions and the effects it had not only on players themselves, but the people surrounding them; an issue that not only resonated for myself but was topical in the context of today's problems in professional contact sports. For Elle, her world is in turmoil when her attempts to stop Sua from playing are unsuccessful; she experiences this loss. These early concepts and creation of the Spirit World became important as further discoveries connected the spirit world as not just a physical representation of the psyche, but a very real relationship between knowledge of oneself and acceptance of oneself.

\section{Exploration into Time and Distance}

The early exploration of the Spirit World dealt with loss and turmoil, extending to ideas surrounding separation and distance from familiarity. These concepts are reflected in the story of the play but are also representative of the struggles of young Pacific athletes of today, as mentioned in Chapter One. There is distance in Sua's relationship to his family, his home and through this context the idea encompassing the search for a better future - the great Kiwi dream - formed. Many young athletes leave home to pursue a career in both forms of rugby: league or union. For the development of Blackout, this search and subsequent problems needed to be encapsulated in the writing; Sua being drawn to the city life in search of money and prosperity. Often with these young athletes, again using Fotuaika as an example, the search for success comes with a life far removed from their homes or familiarity: the unnatural nature of the concrete jungle and city landscapes; busy streets filled with people, cars, buses, trains; all that comes with the fast life. The creation of this busy world in LIFE (Scene 2, Blackout), however, touched on the metaphorical sense of being overwhelmed: the fast life being a bit too fast, too 
uncomfortable and overwhelming. The importance of the Spirit World is emphasized in its role to not only reflect the real world events of the characters, it also acts as forum to physicalize the internal; linking the stage with the spirit world and traditional Samoan ideas of the cosmos.

\section{Connections between the spirit world and traditional Samoan values}

This connection becomes evident when taking into consideration the Samoan concept of Fa'asinomaga, a model bound to Samoan understanding of designation and identity in fa'aSamoa. This designation of fa'asinomaga gives a sense of belonging to Samoa and fa'aSamoa and expresses that every individual is entitled to a designation (Efi, 2008:157 \& 166). As all pieces in the cosmos belong on the stage, so too the characters have with them a sense of belonging in their world. What validates that belonging is what each character believes in and stands for. This is an interesting aspect to consider for Blackout, and for Sua and Jacob's story particularly; exploring their struggles to connect with an aspect of fa'aSamoa that brings a sense of pride to their family and a sense of "fa' asinomaga", or identity. This search is an important aspect to consider for young Samoans living in New Zealand today: the constant struggle between the traditional aspects of belonging and identity against the Westernised settings of $21^{\text {st }}$ Century New Zealand life: the life of a second generation, New Zealand-born Samoan. I do believe the Spirit World can exist to inform or express that strain. A report on the 'Status of the Child in Samoa' by the Samoan Government explains fa'asinomaga as "the genealogical identity of a Samoan child, which forms a fundamental part of every child's life" (cited in Government of Samoa, 2005). Furthermore, it establishes that:

[...] in Samoa, all children have a fa'asinomaga (Samoan identity) regardless of the circumstances of their conception. A child's fa'asinomaga is established through 
kinship connections by blood, marriage or adoption and where they belong in terms of his/her family (Government of Samoa, 2005)

There is an indication here that fa'asinomaga can be found elsewhere than in a village, if so, what then does this identity represent? I believe that while story can represent real life, the Spirit World can expressively - or theatrically - reflect this dilemma. As mentioned in the previous chapter, the idea of pursuing a professional sports contract in order to gain the respect, admiration and a level of fa' aSamoa that Samoan parents can be proud of now becomes a gateway to fa'asinomaga, to one's identity and belonging. A new discovery and further development for Sua's character in the plot is that he has intentionally, or by fate, moved away to pursue the contract and career for the very reasons stated above.

Tui Atua Tupua Tamasese Efi ${ }^{52}$, explains the significance of fa'asinomaga in the beliefs of ancient and contemporary Samoans; that Samoan people do not live as individuals but as beings integrally linked to their cosmos who share divinity with not only their ancestors but the land, seas, and skies (cited in Efi, 2003). Whilst, the characters of Blackout, Sua and Jacob again particularly, deal with issues regarding their head knocks as individuals, the Spirit World can now be seen as what binds the two together in their journey within the broader cosmos of fa'asamoa. This link between character and cosmos is fundamental to the development of the spirit world as its connection with ancestral elements provides a firm basis that this world exists within a Samoan traditional context and, in doing so, discovers a balance between the figures in the Spirit World of the play and its characters. Furthermore, the idea

\footnotetext{
${ }^{52}$ Tui Atua Tupua Tamasese Efi is the former Prime Minister and now "O le Ao o le Malo" or Head of State of Western Samoa.
} 
of fa'asinomaga provides its first associations with the Va, in the relationships between the individual with the land, seas, skies and more importantly, the past.

Va

Va is defined in the 2015 essay collection Whispers and Vanities: Samoan Indigenous Knowledge and Religion as "the space between; a relational space that both separates and joins; a space that is both sacred and secular" (Sualii-Sauni et al., 2015: xxxii). Lilomaiava-Doktor adds that Va denotes "the space between any two loci or entities, including people" (Lilomaiava-Doktor, 2009: 12). This idea of Va is central to, and a part of, the pillars of Samoan relationships as it connotes "mutual respect in socio-political arrangements that nurture the relationships between people, places, and social environments" (cited in Lilomaiava-Doktor 2009: 12). It represents a code of living for all Samoans, at home and abroad, because it governs all relationships. Contained in the framework of human interaction, Va helps to delineate and regulate how relationships between people, between people and their divinities and between people and their environments are conducted. Va connotes the Samoan people as relational beings who have faasinomaga (identity or belonging), tupuaga (an ancestral background), and tofiga (duties and responsibilities to the communal identity) (Tamasese et al, 2005:28). Renowned Samoan novelist Albert Wendt stresses the importance of Va to the Samoan view on life and relationships through a well-known Samoan expression, 'Ia teu le va': to cherish and nurture the Va, the relationships (in Wendt, 1999: 402). Wendt acknowledges the crucial nature of the Va in communal cultures, valuing the group unity as opposed to the individual. As he writes,

Important to the Samoan view of reality is the concept of Va or Wa in Māori and Japanese. Va is the space between, the betweenness, not empty space, not space that separates, but space that relates. [...] This is crucial in communal cultures that 
value group unity more than individualism, that perceive [of things] in terms of group, in terms of va, relationships" (Wendt, 1999: 402).

To gauge an understanding of the Va, Lilomaiava-Doktor notes, it is imperative that this concept is best understood within the context of fa'aSamoa, the Samoan way of life (Lilomaiava-Doktor, 2009). This knowledge implies that to understand Va fully, the context is in fa'aSamoa, however, what the world of the play offers is for the function of Va to inform the understanding of how it can be physicalized or used in the world of young Samoan's today. In terms of the original provocation for parts of the spirit world, specifically, the post-dramatic, how can I apply meaning or function to a particular aspect of a narrative which is created to have no meaning? The answer arrives again with the Va; it assumes no meaning; it is as it is being understood within the context of a group of cultural metaphors that constitute fa'a-Sämoa, or the Samoan way of life. Just as the Postdramatic aspects of the spirit world present the circumstances and subsequent issues of the play; so too does the physicalizing of the spirits express the issues of the worlds it inhabits.

The discoveries of the Va, I believe, further emphasize the Spirit World as a medium between the mind, the frontier of the battle of concussions, and the real world, the outside influences of each character. As Lilomaiava-Doktor notes:

The Samoan idea of Va, or social space, engages the power within and between spaces and places arrayed in opposition to each other (2009: 1).

Where the spaces here are the relationships between people or groups, the theatrical elements of Blackout, and in particular the Spirit World itself, provide a vehicle to physicalizing this concept. This frontline battle is where the exploration and 
discoveries of the first Spirits Workshop took form and will be discussed in more detail in the final chapter.

It is important to note that this is not the first time Va has been implemented or examined in theatre. David O'Donnell, ${ }^{53}$ provides an analysis of Lemi Ponifasio's view on the $\mathrm{Va}$ and how it can be utilised in the creation process of theatrical performance. He notes how Va relates and functions throughout the relationships between Ponifasio and his creative collaborators to inform, advance and inspire the work further (cited in O'Donnell, 2014). Running parallel with Albert Wendt's view on the importance of nurturing the $\mathrm{Va}$ and the relationships between people, Ponifasio stresses the community aspect with his collaborators, stating "I like to cultivate a community of relationships" (cited in O'Donnell, 2014). Ponifasio worked with approximately thirty artists across two shows for the 2014 New Zealand Festival, furthermore, extending the notion of Va from relationships between people to connections between people with the human body:

Here in the Pacific, the notion of the va is the lived and cognisant body relationship with the world. The va or the body's intentionality is the foundation of all expression, including dance (cited in O’Donnell, 2014).

O'Donnell concludes that $\mathrm{Va}$ is therefore a concept that governs relationships between people and things, between communities and the environment, but also between bodies and the cosmos. Ponifasio's work, in collaboration with other artists, creates performance arts grounded in the Va, physicalizing the relationship between

${ }^{53}$ David O'Donnell is a renowned theatre practitioner, award winning director and acclaimed theatre maker. He is the Head of School at the School of English, Film, Theatre and Media Studies, Victoria University of Wellington. 
bodies, the space and cosmos which according to O'Donnell, resemble "butoh or other avant garde aesthetics", however, "remain(s) strikingly original and distinctly Pacific" (cited in O'Donnell, 2014); using performance as a forum for discussion on the $\mathrm{Va}$, as well as utilizing its role in relationships to guide the creative process. The exploration of the Va in the relationships between bodies in the cosmos is reflected in the discoveries of the Spirit World in the first Blackout workshops.

Through the belief systems and traditions mentioned above, the Samoan person is living within multiple contexts as a relational being. Efi describes the role of the individual within the Samoan worldview:

I am not an individual. I am an integral part of the cosmos. I share divinity with my ancestors, the land, the seas and the skies. I am not an individual, because I share a tofi (an inheritance) with my family, my village and my nation. I belong to my family and my family belongs to me. I belong to my village and my village belongs to me. I belong to my nation and my nation belongs to me. This is the essence of my sense of belonging. (Efi, 2003: 51).

A sense of "self" is translated as not just myself, it is yourself and myself together and is designated with fa'asinomaga ${ }^{54}$ and tofi. ${ }^{55}$ Furthermore, self exists

\footnotetext{
${ }^{54} \mathrm{Fa}$ 'asinomaga comprises certain aspects of one's life that validate an individual's identity and places of belonging, including family titles, land and villages.

${ }^{55}$ Tofi is translated as an inheritance and is often associated with the inherited responsibilities and duties of Samoan people in all relationships.
} 
within the context of va fealoaloa' $i^{56}$, va tapuia ${ }^{57}$ and $t u \bar{a}{ }^{\prime} \circ i^{58}$ (Tamasese et al., 2005:2829). To contextualise further, Va tapuia defines specific and sacred relationships enshrined within covenants (feagaiga). There is a va tapuia between a brother and his sister which to this day, orders Samoa's gender arrangements; this covenant between brother and sister is highlighted in the Samoan saying,

E leai se feagaiga e sili atu lona tāua i lo’o le feagaiga a le teine ma lona tuagane (cited in in Huffer and So'o, 2000:172).

This is translated as there being no covenant more sacred or binding that the one that exists between a brother and his sister; represented in Blackout by the characters Jacob and Eva. Relationships between people and their environment, and between people and their divinities are also viewed in light of va tapuia and there remains a very real fear of breaking any covenant of va tapuia; not because of the physical harm it causes, but more so the spiritual. An offence which causes disharmony requires the restoration of harmony, invoked by the communal aspect of Samoan communities which is what I believe drives this fear. One succeeds as a community and one represents that community through the good and bad. Infringement of va tapuia inflicts sustained pain on the spiritual aspect of a person; the collective community is required for this to be healed or righted, but is also directly impacted by this transgression.

${ }^{56}$ Va fealoaloa ' $i$ is interpreted as the Samoan person's social relationships; va translates to relationship and fealoaloa'i refers to the face to face contact.

${ }^{57}$ Va tapuia refers to the covenantal relationships between people that are sacred

${ }^{58} \mathrm{Tua}$ 'oi in this context refers to the boundaries within and across the relationships mentioned in va fealoaloa'i and va tapuia. 


\section{Siapo and the appearance of the Spirits}

The tension between what the Spirit world represents physically and spiritually was explored aesthetically through workshops of the play. Costume development became vital for the script development of the spirit world; to consider all meanings the costumes conveyed or attempted to convey. During the initial Spirits exploration, we discovered the spirits needed to be grounded in a "Pacificness", an indigenous feel and influence because of the setting of the play and its unique Pacificness. Leaving behind the all-white dress of the spirits in the original script, which was written as a direct comparison to the White Sunday ${ }^{59}$ church and grounding the piece in traditional Samoan religious beliefs relating back to Samoan cosmology. We explored the costume design having an aboriginal influence, a fromthe-earth and land' vibe, communicated through the deep brown colouring of the pieces. Incorporated into that was the Samoan lavalava ${ }^{60}$ design of the clothing with traditional Samoan cultural patterns cut and woven into the fabric (see fig. 5). Visible are the Samoan tatau ${ }^{61}$ influences of the prestigious malu ${ }^{62}$ and $p e^{\prime} a^{63}$ designs important to Samoan culture, further contextualising and grounding the piece in a Samoan aesthetic. In the search for something tangible or physical that grounded this piece to Samoan traditional cultural practices, the piece strengthened its ties with the Va relationships and boundaries between the real and spirit worlds.

\footnotetext{
${ }^{59}$ White Sunday or Lotu Tamaiti is a celebration of children across all the Protestant churches in Samoa and can be found in most Samoan churches in New Zealand.

${ }^{60}$ A lavalava is a traditional piece of clothing often worn in the islands consisting of rectangle shaped cloth wrapped around one's waist and worn as a variety of skirt.

${ }^{61}$ Tatau is the traditional Samoan tattooing practice.

${ }^{62}$ Malu is the female-specific traditional Samoan tattooing piece.

${ }^{63} P e^{\prime} a$ is the male-specific traditional Samoan tattooing piece.
} 


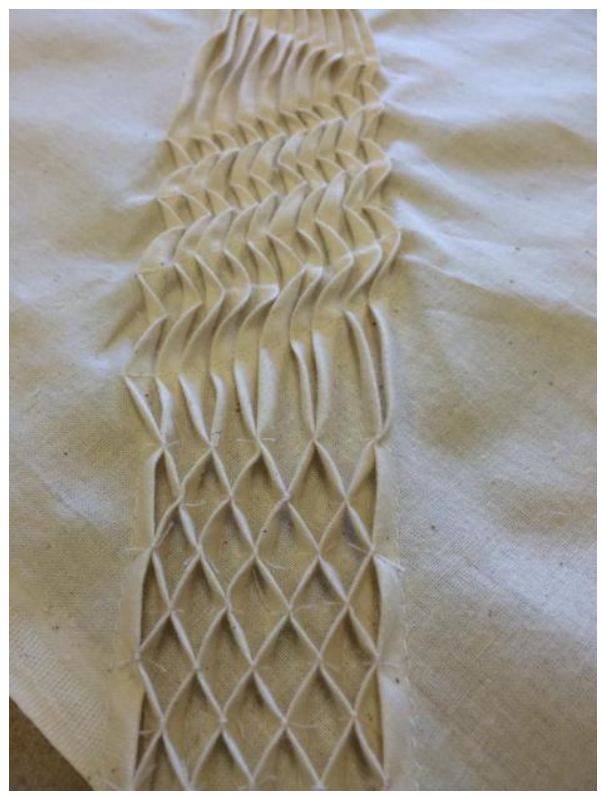

Fig. 5: Early concepts of costume for the Spirits: detailing including patterns of the Siapo and traditional Samoa tatau concepts (photo by: Johanna Friederike Otto; taken: 17 April, 2015).

Efi stresses the importance of culture needing to speak to the heart and soul of its people (2000); the search for a grounding in Pacificness for the play is an overarching quest for young New Zealand-born Samoans today. What can I take from Samoan values and traditions to further enhance this search and what it means for young PI's living in 21st Century New Zealand today? Research led me to rituals of encounter in Samoan life and the traditional element of $\operatorname{siapo}^{64}$ or tapa which is operated as a form of mutually-agreed honour and presentation for important connections. The siapo's design is influenced by all aspects of Samoan life, symbolic patterns evoke and clarify connections to the cosmos, the physical environment including marine life, all of which reveal aspects of Samoan origins and the interconnectedness of all life (see fig. 6).

\footnotetext{
${ }^{64}$ Siapo a piece of fine cloth crafted from the bark of the Paper Mulberry tree, the design comprises imprints of Samoa's natural world, like patterns of tatau; including birds, flowers and sea life.
} 


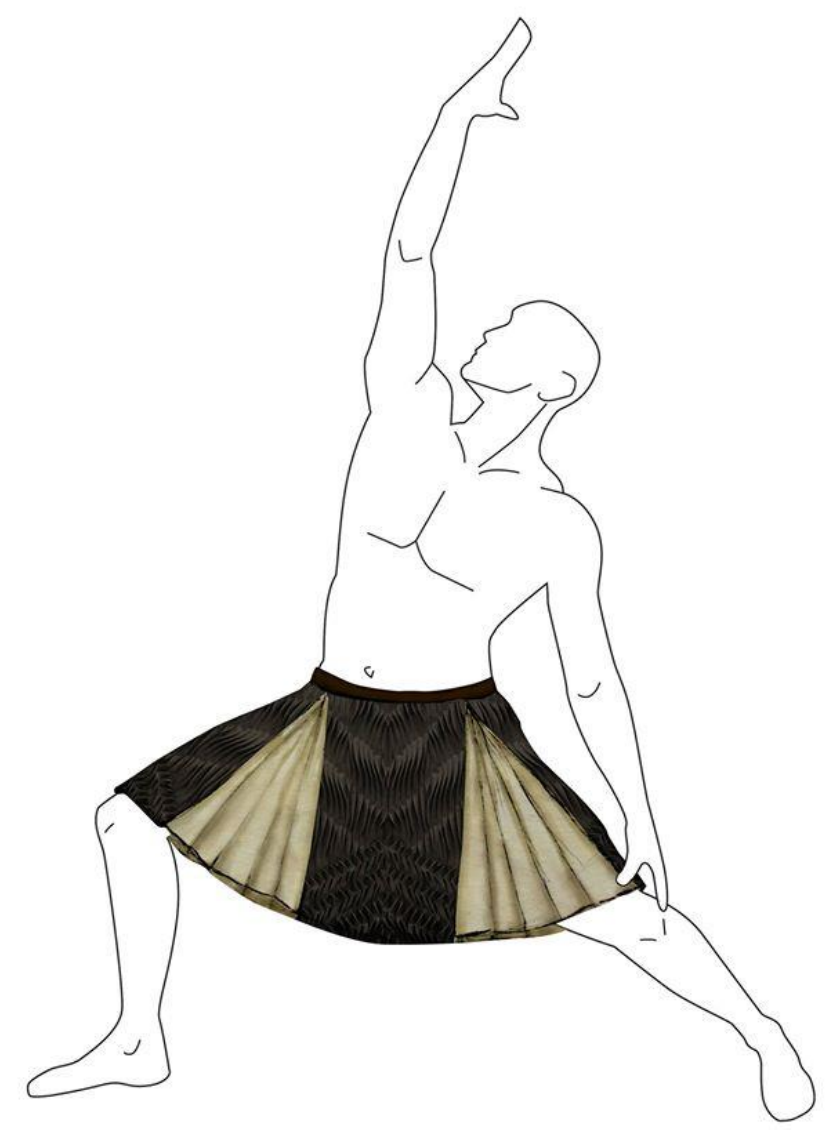

Fig. 6: Final concept for Spirits Costume design: detailing included aspects of Samoan Lavalava with detailing above included (costume design by Johanna Friederike Otto: 30 April, 2015).

Patterns on the siapo have long captured the imaginations of New Zealandborn Samoans, particularly surrounding tatau, the malu and pe'a, and the stimulus for a less expensive and less painful method of achieving tatau status through taulima; commonly referred to arm-band tattoos using traditional Samoan patterns of pe'a or malu. The practice of taulima can be attributed to the response of many young Samoans in the search for a link with traditional aspects of Samoan culture and integrating a contemporary influence using tatau as a medium. The traditional patterns used in the costume are functional in the representation of this search for culture and not only connect but further emphasize this New Zealand born Second 
generation Samoan struggle. The siapo, along with many other revered exhibitions of Samoan rituals of encounter, represents what traditional Samoan rituals and exchanges can do for a culture and shows the full dignity in which these practices are respected because they have earnt the right to speak to Samoan heart and soul. This is a visual, or embodied, way to represent a spiritual connection (see fig. 5).

\section{House of Spirits}

My upbringing and the interaction between my father and myself, including the passing of cultural information of fa'aSamoa, symbolizes the very existence of $\mathrm{Va}$ in our relationship. The Va that fills the space between us gives us the understanding of our roles and responsibilities that not only guides the principles we live by but forms the very mantra that underpins all our relationships. Importantly, how the Va is treated and practiced determines the quality, status and benefits of all relationships. Regardless of what that relationship is, whether it is between a father, son, mother, brother; Va exists and informs the conduct in each space. Interestingly, my father talks of Va existing between the living and the dead. He suggests that the space between him and his father, although he has passed on, remains functional within himself:

The Va between me and my dad was not always perfect in many ways, however, that is the essence of having the Va, it is not always to create perfection in a relationship, but to provide a platform or framework to challenge our relationships and our own expectations of the $\mathrm{Va}$ in a hope to create a relationship that is based on respect and functions effectively (cited in Mua'au, 2016).

Accordingly, though Va does conclude when the relationship is severed by death, it can often strengthen the bond that was not always visible or realised during life. For 
my father, it meant that he could continue a relationship with his father beyond the physical and into the spiritual; to function and perform his roles and responsibilities of the Va despite his father's death. The spirit world therefore, reflects the relationship or boundary between life and death; an interesting aspect to consider as it draws connections with Samoan cosmology and the spirits or aitu.

It is vital to acknowledge the role fale ait ${ }^{65}$ plays in connection with Samoan culture in its purpose to help address serious taboo subjects and help tackle significant social issues through the use of parody, cross dressing and irony (Carter, 2002: 149). This form of performance is what all Samoan theatre stems from, the actors in fale aitu are designated as spirits because of their interchangeable roles and transformation capabilities in embodying the many different roles (Mageo, 1999: 103-104). Furthermore, fale aitu became a 'socially sanctioned vehicle for overtly criticising authority figures through the protective frame of theatre' (Sinavaiana, 1992: 193), functioning to judge and restore behavioural norms to the living (Sinavaiana, 1992: 195-196). Traditional aspects of fale aitu in colonial Samoa served to:

[...] satirize Western rule and comment on the changing social conditions deriving from foreign oppression (cited in Fresno-Calleja, 2010: 182).

However, in the setting of the migrant diasporic communities here in New Zealand, fale aitu found purpose in analysing the experiences of these communities

\footnotetext{
${ }^{65}$ Translated as "house of spirits", Fale Aitu is a form of traditional Samoan clowning and storytelling.
} 
and the "transformations implicit in migratory processes where hierarchies are also questioned" (cited in Fresno-Calleja, 2010: 182; Pearson, 2005: 562). Many of Kightley's plays often use aspects of fale aitu including Fresh Off The Boat ${ }^{66}$ which Fresno-Calleja states constitutes an example of "reverse colonial mimicry" ${ }^{7}$; a variation of Homi. K Bhabha's ${ }^{68}$ mimicry, whereby, rather than imitating colonial models it consists of the "mimicking of European projections of themselves" (cited in Balme, 2007: 182). Sinavaiana further clarifies that often during fale aitu the comic steps out of the embodiment of character to commentate on the action, a breaking of the fourth wall, to distinguish the actor from the stage persona (Sinavaiana, 1992: 196). Fresh Off the Boat recycles the subversion of well-known stereotypes and the play itself becomes one of the first examples of what became a growing body of plays seeking to revise stereotypical representations of Pacific migrants (Fresno-Calleja, $2010 ; 171)$. By capitalizing on the stereotype of the naïve islander ${ }^{69}$ and parodically reversing it, Kightley questions its effectiveness and eventually raises issues of the conflicts of dislocation and cultural clash deriving from the migratory process (Fresno-Calleja, 2010: 180). Fale aitu has and remains an important medium for confronting issues and concerns through comedy and parody of characters and pushing the boundaries of humour. Kightley holds up those attitudes and

\footnotetext{
${ }^{66}$ Fresh Off the Boat is a play by Oscar Kightley written in 1995 and published in 2005.

67 "Reverse colonial mimicry" is a term coined by Christopher Balme, author of Pacific Performances: Theatricality and Cross-Cultural Encounter in the South Seas

${ }^{68}$ Homi K. Bhaba is the author of The Location of Culture and is a leading figure in contemporary post-colonial studies.

${ }^{69}$ The stereotype of the naïve or happy go lucky islander presents migrants who exhibit their cultural identity unashamedly and display unawareness about the Palagi culture and which shows Pacific peoples as naïve children in need of instruction.
} 
commentary for thought and often ridicule (cited in Mallon, 2002). Popular targets for the fale aitu practitioner are those authority figures normally commanding deference and respect, like political leaders, parents, teachers and even ministers.

It is fundamental to acknowledge the origins of fale aitu, as well as its changing role through the 1990s, in order for it to create its own meaning for the Spirit world in Blackout. This Spirit world in the play speaks to the innovation of the script in that Blackout is not using this form of parody, slapstick and costume directly but is showing the spiritual influence in another theatrical format. The spirit world in Blackout is not humorous, however it utilises the same principles of fale aitu by holding up attitudes for investigation and ridicule. The spirits form a bridge between the world of the actors, the audience and the spiritual world.

\section{Conclusion}

The discoveries of the Spirit World grounded the piece in traditional aspects of Samoan culture. Blackout remains a commentary on the stigma and attitudes towards head knocks, however the breakthrough in exploring the spirit world also offered an analysis of the struggle between traditional Samoan culture and contemporary aspects of living in New Zealand today. The world not only offers a commentary on these struggles but considers these aspects through the lens of the Va; exploring the governing relationships and code which all relationships adhere to. The production offered the notion that the spirits are not contained in the spirit realm scenes but occupy both worlds, not just at the end. As will be noted in the development of the script, the spirits express the Va when they are immersed in almost all the scenes, ever present, as is the Va, particularly during times of distress for Sua and Jacob. The discussion on concussions in Chapter One denotes the physical and mental nature of the battle, whereas the spirit world discoveries give the struggle a sense of spiritual worth and dependency. The spirits not only represent 
the $\mathrm{Va}$, they provide a gateway to physicalizing the $\mathrm{Va}$ and in doing so structure a world rarely explored in the Samoan community. Although it is ever-present in every aspect of Samoan culture. 


\title{
CHAPTER THREE
}

\author{
From Page to Stage:
}

Mapping the developing journey of Blackout from the first to final draft.

This chapter will note the continual development of the work through practice and reflection, and the search for dramaturgical arcs for the play itself. Every aspect of the play was delved into and explored throughout the year, however, for the purposes of the thesis, only investigations specifically affecting the script development will be reflected on in this chapter. Questions considered were delineating the roles between writer, playwright and dramaturg, and finding a middle ground to explore and expand on aspects of script and production without overstepping boundaries. The most practical method of interpreting the process is from a chronological standpoint and so the chapter will follow from the Spirits exploration in the MTA Technical Project, to the character exploration in the MTA Actor's Piece Project, the Brown Ink workshops with Nathaniel Lees, moving onto the fully realised Major Production Development season of Blackout along with postproduction feedback, and lastly the development of the final draft.

\section{Clarifying the projects 2.0: The Technical Direction Project.}

As mentioned in Chapter two, this aspect of development focused on the devising of the 'Spirits scenes in Blackout, specifically to realise the potential of the physical movement and aesthetic form of the spirits and the world they inhabit in order to identify its relationship to the real world in the narrative. 


\section{TATAI}

PRESENTS

A MASTER OF THEATRE ARTS (DIRECTING) PRODUCTION

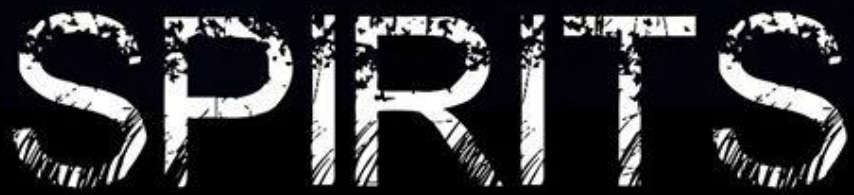

WHITIREIA PERFORMANCE CENTRE

$26,27,28$ \& 31 MAY 6:10PM

29 MAY 5PM

\$5 PRESALE \& DOOR

$\$ 2$ UNDER 12

UNDER 5 FREE

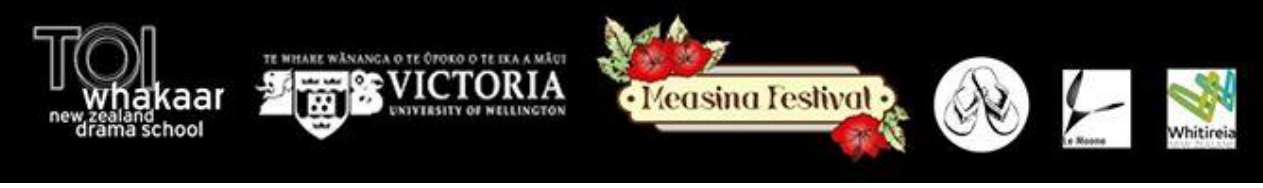

Fig. 7: Spirits, Technical Direction Project Poster (photo by Leigh Minarapa; performer Raai Badeeu; poster finalised: 20 May, 2015)

The production and design team for this project were all current or graduate students of Toi Whakaari: New Zealand Drama School; they were approached by director Lesa and offered the chance to collaborate on at least one of the MTA 
Projects. The names and specific roles for the production and design team for Spirits, aside from the writer and director, were:

$\begin{array}{ll}\text { Producer: } & \text { Kirsten Lee } \\ \text { Production / Stage Manager: } & \text { Bridie Collins } \\ \text { Production Designer: } & \text { Ivo Deliyski }{ }^{72} \\ \text { (H.O.D) Costume Designer: } & \text { Alex Guillot } \\ \text { Costume Designer: } & \text { Johanna Friederike Otto } \\ \text { (H.O.D) Lighting Designer: } & \text { Jeremy Larkin } \\ & \\ \text { Lighting Designer: } & \text { Dominic Crossman }\end{array}$

Having a set production/design (presign) crew from the beginning was very humbling, to have my first ever work put through rigorous review and interpretation was something I had never imagined for Blackout. A key point for this first development was that the spirit world had never existed outside of the

\footnotetext{
${ }^{70}$ Kirsten Lee is a Bachelor of Performing Arts (Management), Year 2

${ }^{71}$ Bridie Collins is a Bachelor of Performing Arts (Management), Year 1

${ }^{72}$ Ivo Deliyski is a Bachelor of Design (Stage and Screen), Year 2

${ }^{73}$ Alex Guillot is a Graduate of Diploma in Costume Construction (for Film, Theatre and Allied Industries)
}

74 Johanna Friederike Otto is a Diploma in Costume Construction (for Film, Theatre and Allied Industries), Year 3.

75 Jeremy Larkin is a Diploma of Entertainment Technology, Year 2

${ }^{76}$ Dominic Crossman is a Diploma of Entertainment Technology, Year 1 
pages of the script or even outside of my mind, everything that was to be physicalized in this world had to be interpreted or informed from the script and due to the lack of a dramaturg, from my own understanding. It became evident here that a dramaturgical link between writer and director was missing, that at times I had to fill the void. The movers and actors themselves were also selected from a group of current or recent graduates of Toi Whakaari, with the exception of Alexandra Dunn; a current student at Victoria University. The lead choreographer Taufa Fisi'inaua ${ }^{77}$ was also one of the three spirits/movers, the other two were Joshua Crammond ${ }^{78}$ and Raai Badeeu ${ }^{79}$. Incorporated into the Spirits project were the characters Elle and Sua played by Alexandra Dunn ${ }^{80}$ and Chris Alosio ${ }^{81}$ respectively. Each presign or performing member brought with them their own experiences and knowledge, however, what united the group was the chance to work on a body of work never performed before and the opportunity to work in a semi-professional manner. I say semi-professional for the reason that to develop a running piece throughout the year cohesively in a number of projects, it was decided that a mock theatre company 'Tatau' would be created to release all the performances under. My role in this project drifted between dramaturg and writer in the rehearsal space; making clear decisions on how I saw the spirit world enabled the presign team to define their interpretations of the spirit realm and offer their own discoveries. This role, as will be discussed later

\footnotetext{
${ }^{77}$ Taufa Fisi'inaua is a Bachelor of Performing Arts (Acting); Year 3

${ }^{78}$ Joshua Crammond is a Bachelor of Performing Arts (Acting); Year 3

${ }^{79}$ Raai Badeeu is a Bachelor of Performing Arts (Acting); Year 1

${ }^{80}$ Alexandra Dunn is Media Studies and Cultural Anthropology student at Victoria University of Wellington

${ }^{81}$ Chris Alosio is a Bachelor of Performing Arts (Acting); Year 1
} 
in the chapter, became a difficult process and an important learning curve for the future development of Blackout. Once the presign team had read the script; it became apparent through their own interpretations of the realm of the spirit world that it needed to be explored as a whole and not as separate scenes compiled together. The presign team discussed the spirit world itself and what they saw in it; words such as abstract, ritual, intangible were used (see fig. 8).

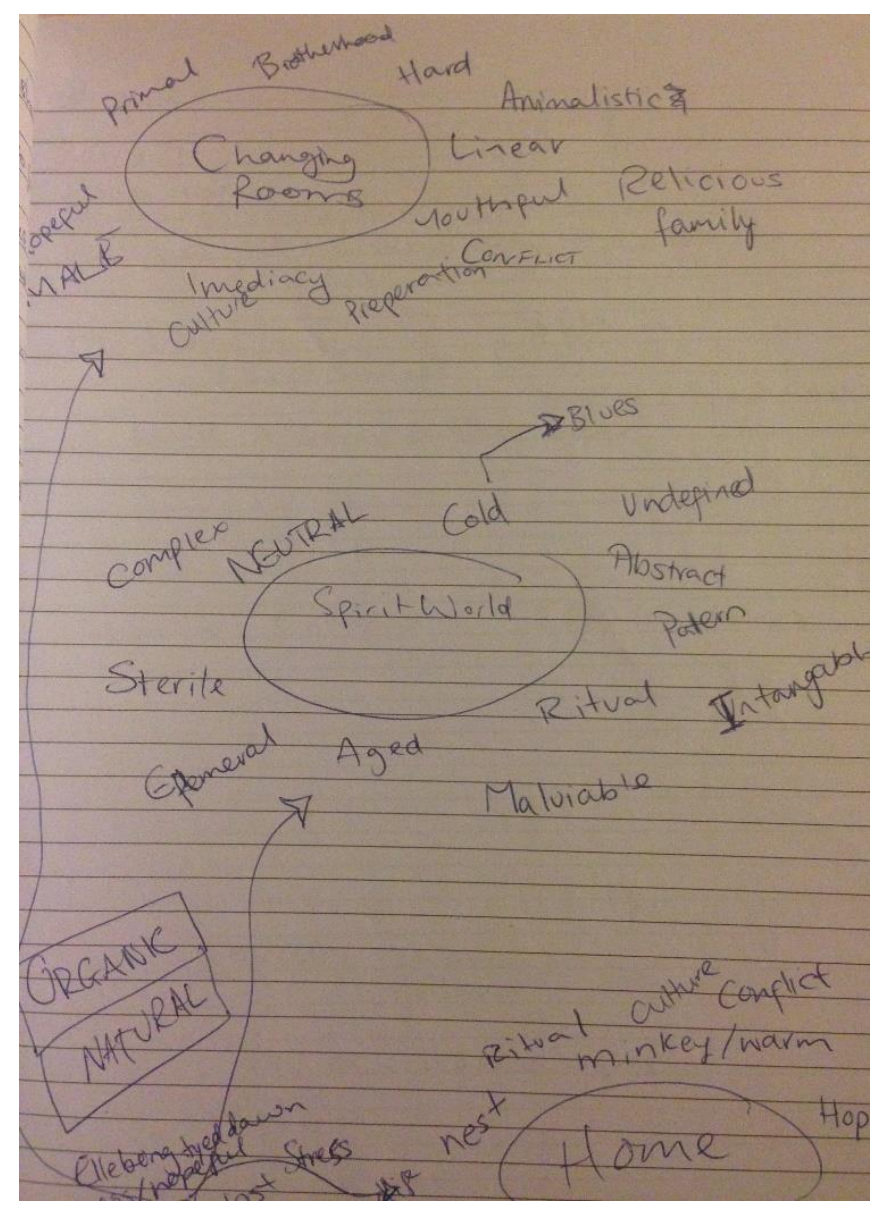

Fig. 8: Presign meeting notes: Exploring three worlds of the play; changing room, spirit world and home (notes by Kirsten Lee; taken 26 March, 2015).

These ideas formed the basis of the spirit world exploration for each of the creative processes; costume, lighting and set design as a whole. My own discovery and imagined spirit world were similar to these initial ideas. These discoveries in the rehearsal process and reflections of the performance of Spirits are discussed later in chapter three. 


\section{The Actors Directing Project.}

This part of the process turned the focus from the technical aspects onto purely the acting of the characters. For the actor's project - staged as an intimate 3 night showing at the studio at 93 Kelburn Parade - both Elle and Sua were recast. Chris Alosio, who played the part of Sua in the Technical piece, was replaced by Sonny Tupu ${ }^{82}$ in order to fit closer with the age of Sua and partly due to Sonny's experience as an actor. Alexandra Dunn pulled out due to ongoing University commitments and was replaced by Olivia Monks ${ }^{83}$. The 20-minute workshop piece that was shown focussed on Scenes, 3: Names, 5: Cleaning, 8: Home, 11: Coward, 13. Big Game and 14. Hospital all in chronological order. The discoveries of the actor piece will be discussed later in the chapter.

\section{Brown Ink Workshop}

This workshop was run over two days in November 2015, specifically for the purposes of developing the script itself. The timing coincided with rehearsals for the major production, which had now been cast and script finalised. Because of this, it was decided any discoveries and insights into the play and the scenes involved would have to impact the final script and not the script being used for major production. Chris Alosio was cast as Jacob, Tini Vaofusi ${ }^{84}$ as Lui, Saufo'i

\footnotetext{
${ }^{82}$ Olivia Monks is a Bachelor of Performing Arts (Acting); Year 3

${ }^{83}$ Sonny Tupu is a recent graduate of Toi Whakaari: Bachelor of Performing Arts (Acting)

${ }^{84}$ Tini Vaofusi is a first is a Bachelor of Performing Arts (Acting); Year 1.
} 
Fa'avale $^{85}$ as Vale and John Va'a ${ }^{86}$ as Mangere. Joshua Crammond, Raai Badeeu, Moana Ete and Morgan Diprose ${ }^{87}$ were the Spirits. Sonny was unfortunately, unavailable to attend so Joshua Crammond, stood in as Sua, and Olivia Monks as Elle. As mentioned earlier, the workshops concentrated on the following scenes: 3. Names, 8. Home, 9. Party, 11. Coward, 13. Big Game and 14. Hospital. Whilst the focus of the workshops was specific to how the script could be further developed, the fact that we were able to use the cast made the workshop a worthwhile tool for them to further explore the characters.

\section{Major Production Project.}

The development season of Blackout ran from December 2-5 $5^{\text {th }}$ (see fig. 9) at Studio 77, Victoria University. This part of the process combined all aspects of the previous workshops and rehearsals into a fully realised production. As mentioned above, the cast remained the same from the Brown Ink workshops. An important aspect of the development season was the need to gather feedback in order to develop the script further. To ensure this, we invited a Victoria University Theatre Summer Trimester Course to our dress rehearsal and had them fill out a questionnaire form afterwards (see fig. 10). These same questions were then printed and placed in the foyer for audience members to write feedback after each show. The amount of

\footnotetext{
${ }^{85}$ Saufo'i Fa'avale is a trained actor out of Whitireia Performing Arts Centre, Wellington.

${ }^{86} \mathrm{John} \mathrm{Va}^{\prime} \mathrm{a}$ was a student at St. Bernard's College, Lower Hutt. Currently studying Performing arts: acting at the Whitireia Performing Arts Centre, Wellington.

${ }^{87}$ Morgan Diprose is a second year dance and acting student at the Whitireia Performing Arts Centre, Wellington.
} 
feedback was overwhelming and most of the ideas touched on contributed in some way to the final draft. The feedback will be discussed towards the end of the chapter. 


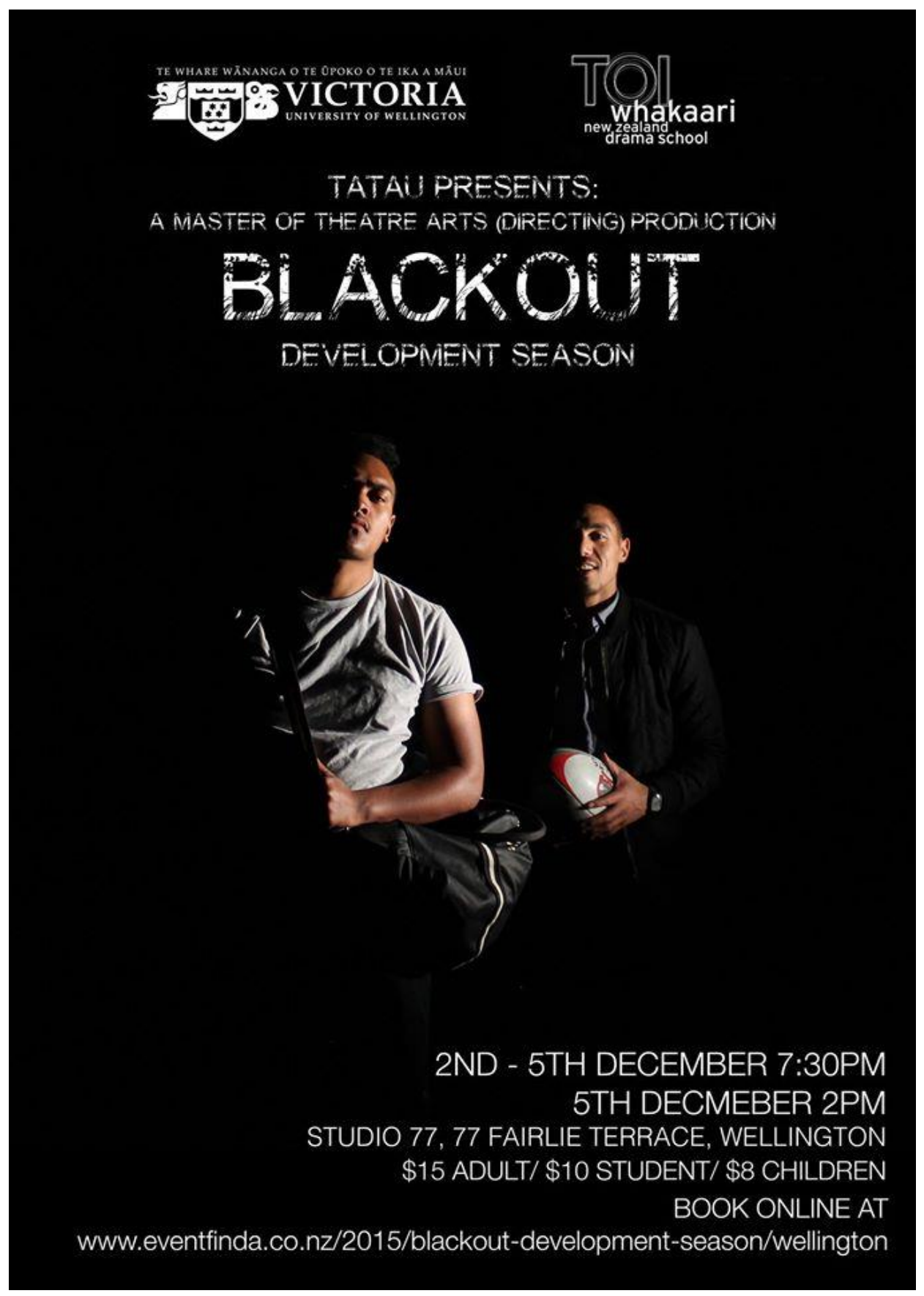

Fig. 9 Blackout Development Season Poster, photo by Bridie Collins. 


\section{Blackout Development Season Questionnaire:}

1. What is Blockout about?

2. What parts of Blackout required more clarity?

3. Which character(s) did you want to know more about? Why?

4. What is the connection of the Spirit-world and the Natural-world?

5. How did space contribute to meaning?

6. How did the play deal with the social, cultural political issues theatrically?

7. What makes this work unique?

Fig. 90: Blackout Development season

\section{Writer \& Director relationship: role of the playwright in the rehearsal room}

As Ian's first MTA block approached and our collaboration was finalised, the question at least for myself as the writer was how I was to fit in the rehearsal room. How much of an input could I make without hindering actor and director discoveries and exploration? Where was the line drawn for a director's take or influence on the script itself? And where in the process did the writer have room to make script changes during rehearsals? These questions were answered throughout the course of the year and it was evident from the beginning that my role would morph back and forth from playwright to dramaturg. 
My role in the Spirits workshop season involved a combination of realising the dramaturgy, ensuring the intended purposes of the spirit scenes were correct whilst also providing my own notions of the spirit world to the production team. During the very first rehearsal and production meetings, questions surrounding the spirit world and Blackout all needed answers. What did the spirit world mean to me? How did I envision it? What did the spirits look like? All these questions pertinent to the development of the spirit world were directed at me very early in the collaboration. As the process continued into the initial rehearsals of Spirits, I noted specific elements that caught my eye or that I thought would aid in the development of the script. My capacity to assist in the process grew and I was given freedom to initiate conversations with the cast and offer them my own interpretations of the script if appropriate. However, directorial decisions were restricted to Ian. Technical aspects of lighting, sound and design, as well as movement and aesthetics, were strictly in his control.

Important to note, the actor's piece was explored in rehearsals only by the director Ian. Compared to the input I had in the technical and major developments of Blackout, the actor's piece featured the least amount of involvement from myself. This was done out of respect for Ian, who wanted to have the chance to explore the subtext of the scenes between Elle and Sua without the writer in the room. Part of the development of Blackout was to explore the script and develop it further and, in doing so, I knew at times I would have to let the piece go and embrace for interpretations separate from my own. Accordingly, I wholeheartedly accepted the decision to not be involved in the piece for it to be explored fully. However, because we did not assign a dramaturg from the beginning, there were ramifications that impacted on the final piece. These implications will be discussed later in the chapter. My role in the Brown Ink workshops was central to the purpose of the workshops 
themselves, they were focussed on the development of the script itself and therefore aspects I felt needed the most reworking were the ones we focussed on.

My role in the final major production was essentially that of a production dramaturg, ensuring that actors were achieving the intended purposes of their lines or character arc narratives. Since this was the first time the actors came together with the playwright and director - and the first time we'd worked with the young boys' scenes - many questions regarding the characters were asked during the course of rehearsals. Why were certain characters doing [this]? Why weren't they doing [that]? Questions pertaining to characters, plot, and structure were all needing answers. I also provided an extra eye for Ian to explore different scenes and offer new views on any rehearsed scenes. These instances were important for myself as the writer as they gave me an opportunity to actively work and rework the characters and the stories of Blackout.

It became important from the very start to draw these distinctions between my roles of writer and dramaturg, fortunately for myself, the two worlds in Blackout offered a solution for both: sticking to the script in the 'real world' of the play and having the freedom for actors and director to explore and have free rein in the Spirit World. It was decided for the first block production that we were going to put the Spirit World on stage; an important time for me to explore this world that had only existed in my mind. The following discoveries were made during the initial Spirit World rehearsals and led into the performances themselves. 


\section{Spirits exploration and rehearsal room discoveries}

With the preliminary casting of the Spirit World completed our first consideration was to delve into the sound of this world. What do the spirits hear in the Spirit World? What sounds emanate from the spirits to the outside world? The spirits explored the soundscape of the rehearsal room, the sounds the body makes when walking, crawling or shuffling and the bangs and echoes if one were to hit the floor or the body. Exploration of the breath, being able to hear the spirits as they move about the space. A question arose as to whether there is a collective breath of one's ancestry, of those who've come before you? The sounds originating from the spirits again evoked traditional Samoan elements of slapping; the slapping of one's body during a Siva Samoa, ${ }^{88}$ inspired by techniques of swatting away to ward off mosquitoes, and tapping; a reflection of the art of traditional tattooing or tatau; markings on the body and a sense of permanence. These traditional elements were contrasted with heavy hitting or stomping. This resonated with the visceral nature of rugby and its violent history and nature - the sounds heard during warm-ups, pregame talks and even on the field centred the piece in that world. During the development of the spirit world, the opportunity arose for me to contextualise the Spirit World and shape it to represent the struggle it attempts to replicate via the sounds and meanings mentioned above.

\section{Movement exploration}

The actors performing as Spirits were challenged to articulate their physical movement by learning how to manipulate the body with self-control and to become

\footnotetext{
${ }^{88}$ A Siva Samoa is the term for a Samoan dance; the choreography of the arms and hands completed in a subtle but graceful manner while requiring the dancer to maintain elegance.
} 
more aware of working with the shifting of one's body weight and balance (Spirits Workshop, 2015). The framework of the movement started off with simple rolls backwards and forwards. The performers were made aware of their entire body and how it interacted with the space: how one shifts one's weight to balance against opposing forces. The 'spirits' moved across the space in a "chimp" like walk on all fours - shifting their weight from feet to hands forwards and repeating. In response to the weight shifting movement, they put their knees on the back of their arms/elbows and leant forward - holding their whole weight on hands and knees (see fig. 11).

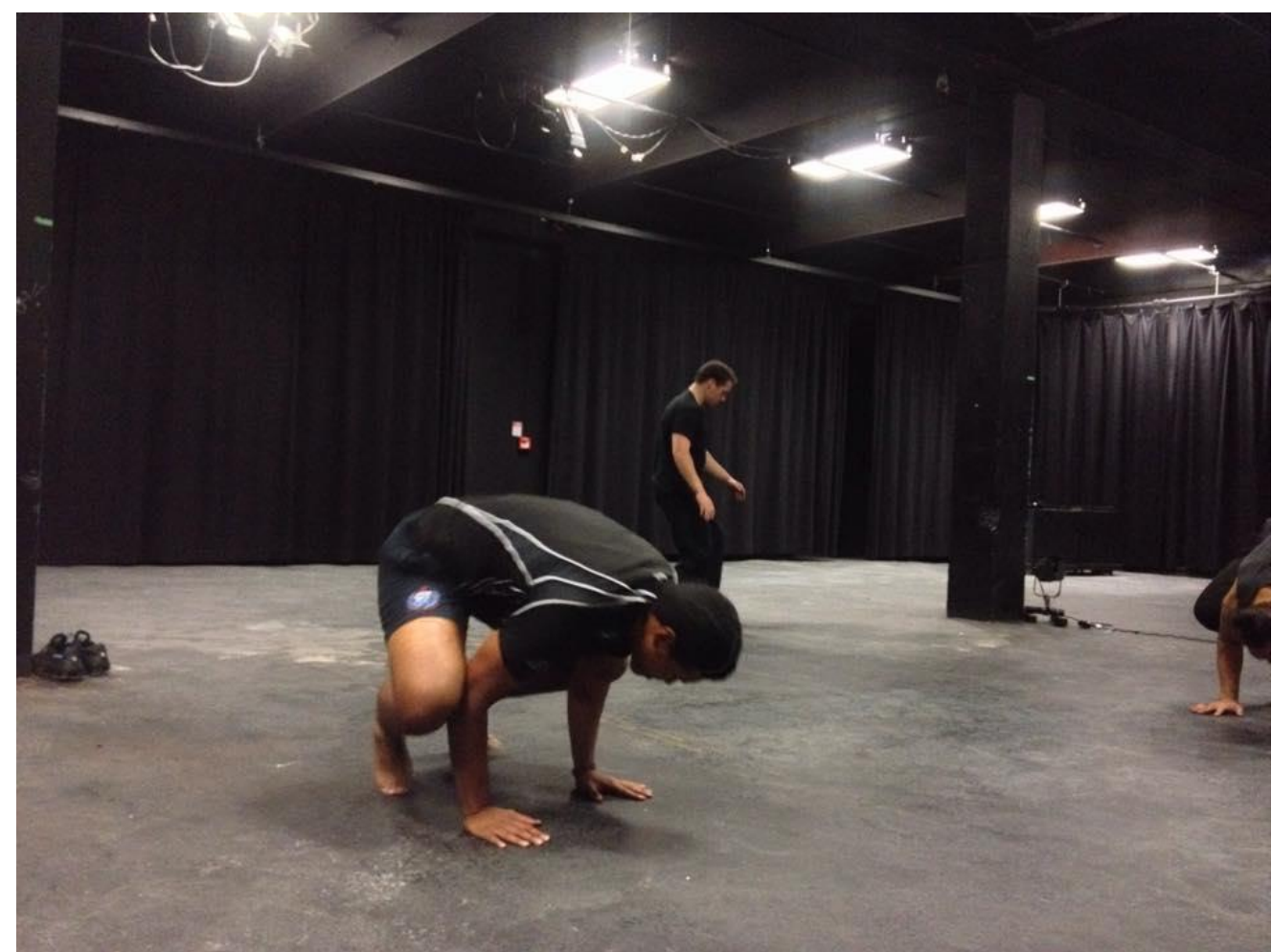

Fig. 101: Movement exploration: shifting of weight from arms and body onto your feet whilst supporting your entire body (photo by Sepelini Mua'au; taken: 17 April, 2015)

These basic actions formed the foundation of the spirits' movements across the stage. A question posed to the spirits was 'What kind of animal - predatory or other - could your "Spirit" be / or take the form of?' (Spirits Workshop, 2015). In this 
manner, the spirits were able to embody or channel their 'inner animal' in their initial discoveries. This attempt to realize an internal being or animal was important for the development of the spirit world because it grounded the world in an indigenous landscape. Something primal and instinctual about the world is important to grasp; firstly, because it initiates a discussion of time, an eternal or 'from the beginning' notion and secondly, it denotes fluidity and survival.

\section{Spirits choreography exploration}

The choreography for the spirits discovered a tendency to connect or ground itself in elements of traditional Pacific movements, particularly Samoan. The choreography involved foundations of Siva Samoa as well as incorporating the Tau'olunga ${ }^{89}$, aspects of the ava (kava) ceremony rituals ${ }^{90}$ and even Māori Haka ${ }^{91}$ elements, which were all interwoven with contemporary actions reflective of the world the play is encapsulated in (see fig. 12).

\footnotetext{
${ }^{89}$ The Tau'olunga is the traditional Tongan dance comparable to the Siva Samoa

${ }^{90}$ The Ava Ceremony is one of the most important customs of Samoa. It is a solemn ritual in which a ceremonial beverage (Kava root) is shared to mark important occasions in Samoan society.

${ }^{91} \mathrm{Haka}$ is a form of Māori war dance traditionally used on the battlefield, however also used on many occasions including before rugby matches. Most notably, Ka Mate and Kapa O Pango are Haka used by The All Blacks.
} 


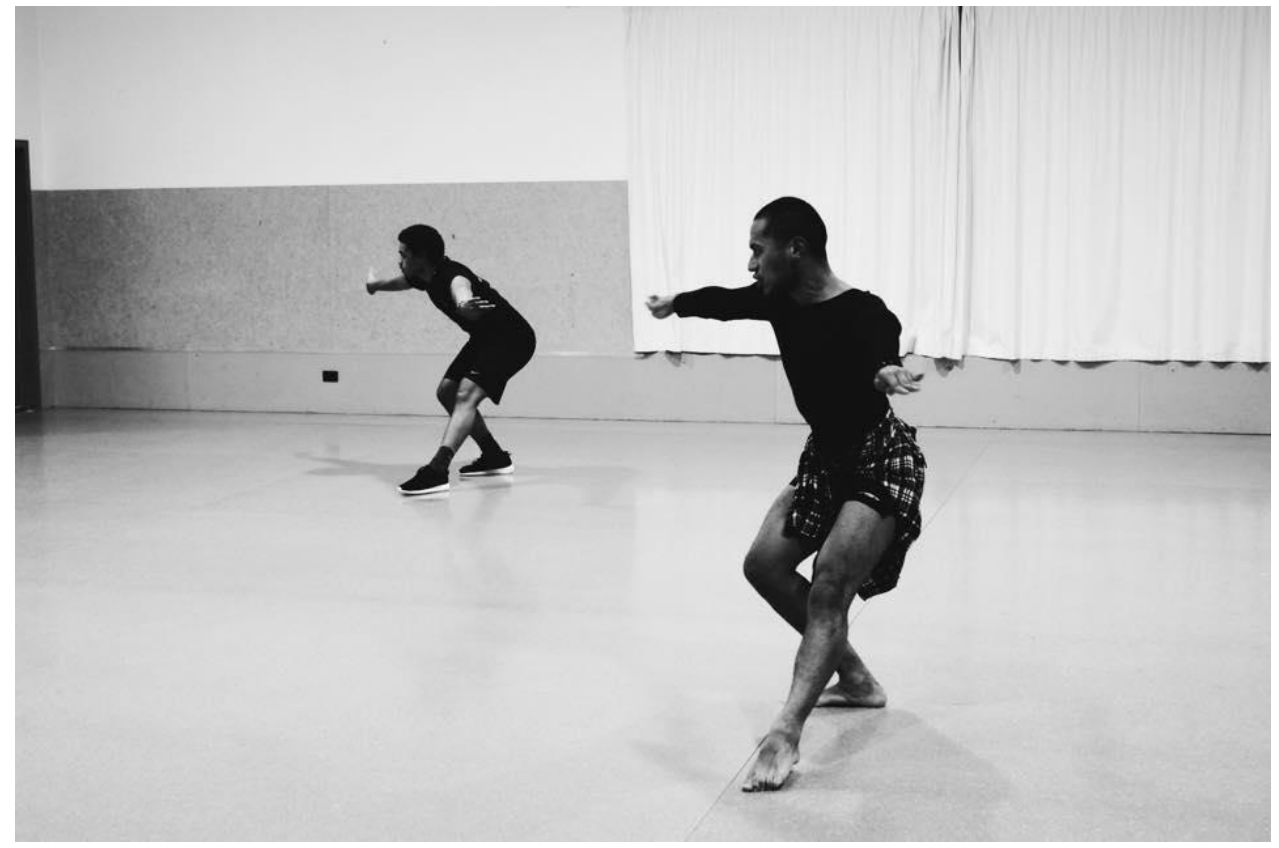

Fig. 112: Choreography exploration: exploration of traditional Pacific Island dance practices; specifically Samoan. Choreographer: Taufa Fisi'inaua (photo by Leigh Minarapa; taken: 12 May, 2015).

Alongside the beautiful slow and precise movements of the Siva Samoa and traditional Tau'olunga moves were actions acting as a running commentary on all aspects of New Zealand life, from rugby culture to rugby games themselves (see fig. 13), to hip hop and vogue dance styles all in a few precise movements. Lifting a beer as if one were drinking at a bar, varied with a Tongan $\operatorname{dek} \imath^{92}$, blended with a rugby line out throw. These interspersed ideas of traditional culture and pop culture are a direct reflection of the lives that young PI's, specifically Samoan's live today. A further example is found in the 2016 Super Rugby \#SuperBangBang93 campaign where New Zealand dancing troop REQUEST ${ }^{94}$ introduced the new Super Rugby

\footnotetext{
${ }^{92}$ The Tongan deki is a part of the Tau'olunga. It involves tilting ones head to the side and back straight again.

${ }^{93}$ \#SuperBangBang is the social media hashtag campaign kick-starting the 2016 Super Rugby Season.

${ }^{94}$ REQUEST are an all-female hip-hop dance crew from Auckland, New Zealand. Made famous in the dancing world by winning the HHI World Hip Hop Dance Championships Varsity and Adult divisions in 2009 and 2010 respectively.
} 
season with a series of hip hop/ vogue ${ }^{95}$ and pop culture "dabbing"96 references. Headlining the advertisement for the NZ Super Rugby players is none other than Julian Savea ${ }^{97}$, famous not only for his try scoring prowess but also his dancing abilities.

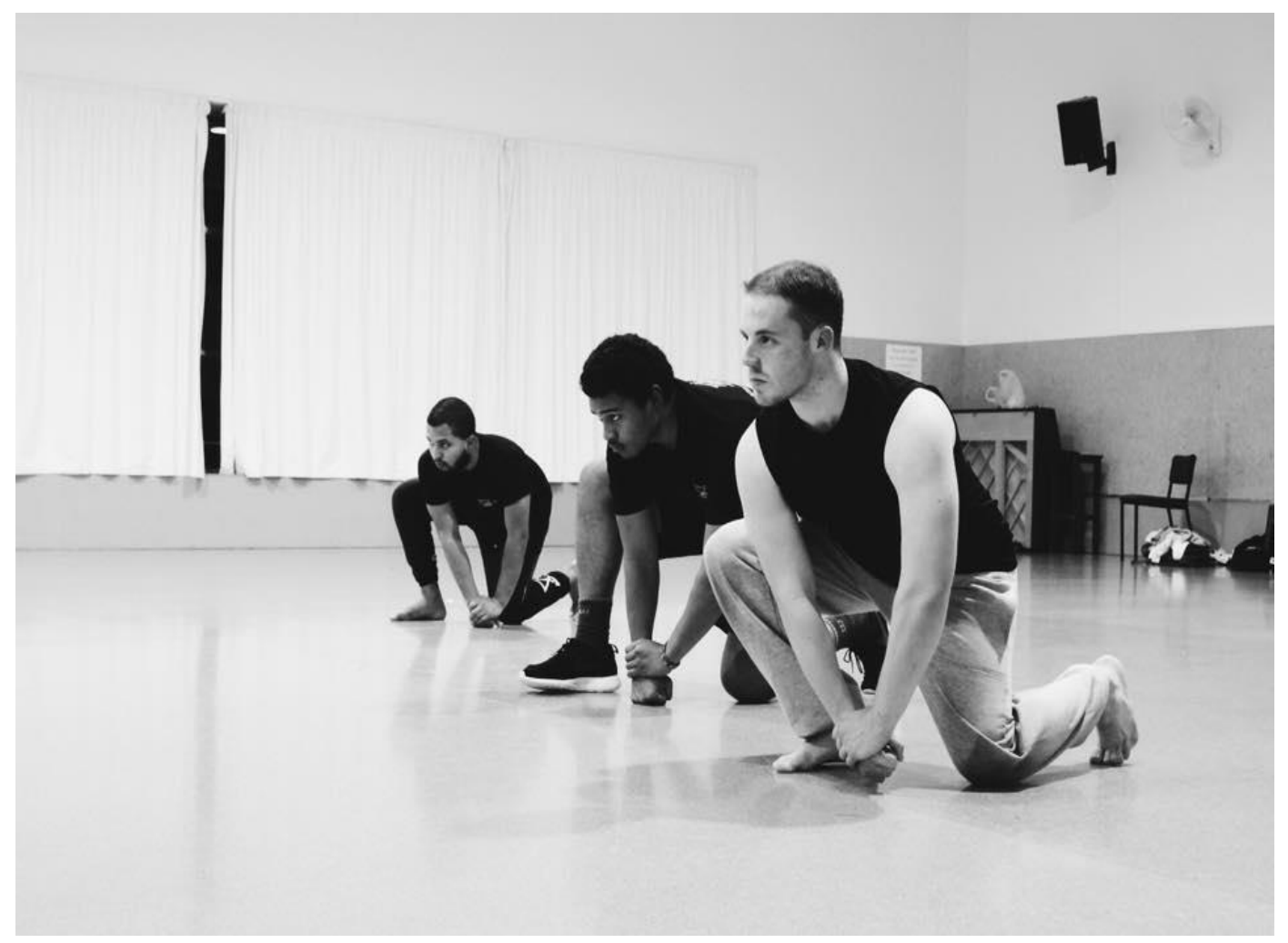

Fig. 123: Choreography exploration: incorporation of Māori Haka practices including a sequence used in 'Kapa O Pango', a haka used by The All Blacks. Choreographer: Taufa Fisi'inaua. (photo by Leigh Minarapa; taken: 12 May, 2015).

The spirits, in enacting these moves, mirror society and more importantly refer to the $\mathrm{Va}$ and the physical space between the worlds in doing so. The fast and grotesque movements of vogue style dancing (see fig. 14), woven together with

\footnotetext{
${ }^{95}$ Vogue, or vogue-ing, is a highly stylized, modern house dance that evolved out of the Harlem ballroom scene in the 1980s.

${ }^{96}$ The $D a b$ is a dance routine in which the dancer simultaneously drops the head while raising an arm and the elbow in a gesture.

${ }^{97}$ Julian Savea is a current Wellington, Hurricane and All Black Representative.
} 
beautiful slow traditional Pacific actions, evoked a discussion on the impact and struggle of two cultures. While the spirits enacted the specific choreography, the nature of this world and Va enabled them to find their own rhythms which suggests a certain freedom or break away from conventional aspects of Samoan tradition and rules encoded into everyday life.

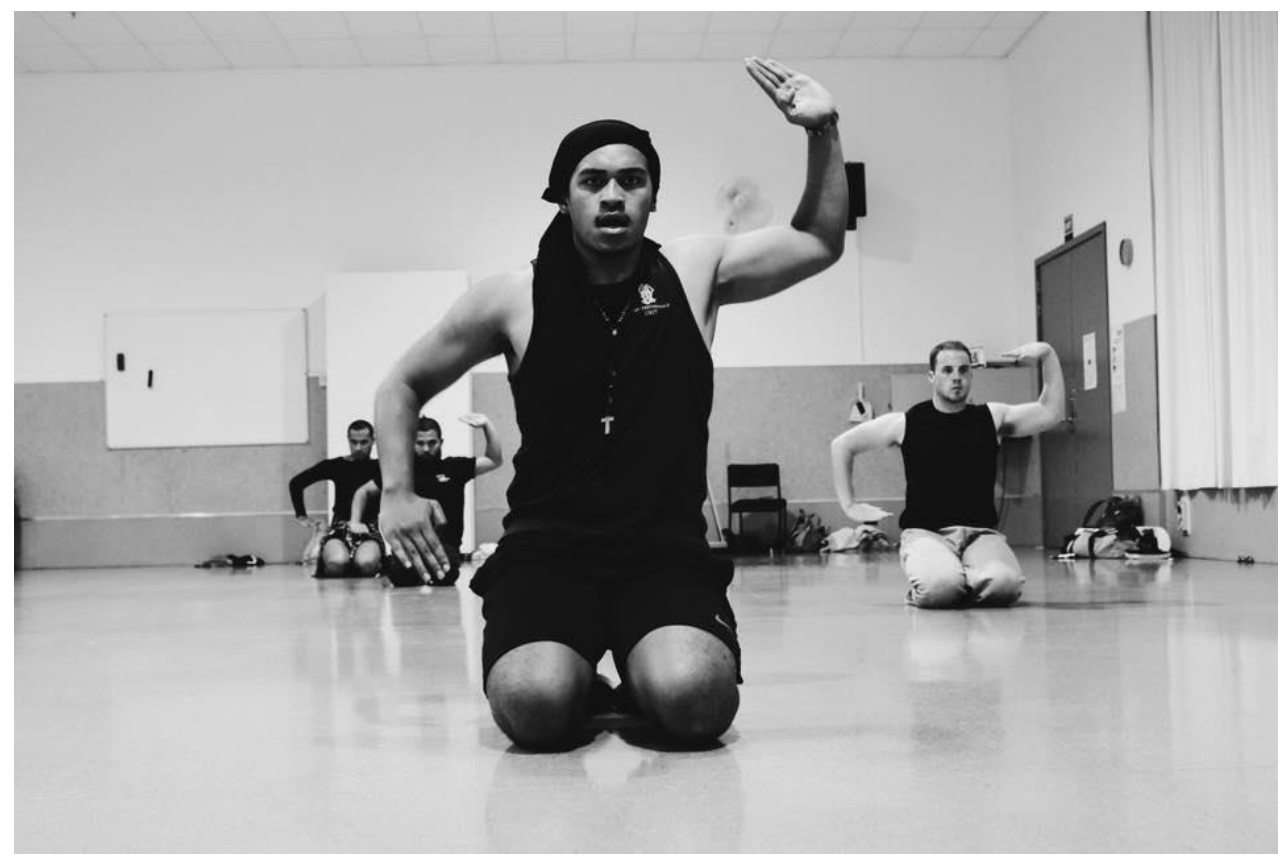

Fig. 134: Choreography exploration: integration of 'vogue-esque' style dance movements: running commentary on popular culture today. Choreographer: Taufa Fisi'inaua. (photo by Leigh Minarapa; taken 12 May, 2015).

Pop culture references such as the hashtag 98 and use of mainstream pop music ${ }^{99}$ together portray rugby players as celebrities, or at least social media idols. The media plays on this ideal with young people acknowledging the success of professional rugby athletes and associating their sporting success with celebrity status. The choreography expresses the struggles of young Samoans attempting to

\footnotetext{
${ }^{98} \mathrm{~A}$ hashtag or \#, is a tool used in social media to inform websites of trending topics; used by sites such as Facebook, Twitter, Instagram and YouTube.

${ }^{99}$ Popular music used in the campaign was Bang Bang by Jessie J featuring Nicki Minaj.
} 
integrate traditional Samoan practices with New Zealand society. This integration connects back to our discussion on the Va and the relationship of feagaiga ${ }^{100}$ whereby the worlds are opposite, however not in opposition to each other. For the choreography to impact the development of the spirit world script-wise, I tried to strike a balance between connecting the movements with both traditional and contemporary styles while also letting the world exist on its own, free from too many constraints (see fig. 15).

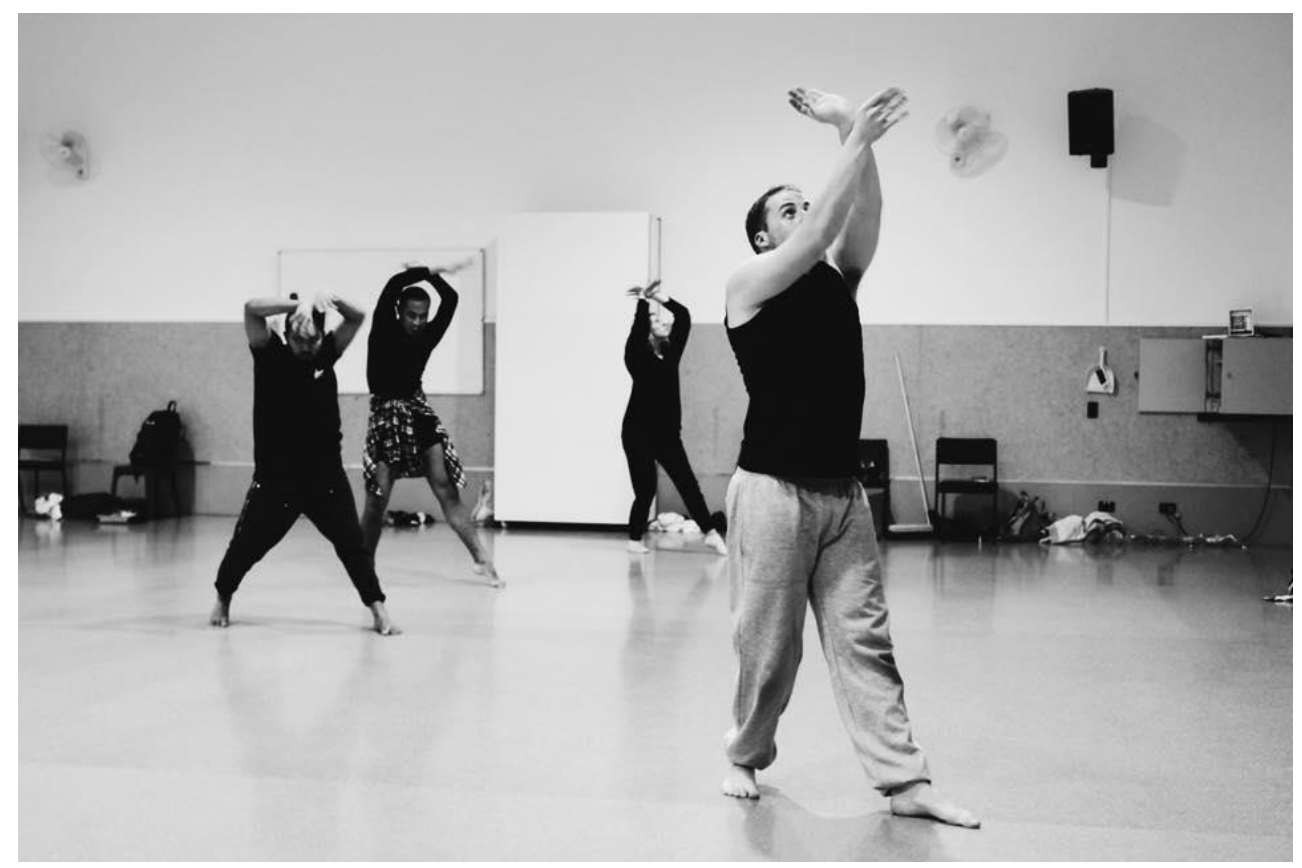

Fig. 145: Choreography exploration: combining traditional aspects of Siva Samoa with contemporary dances. Choreographer: Taufa Fisi'inaua. (photo by Leigh Minarapa; taken 12 May, 2015).

${ }^{100}$ Feagaiga is defined in Whispers and Vanities: Samoan Indigenous Knowledge and Religion as "an established and sacred relationship between different parties. As brothers and sisters and their children, the masculine and feminine, tulafale and ali'i, and pastor and congregation" (Sualii-Sauni et al., 2015: xxvi). 


\section{Light exploration in the spirit world.}

The spirits explored an interesting relationship with light. At one particular point, the spirits are met with a wall of light; the spirits can see out to the audience yet this wall of light separates them from moving into the world of the audience. In reflection, this light is not only representative of the barrier between traditional and contemporary cultures, but can also be interpreted as the spirits living in between the worlds; occupying the liminal space in between. Their relationships with the shadows is closely related to this idea of being ever-present; living in the shadows, in spaces unseen or unoccupied. My exploration into this relationship posed a question of complication; am I applying meaning or assumed meaning to this world and not giving the audience a chance to discover meaning for themselves?

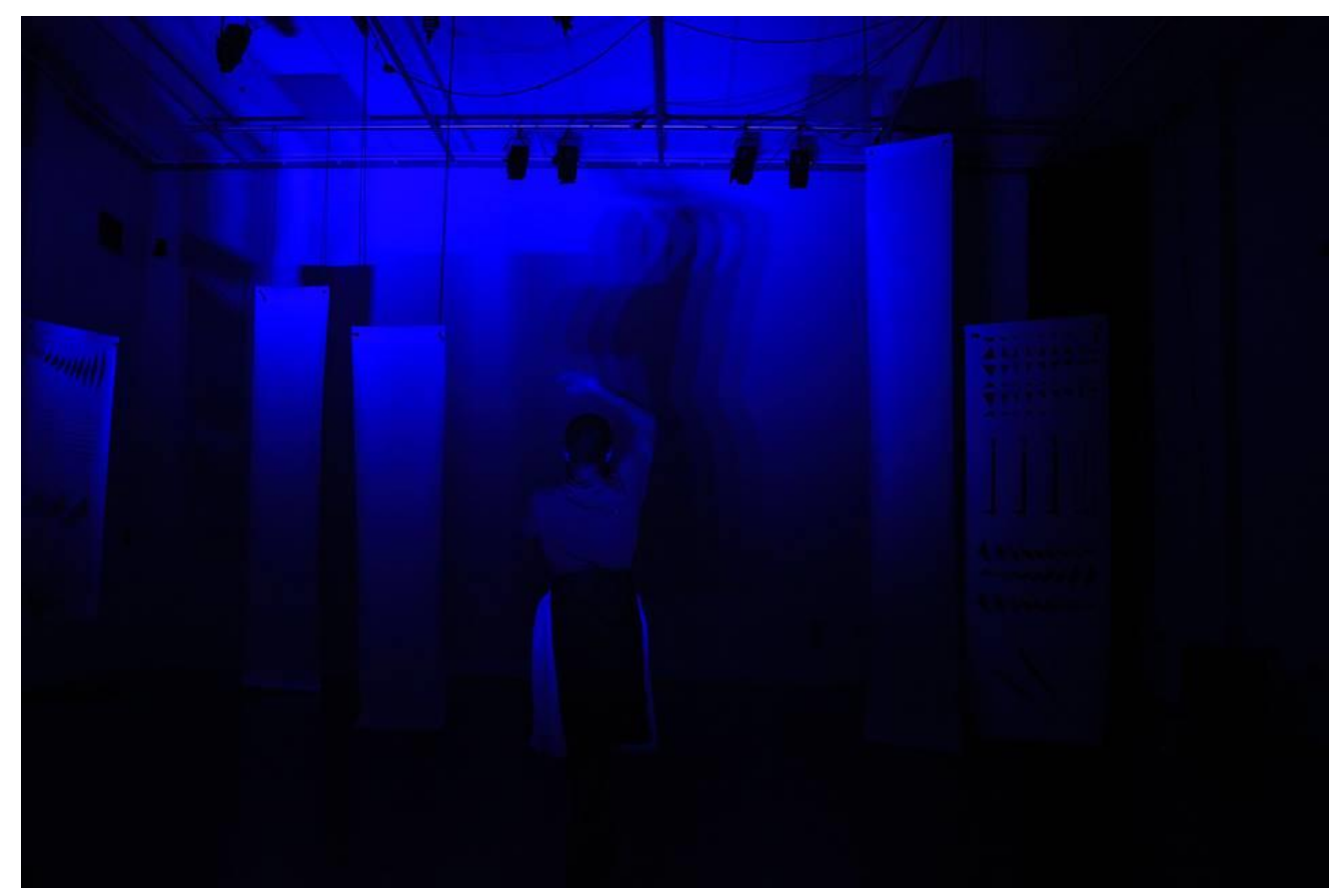

Fig. 15: Light exploration: playing with dark hues, casting shadows and integrating a black-light to enhance the spirit world. Lighting design by Dominic Crossman \& Jeremy Larkin. Set design by Ivo Deliyiski. (photo by Leigh Minarapa; taken: 15 May, 2015). 
To combat this frustration, I had to dig a little deeper and explore further; not to give meaning but to just explore what this world means. Questions arose about what the spirit world would look like? What were we reminded of when we see this world? Experimenting with light technology, we played with different tones of dark colours but what intrigued the most were the dark blue hues, a night time glow filled with shadowy movements harking back to the Va and space between (see fig. 16). This was further enhanced with the black light used during the shows to highlight the white powders on the spirits and scattered across the space (see fig. 17).

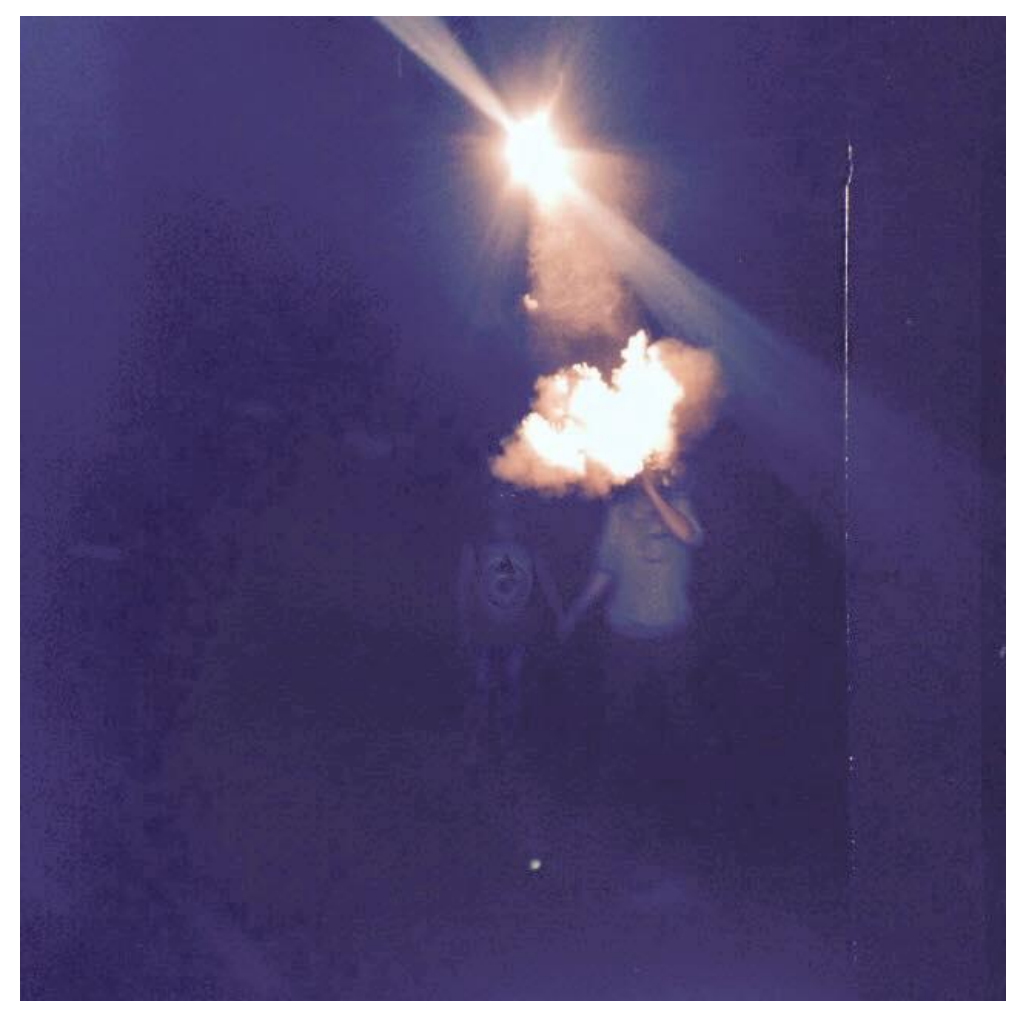

Fig. 17: Light and powder exploration: casting different lights, strengths and from different angles onto scenes of spirit and powder movements to explore the relationship between light and powder. Lighting design by Dominic Crossman \& Jeremy Larkin (photo by Ian Lesa; taken: 16 April, 2015).

\section{Set and space exploration.}

The design of the Spirit World began with discussions around working with abstract design and reducing the space down to the essential components which 
concluded with the idea to work with panels/ screens. These panels varied in size, hung from above and offered space to project light onto but also cast shadows.

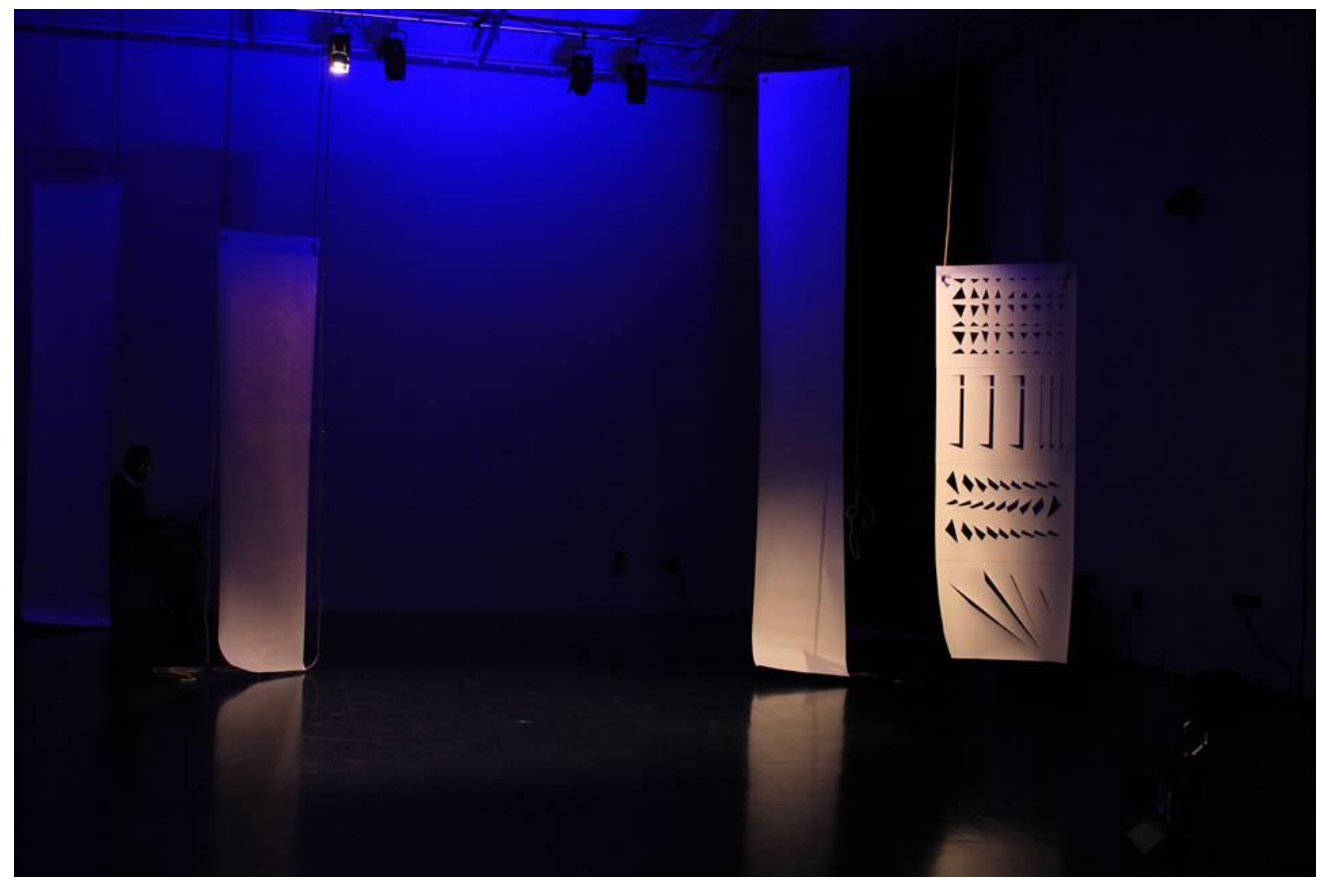

Fig. 1816: Set and space exploration: Hanging panels for the set, showing lighting hues. Far right panel has tatau patterns laser cut into it. Lighting design by Dominic Crossman $\mathcal{E}^{\circ}$ Jeremy Larkin. Set design by Ivo Deliyiski (photo by Leigh Minarapa; taken: 15 May, 2015).

A few of the panels had patterns laser-cut into them, these patterns were similar to traditional Samoan tatau designs and in certain lights the reflection on the back wall created abstract skyscraper shapes of a busy city. The space became important in conjunction with the panels and the spirits themselves creating triangular formations, relating back to liminality (a third space) and the Va (see fig. $18 \& 19)$. 


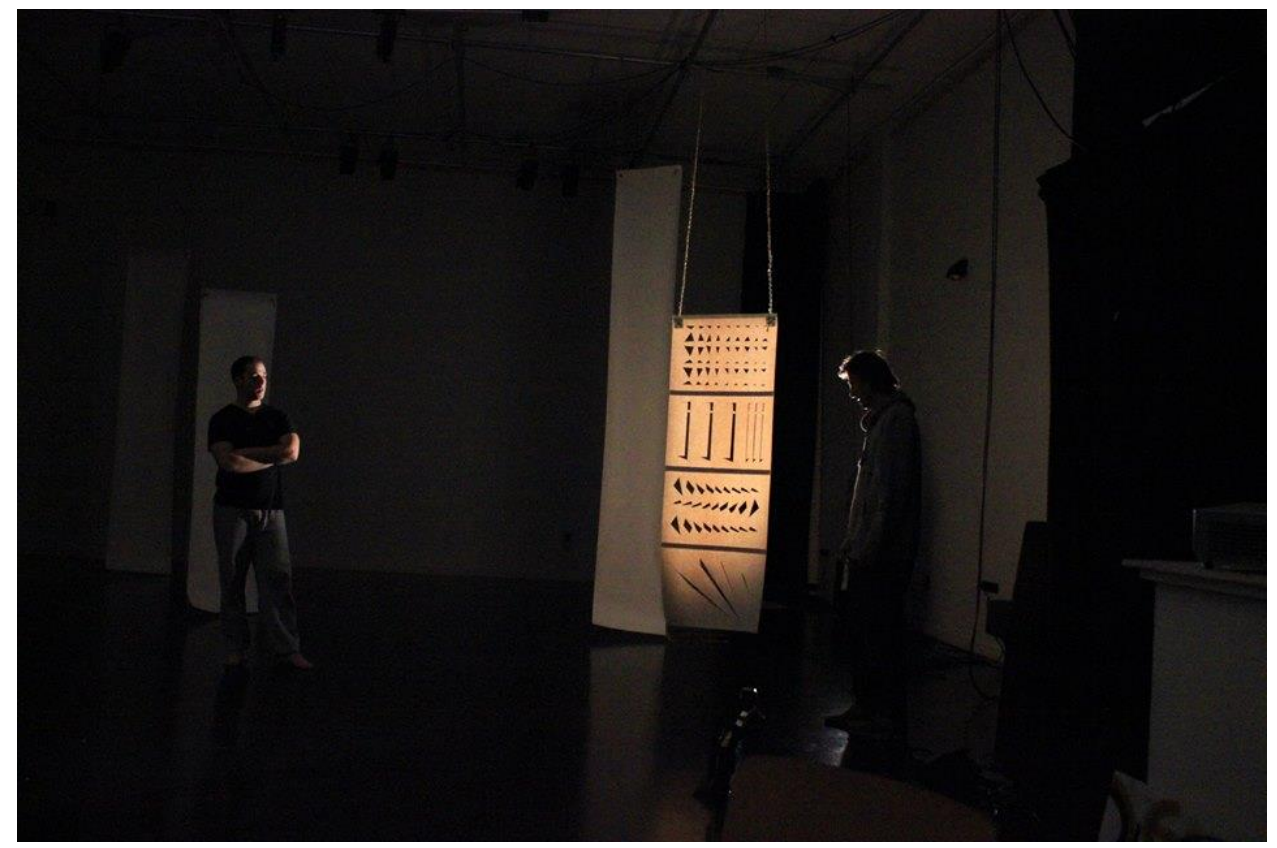

Fig. 179: Set exploration: another view of the tatau design on the panel; coupled with a light shining from behind; evoking a discussion about the shadows and relationships with panels themselves. Lighting design by Dominic Crossman \& Jeremy Larkin. Set design by Ivo Deliyiski (photo by Leigh Minarapa; taken: 15 May, 2015).

\section{Powder exploration.}

We were drawn to this idea of powder being used in the spirit world right from the start because of its physical qualities, the fact that it can move in and with the spirit world. From the audience's perspective, it became a source of mystery that had the potential to be in both worlds; a living part of the spirits as they move about and also present in the real world as an actual substance - chalk or dust from the classroom or changing room. 


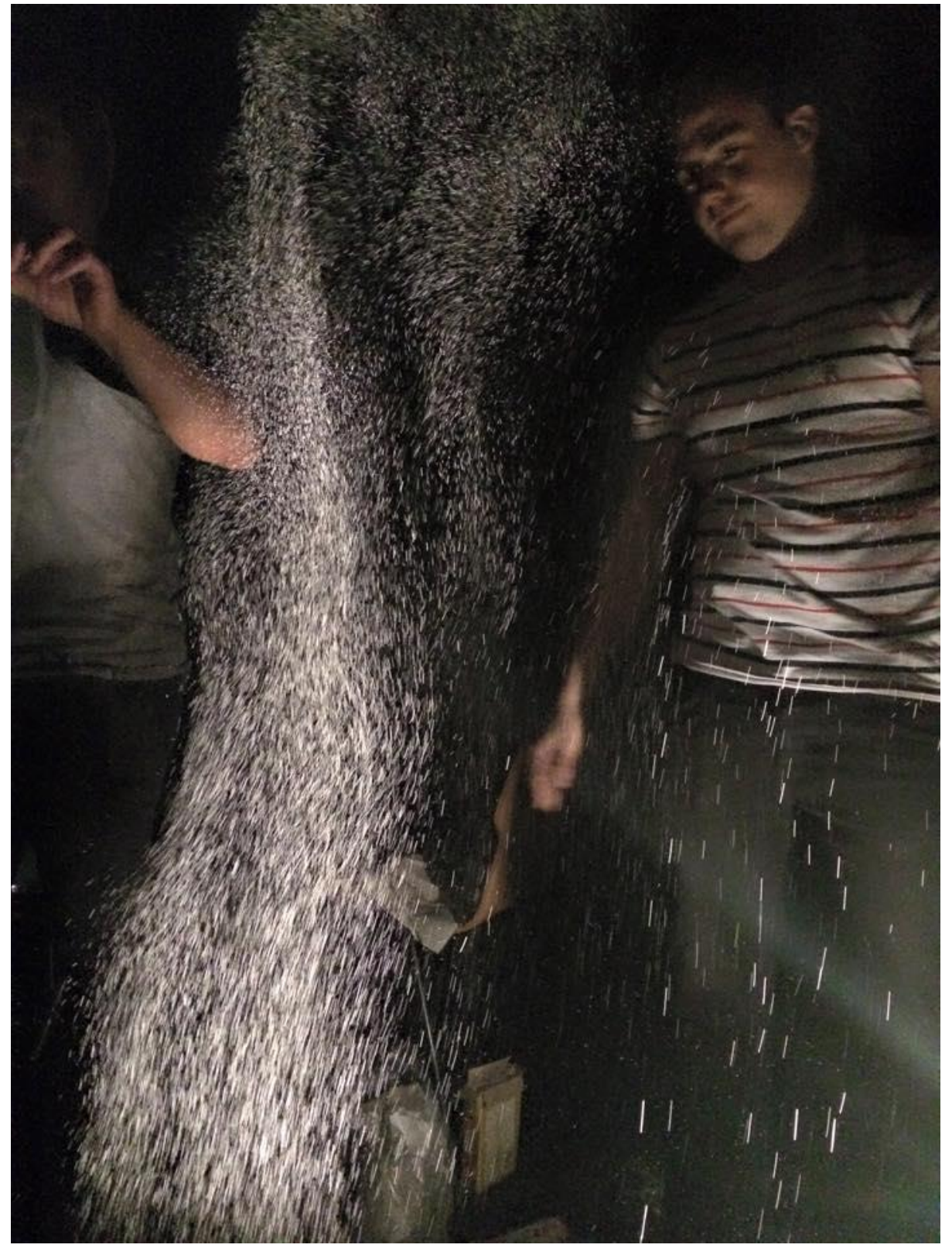

Fig. 180: Powder and light exploration: distinguishing the characteristics of the powder interacting with the light and how the light reveals the individual particles of powder. Lighting design by Dominic Crossman \& Jeremy Larkin (photo by Sonny Tupu; taken: 16 April, 2015).

We explored the powder as being "traces of the spirit world left behind" in the real world (Spirits Workshop, 2015). The way it floats in the air and reacts with and latches onto the spirits themselves (see fig. 20). Cocoa powder was mixed with flour to create a rich white and brown combination that initiated a synaesthesia effect and interestingly triggered more senses than we had anticipated. The smell of the 
cocoa powder evoking responses which took audience members back to the islands or were reminiscent of home cooking.

\section{The spirit world and rugby}

A significant discovery of the spirit world as it came to fruition was that there was a certain primal energy to the spirits themselves, in their movements and choreography: a degree of masculinity and intensity coupled with quite beautiful movements. For a play that exists in the rugby realm, there are no specific scenes of rugby being played itself, this was a conscious decision in the writing of Blackout because I did not want a representation of rugby to take away from the real issues at hand. However, in creating this piece, the lack of any form of rugby onstage takes away from the feeling of rugby. For the development of Blackout, the need for more sense of rugby is apparent and the spirit world I believe is the key. The spirits need to not only symbolize but play a role in creating the energy of a rugby match; embodying the feeling of night trainings, pre-match warm ups and games themselves. Through the physicality and even the unity of bodies, a question that could be pushed further is the importance of the bodies being male within the symbolic creation of the rugby world. Furthermore, for the development of the final draft, considerations on how formation and stylised movements could contribute to ideas surrounding not only rugby but concussions were revealed; creating feelings or sensations rather than literal representations of rugby to help push the arc of the narrative and (important to the story): to build tension.

There were many successes taken from Spirits, including the aesthetic of the spirits, the world they inhabit and movements themselves. However, because of the 
time constraints and practicality; Spirits became less about the actual scenes and more about creating the whole world and aesthetic of the spirit realm and how it interacts with the real.

\section{Actors' piece exploration}

The next stage of development came in the Actors Piece or MTA Block II, where the focus turned to the relationship between Sua and Elle. As mentioned earlier, this piece was solely rehearsed with the actors and the director. The implications of there being no dramaturg and the writer not being present in rehearsals meant that there were cuts made to the script that were not cross-checked to see the impact it had on the character relationships, dynamics and the script or story as a whole. The cutting of the script made changes to the way in which the words were intended and, in turn, the way the action is played out. However, as the playwright, I do take responsibility partly due to the many stage directions in the script that come across as directorial directions. Nonetheless, the changes and cuts made were in some cases against the intention of the writing and ultimately, affected the way the script was read and how the mood was interpreted (see comparison of fig. $21 \&$ fig. 22). 


\section{Sua}

You crack me up. Can't imagine us with a little (mocking) farlay-art-are waking us up every morning.

Elle

Yeah you're right, one syllable for his name sounds good.

Sua

Speaking of one-syllable...

Sua takes Elle's hand and bends down on one knee. She clasps

her other hand over her mouth and immediately starts crying.

Oh shit hun, I'm just joking. I'm joking!!

Her cries turn to sobs.

Oh fuck, Elle! I'm so sorry!

Sobbing louder and louder.

Fuck, I'm an idiot! Babe, I'm so sorry, I didn't mean...

Her sobs turn to laughter and she reveals grin.

You asshole.

I got you good!

Elle

Fig. 21: Excerpt from Blackout First Draft, Scene 3: NAMES.

\section{Sua}

I can't imagine us with a little (mockingly) Faleata waking us up every morning.

Yeah, one syllable sounds good.

\section{Elle}

(Sua "stalks" Elle before pretending to propose.)

\section{Sua}

Elle... Hun... Babe!?... (Elle reveals grin.) You asshole. And you wonder why I don't take you out in public.

\section{Elle}

Speak for yourself. Don't you ever do that again.

Fig. 22: Excerpt from Blackout Workshop draft, Scene 3: NAMES. This draft was the cut draft that was used for all the projects. 
The excerpts shown are an example of how changes made can influence a scene and the mood, the light playfulness of Sua is lost in the second cut and he does not come across as apologetic for his prank. As mentioned above, I do take responsibility for the many stage directions coming across as directorial directions, as the actors and director would be left without any room to explore and discover anything about the characters. Again, as will be made clear later in the chapter, a dramaturg could have filled a role here in speaking for the playwright and negotiating a balance between the director and actor exploring the character, while keeping within the intentions of the playwright and in this example, keeping the playfulness of Sua evident and ensuring this soft side of him is clear for the audience. For Ian, the aim of the actor's project was to see if the character relationship made sense in isolation from the rest of the play and whether action can be a more effective way of communicating ideas instead of the words themselves. For the latter, it would make sense to take unnecessary words out of the script and again, a dramaturg could have acted as a middle person to assist in the cuts. For the former, the exploration into action as opposed to words did illuminate ways in which the development of the script could benefit from replacing dialogue with action.

For example, the cleaning scene in the actor's piece offered a new avenue for Sua's character exploration. Sua's job as a cleaner in the first draft of Blackout has him picking up a pieces of rubbish without ever really getting into any cleaning of the place. In the actor's piece, Sua came in with a broom and immediately started cleaning the changing room floor. The most interesting part of the scene came through Sua's unknowingly repetitive actions and forgetfulness. He sweeps the same patch of floor a couple of times before pulling out a spray and wipe and going over the same spots again. His actions are almost obsessive in nature as he feels the need to clean certain 
parts that he's already cleaned. The simplicity of the actions speaks volumes about Sua and his mental state, more effectively than any words could. These lapses in memory are important because they mark early symptoms that later impact on his health; not only that but they feed into the overall discussion of head knocks and Sua's attempts to deal with them. The action in this scene becomes very important, particularly because of the fact that Sua is alone with his thoughts and demons and here the first connection with Sua's mental state was discovered. Whilst these discoveries were made during the Actor's Piece, it is important to note that during the Major development season, many of the discoveries from the Technical Piece Spirits and Actors piece were not fully realised in performance due to the director's own goals; however, they have benefitted the overall development of the script. There are multiple layers of Sua that were further discovered and will be discussed in this chapter.

\section{Miscasting dilemma}

It is important to note in this part of the process that a lack of communication between the director and producer, along with a range of outside commitments by several of the performers, led to a very short rehearsal time frame. I believe this put pressure on Ian to make a call on who to cast and led to a rushed decision to cast Sonny as Sua, which I now realise was a miscast. The markers for the actor's piece for Ian were both in agreement that Sonny's portrayal of Sua was not believable with one marker stating:

“...I'm not sure I totally bought him as a rugby player in terms of how he moved, as he was very fluid and lithe, and I tend to think of rugby players as having more hard muscle, which tends to mean less flexibility...” 
Whilst not resorting to clichés, I can see the critique in the markers comments, another marker also noted:

... Casting was a significant obstacle to a compelling realisation of the world of this piece $[\ldots]$

... His (Sonny's) intrinsic qualities (playfulness, lightness, a silliness) were not right for the material - and thus any believable tension, stakes, and the ability to invest us as an audience in the drama suffered accordingly.

The director and I did not work together on the casting and an opportunity was lost when a dramaturg was not assigned. The miscasting and subsequent loss of believability was the result which is a reflection not on the actor, but the process by which he was cast. This lesson came at a small cost to the overall production, but became a valuable lesson learnt about the role of the writer in the rehearsal room. As the playwright, if there is no dramaturg, I need to take necessary steps to ensure the qualities of the actor fit with the qualities of the character. In this mis-casting, the issues with Sua's lack of character arc were clouded by what seemed to be problems with the way he was played, while in fact the character arc needed to be addressed in the structure of the narrative.

\section{Exploration and development of Sua}

In the actors' piece we meet a heavily complex Sua in three different environments: his work as a cleaner, contrasted with his social life out on a date with his partner Elle, and finally at home. This was the first time seeing Sua being played in person and as a writer, automatically the embodiment of a character you created can illuminate ideas that were not clear in the initial writing. These revelations were explored earlier, concerning Sua's mental capacity to work and deal with his inner issues. The physicality and demeanour Sua provided during his cleaning scene 
offered more understanding of the person Sua is. One of the most striking pieces of feedback we received came from his actions of sweeping and the fact it was read as the trope of subservient slave/servant. The defeated attempts to sweep sees Sua carry a heavy burden of shame and embarrassment, and he carries this in his shoulders. This discovery was important because it alluded to earlier notions explored in Chapter One about the struggle to find an aspect of fa'aSamoa that young Samoans can be proud of and identify with: that of providing for his family. Compounding this is that Sua must clean the very place he grew up in being idolized and afforded great status - the school changing rooms. These ideas of a man struggling to come to terms with the fact that he cannot continue to lie to his family and his partner are all part of the character and needed to be reflected in the developed script in order for the audience to truly empathise with this character.

\section{Brown Ink Workshop discoveries.}

As noted earlier, the workshops, led by Nathaniel Lees, concentrated on five key scenes: 3. Names, 8. Home, 9. Party, 11. Coward, 13. Big Game and 14. Hospital. For the workshops, in particular in scene 11. Coward, we explored the characters of Elle and Sua and the internal and external battles they face. Elle and Sua ran through their lines face-to-face, after a full run-through, the cast split into two groups and stood behind either Elle or Sua. Before each line was spoken, the supporting cast would act as their character's brain or conscience feeding their feelings to Elle and Sua. Before we knew it, our characters had motivations, underlying feelings and unresolved issues that sat at the core of the breakdown between the couple. Words fed to Elle were that Sua had been lying to her all this time, and that he didn't care about her or their baby. Sua's 'inner voice' leaned more towards his struggle to provide for his family and the absolute need to continue playing. Whilst these may 
have not all have been necessarily true, the exploration provided insight into the couple's inner thoughts and in doing so gave more weight to each other's replies. As mentioned earlier, because of time constraints the discoveries from the Brown Ink workshop would not directly influence the script for the Major production of Blackout, however these inner thoughts did would play a key role in the development of the two characters in the final draft. The exercise highlighted the importance of motivations in establishing the stakes of the relationship and the subsequent rise and fall of the characters.

\section{Eva and Jacob's relationship}

As the workshop progressed, an interesting relationship that was explored was between Eva and her younger brother Jacob. This sibling connection intrigued the cast, including the two who played them Moana Ete and Chris Alosio. They spoke about their own connections with their siblings and both made similar remarks regarding a special bond they share with them. This bond is quietly evident in the manner in which Eva speaks to Jacob, the fact that she feels comfortable enough to scold him and praise him at the same time; and also the way in which she says:

And I would have smashed you... (Blackout first draft, 9: 33).

This bond is an important one for Jacob not only because it is one of his only outlets outside of the boys to speak about anything, but it offers insight into his home life and more importantly can allude to the cultural struggles young pacific islanders face today and how they deal with them. My reworking of the script in the final draft explored this relationship as mode to examine those struggles. The 
development in the relationship between Eva and Jacob in 9. Party opens up a discussion on the battle between contemporary and traditional cultures as discussed in Chapter Two. The dialogue voices Jacob's concerns over his role in looking after the family, with him feeling the pressure from his Dad to succeed because of Eva's perceived lack of success.

\section{Structure of Blackout}

The Brown Ink workshops also enabled me to re-evaluate the positions of the final scenes of Blackout. During a run through of 13. Big Game and 14. Hospital, it was questioned whether the placement of the two scenes made sense, particularly in terms of the rise of tension and action contrasted with its fall. The culmination of the play and the all-important decision plaguing both Sua and Jacob leads to scene 14. Big Game, which climaxes with the entrance of the spirits, Sua and Jacob standing side by side and a crowd cheering in the back. What follows is a complete anti-climax, Scene 14. Hospital, all the momentum from the previous action is lost and the scene attempts to pick up again from scratch. In discussions with Nathaniel Lees, he suggested I reconsider the ending so as not to let the piece lose any momentum, unless it were my purpose. Thus, the final draft of Blackout merges the climactic scenes of 13. Big Game and 14. Hospital into one to maintain and build on the energy until the final scene.

\section{Major Production: (Development Season of) Blackout with post-feedback}

\section{Exploration and development of Elle.}

For Elle, the discoveries in the actor's piece came about her movements, demeanour and the static images the actor playing her created during the rehearsals. An image of Elle on her knees with her head bowed became a recurring position for 
her character. As it was with Sua, being able to see Elle in the flesh added elements that I believed could not have been discovered through just my own writings and exploration of her: a contrast to the dominating masculine roles of the other characters in the narrative. The image itself brought impressions of loss and hurt and brought me back to my initial spirit explorations; the feelings of helplessness. Contrasted with that is her demeanour during her scenes with Sua; she holds her own on stage; against Sua whom the boys have looked up to since forever. There is a balance between the two throughout all the scenes, especially during the museum scene and the scenes at home; however this balance is broken later when she finds the pills and finds out Sua hasn't been to training for the last couple of months. The power shifts and for the development of the script this power shift was key to restoring the balance. In the original script I had Elle letting Sua leave to go to the game and her being left on stage to ponder that choice. I believe for the development of the script the power needed to shift into her hands and it was better for her to leave Sua to ponder his decision.

The major season of Blackout provided the platform to experience a full season of development that included progressing the piece night after night. It gave me the biggest indication of where the piece lay and where it needed to go. Whilst there were design and production elements I could not control, for the most part the development of the script in performance would benefit the development of writing Blackout the most. As a writer, I needed the characters to drive the story in order for it to impact the audience and for that I needed them to either care for the story and/or characters or at the very least, empathise with them. Throughout the development, I knew I had to raise the stakes for every character. For some of the characters, the stakes may have been high in my mind; however, I needed to make them clear for the 
audience. I went back and looked at all the characters and their motivations to help enhance their character and their role in the play.

\section{Development for the young boys: Jacob, Lui, Vale \& Mangere.}

For Lui, his driving factor is the recent passing of his mother after a yearlong illness and the fact that he felt helpless because he couldn't do anything to help her. In response to this, Lui is in a battle with his best friend to stop him from risking his life from another head knock; his motivation is that he knows he can do something to help Jacob and save him from possible death - one thing he couldn't do with his mother. Lui's character is not in a good headspace to begin with and with this motivation and drive his intentions become clear. The task here was to add or rearrange the script to include these details and characterization. Lui is torn because he understands Jacob's position of being academically below average and needing to succeed in sport to provide an earning opportunity in the future. Lui doesn't want to stop Jacob from achieving in life but doesn't want to see him lose the battle to succeed for himself and his family through brain damage. Lui's relationship with his Dad is strained because of the loss of his mother; throughout it all, he pleads with Jacob to rethink his decision. Another aspect focussed on in the development was during the Party scene where Jacob and Lui get into a heated exchange. I believe this needed to be stretched out with more context for both characters; certain lines explored from Lui to Jacob were:

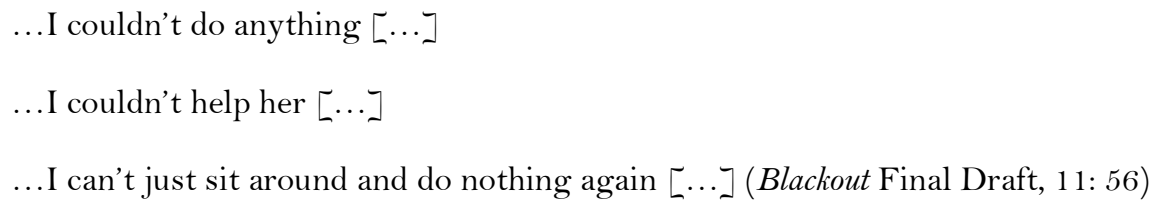

The argument cannot end that unresolved; as with the confrontation with Sua and Elle. One final development is for Lui to be experiencing his own demons resulting 
from the loss of his mother. At his mother's funeral, a song was sung during the burial which haunts Lui; he can't get it out of his head and it pushes him deeper into a depressive state. For him to crawl out of this hole, the boys need to be there for him. Jacob meets Mangere who has a troubled upbringing and Jacob realises he could be the one to help Lui. Mangere learns of Lui's troubles including the song which haunts him; he convinces Jacob to teach him and the rest of the boys the song in order for Lui to turn it into a positive and something that he can remember her with. This arc for Lui, Jacob and Mangere offers the opportunity for them to be seen in a more vulnerable state.

For Mangere, I needed to flesh out his story and his role within Blackout. I decided he moved down from another city to live with his aunty; he had a rough upbringing and he has dealt with his own losses, similar to Lui. Mangere was a representative rugby player where he was from (Mangere, South Auckland), he's as stubborn as Jacob when it comes to rugby, however, he never had someone in his corner reminding him there's more to life than rugby. These boys are Mangere's first taste of family as he does his best to fit in and prove to them his worth. Jacob sees himself in Mangere's struggle and he knows what he's going through; there is room here to create tension between the two, however I believe the cohesion Mangere has with the group is more valuable to the story.

A new scene development came from this exploration when Jacob realises that Mangere can help with Lui so he invites all of the boys over for a sleepover. We have the chance here for more exposition as well as delving deeper into the minds of the characters including Vale - the clown and joker of the group. Vale never gets treated equally, he is always being ignored and 'ganged up' on, however he is always 
quick to praise others, especially Jacob. Finally, he 'talks himself up' but does not really give himself a chance. Questions arose about whether Vale's constant joking is a façade for something? This took the exploration into his fears and his dreams. I believe Vale is scared about what to do after school. As he says himself, he is the "Big dog on campus" (Blackout, 2014: 1, draft 1): school is his life, it is all that he knows. It is during the sleepover - developed in the final draft - that they question what they're going to do with their lives. For Vale, it is the first time he is completely honest and candid with the boys and it foreshadows the future Vale who covers for Sua when the others question where he has been the past couple of months.

Jacob's development took the form of raising the stakes for him and foreshadowing symptoms of repeated concussions. In the early scenes, the boys need to allude to his impending Captaincy selection as a massive deal. As a rugby player in school you're afforded "jock" status and as Captain you become a cult hero. The scouts who are attending trials are there to see him, his future is all but signed and Jacob is on the road to professional rugby stardom. His parents, the coaches and himself add the pressure of success and fear of failure into his mind - compounding this are Jacob’s symptoms of memory loss, depression and headaches running parallel with Sua. An indication from the early developments is that Jacob’s story will mirror Sua's journey in many aspects, including his search for scholarships abroad in order to receive a contract to help his family.

\section{Development of Sua and Elle}

Sua's development emulates that of Jacob's, finding ways to raise the stakes and reinforce his battle with the effects of concussions. Important for Sua are his relationships: with his partner, with his sick mum and with his future son. In order to 
raise the stakes, his Mum's sickness needed to be revised. Setting this piece in New Zealand offers me the chance to explore problems facing New Zealanders today and this led my research into the impact of cold or damp houses, specifically, Government state houses. Recent articles ${ }^{101}$ linking poor or often non-insulated state houses with respiratory illnesses leading to death are alarmingly common. Moisture from cold weather condenses on surfaces which can lead to dampness which can further lead to mould growth, contributing to respiratory problems. Hawaiiki Edwards moved into a state house in Porirua and after six weeks wants out:

Edwards is worried for their health and for that of their mother, who suffers from a weak heart brought on by childhood rheumatism from growing up in a damp state house (cited in Edwards, 2015).

Sua's mother and her health issues can reflect this dilemma; whilst not necessarily speaking directly about it, I believe I can create a discussion surrounding the housing qualities in state houses across New Zealand.

For Elle, a lot of the development comes from who she is as a person and what she does in her life; separate from being "Sua's girlfriend”. For this development, Elle not only needed her own life outside of her relationship with Sua but also for this life to be sketched in throughout Blackout. Specifically, that Elle is in her last year of university and that she has been working in retail part time for the most part of her studies. These minor developments not only provide her with extra characterisation but also enhance her own struggles and show that she is multidimensional. A major development is that Elle is aware of Sua's mum's condition and during their

\footnotetext{
${ }^{101}$ See http://www.stuff.co.nz/national/health/69249015/Another-death-linked-to-damp-state-house \& http://www.stuff.co.nz/national/health/69385415/Porirua-dad-fears-for-familys-health-in-freezingdamp-state-house, accessed 10 March 2016.
} 
argument at home, she tells Sua just how bad it is. Elle needs to leave the argument on high ground and the audience need to have a little 'hate' for Sua in order for the decision he eventually makes to become all the more important for everyone involved.

\section{Development of Eva and other minor character shifts.}

Eva's story, I believe, enhances Jacob's motivation. Their dad wanted her to succeed in becoming a lawyer or doctor; instead she resigns herself to becoming a nurse, which in itself is impressive however, is not enough for their dad who always wanted the best for them to reflect on the family. Eva also has the opportunity to cast a light on the role of women in Samoan culture through the duties and responsibilities noted in Chapter Two and how they affect her relationship with Jacob. The fa'aSamoa aspect comes into play; the search for an aspect of fa'aSamoa that Jacob can be proud of is found through rugby and fulfilling his dad's aspirations for him; to repay him and the family. An opportunity to raise the stakes is for Jacob to receive new rugby gear from his dad for his birthday; shoulder pads, new boots all the newest and high quality.

The role of the coach was in need of revising; the original script had him as a sort of bumbling coach who never really had a clue about his players. I think to give more emphasis to the concussion discussion, he needs to know that Sua has not been playing for that very reason. With this knowledge he intentionally questions whether Sua believes he is up for the job. Sua agrees to play on one condition: that his contract be renewed and all stipulations of player welfare including family welfare are adhered to in any event. Sua, with the newfound knowledge of his mum's sickness and knowing his family is about to grow by one, decides that this game will define 
the direction of his own life. This piece of information is crucial in the play as it cements Sua's final decision to play; with the knowledge that his family is going to be financially alright.

\section{Dramaturgy}

There are overall script developments that I believe will further the work. These are to do with transitions, the characters entering scenes with energy or one scene building another and not allowing the energy in the space to drop during transitions. An important factor to consider along these lines is space and setting; creating motivation for the scene locations and realising the importance different settings can hold. This was explored and developed through the museum scene. Instead of Sua and Elle stumbling into the exhibition, it is established that Sua first took her there in order to impress her on their first date and since then it has become their 'thing' to hang out and explore the new exhibitions every so often to not only remember but poke fun at Sua's childish attempts to woo Elle. This gives the space more meaning and more drive for the characters to be there.

Along these lines, the setting of the bus stop comes into question. The relevance of it is that Vale and Sua have often caught up there - however, what purpose does it serve during the arguments? What settings can be changed to enhance the interaction and story? Another aspect for consideration is the impact of 'reveals' of important information. In the phone message from the coach to Sua that Elle intercepts, could this be explored with Elle taking the phone to training and finding out there; what are the implications or power in that reveal? The time travel jump in the original script was rearranged to occur in chronological order for the 
production and I believe this was the way to go with the final script; it enabled the dialogue to flow better and the tension to build and release further.

Another 'reveal' to look at is at the hospital with the audio over the intercom reciting the details of the now-deceased Sua in hospital; this for me did work during the performance yet in the final development will be addressed differently, with Eva finding out about Sua's passing and giving his jacket to Elle, along with the ring inside the jacket pocket. The crucial ending to Jacob's dilemma is concluded with him not playing altogether. Here I am offered the chance to frame his decision as a cross generational theme of change. The generation of Jacob's parents represent a world of diaspora, that of change, that of acclimation to a new world. Sua's generation is the product of this world integrating into the new world and the struggle between traditional and contemporary values; and whilst Jacob's generation is not far removed from Sua's, his generation represents the change for the next generation that of, Sua's son. In this respect, Sua's son and the world he will grow up in is the one that will benefit from Jacob’s decision.

Finally, the Spirit World I believe holds the key to unlocking the discoveries made in the development of the final draft. Their energy, persona and visceral nature provide the basis for all things required of Blackout; using the spirits to create powerful imagery, tension, the feel of a rugby match, the nature of a Samoan person, distinguishing relationships and the space between them; they need to drive the message when the story ends. 


\section{CONCLUSION}

The research and subsequent development of the play enabled the experiences of second generation New Zealand-born Samoans of today to be explored and advanced through the narrative of Blackout as well as the expansion of characterisation and subplots. I wholeheartedly believe that without the staging of both the real and spirit worlds in the play, as well as the preceding review and postproduction discussions; Blackout would not have fully realised its potential and reached its stage of development now at the final draft.

The major production and development of this script revealed what it meant to be an emerging playwright; through the feedback process, we garnered responses from an array of people including rugby players, youth members, church goers and plenty of Pacific faces within the Samoan community enabling this play to become a forum for discussion on matters relating to that very community. For the major project, through social media campaigns, word of mouth and online ticket sales; we were able to sell out all four of the night showings and almost sell out our only matinee show on the last day. The characters resonated with the audiences: "Amazing realistic depiction of the friendship and Pacific culture..." (see fig. 23); they were intrigued by the stories "Loved that the topic was dealing with rugby (head) injuries and the shame, pressure to continue playing..." (see fig. 24); captivated by the fruition of the Spirit World and what it could represent: "Enjoyed the symbolic movement around the space to represent the humans/spirits and the va in general..." (see fig. 24); but importantly, they were grateful to have witnessed a piece of Pacific theatre, grounded in Pacific aesthetics and life and true to the real world of young Pacific Islanders today. 


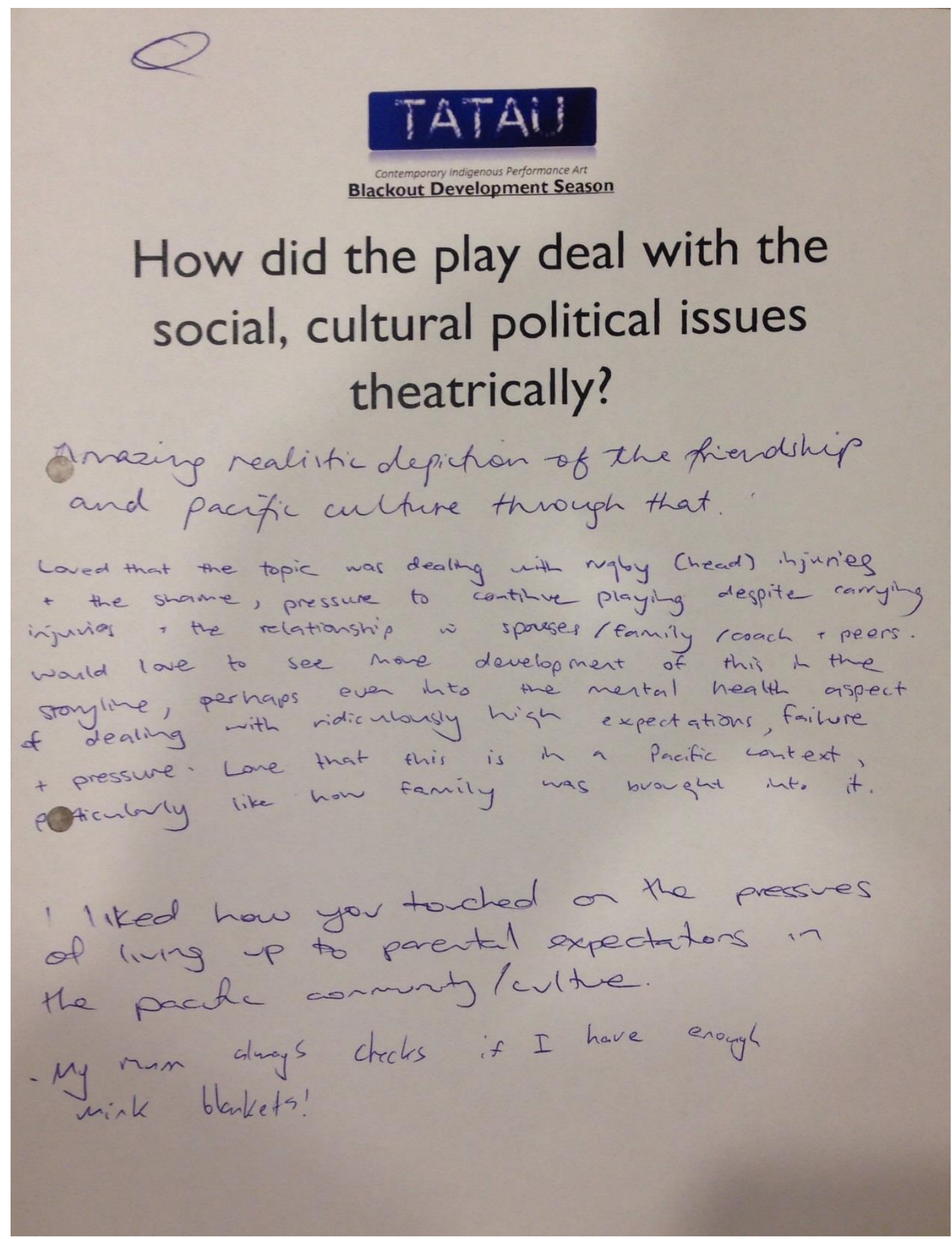

Fig. 19: Audience feedback response sheets for Development Season of Blackout. 


\section{TATAII}

Blackout Development Season

I really erijoyed the of the ytart cunjettling' Sounds w/ the spirti world and then the spists corforing the sople

\section{What is the connection of the Spirit- )}

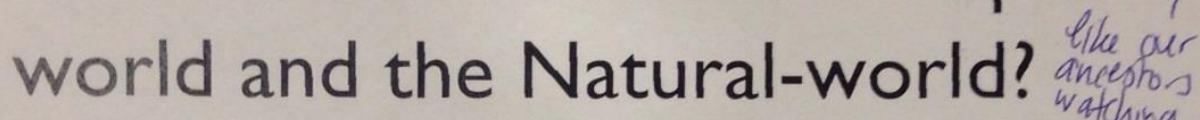

- Spintworld was expressing \& reflecting the feelings of the characters. Thiswas a fantasticidea \& came off really well-you could Aell how the actors ram felt underrealth.s

- Taleing awang the spivits dialogare neygle.

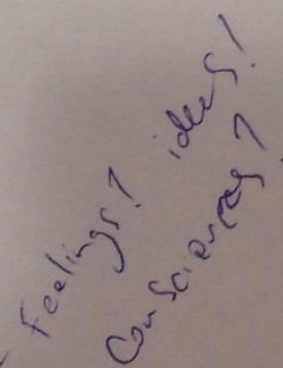

Fig. 20: Audience feedback response sheets for Development Season of Blackout.

In aligning the work of Spirits (MTA Block I) with a specific Pacific Arts Festival: The Measina Festival, the work reaped the rewards of connecting with nontheatre goers as well as audiences that were not familiar with Pacific theatre. One of 
the major challenges faced was the role of the writer in the rehearsal room. On the one hand I was able to provide clarity for director and actors when approaching aspects of the script and when it became apparent what needed work, in most instances I was able to address this immediately. However; it did provide its own challenges; a need for a clear cut-off point where script enhancements would stop as I found myself constantly wanting to change this here and that there. Another challenge was adjusting to the roles between director and writer and finding clarity between both. In a script which is almost semi-autobiographical, it became a constant balance between having a vast amount of freedom to direct the actors in certain ways and controlling myself to let them discover new and exciting ways of performing the text and then letting the director take control of the script and find what was necessary for his interpretation of Blackout.

Finally, the biggest challenge faced in this whole process was attempting to clarify and develop the narrative without any dramaturgical work on the script itself; this I believe set back the development process of the script more so than I had imagined. I filled the role of production dramaturg; answering any questions regarding motives and objectives for characters; however, I did not seek any dramaturgical help in the development of the script pre, during or post-production; a change I would almost immediately make during the next phase of Blackout. A dramaturg acts as a representative for the playwright, knowing as much about the play and the language used as the playwright did writing it and also having a grasp on the context in which the play was created. The dramaturg then provides this information to the production team in the creative process and remains a valuable source of knowledge on the play throughout the rehearsal process. The dramaturg negotiates between the words of the playwright and their intentions and the actions 
of the directors. This key role was missing in the development of Blackout and is reflected in the miscasting of Sua and the editing of the script from the first draft to the workshop version: changes as seen in the scenes between Sua and Elle previously mentioned but also in the argument between Jacob and Lui in the party scene where the point of the argument is missed when Lui's lines concerning Jacob trialling were taken out, causing confusion as to why he was angry in the first place. These minor changes had a snowball effect that could have easily been avoided had a dramaturg been present.

Masculinity in New Zealand stemmed from cultural and practiced attitudes surrounding rugby and ideal "manliness" that are still attached to young kids all over New Zealand today. Compounding this for young Samoans is a search for culture or fa'aSamoa, which enables acceptance and prescribes identity for them today. If masculinity provides a basis for acceptance in New Zealand culture today and sporting success can provide financial success which leads to cultural acceptance, then a loss of both creates a loss of identity. The sustained shame of not being able to either perform or provide for family is thereby pushed beyond the physical. Greater than a financial loss; of more concern is its effect on the mental and spiritual. The spirit world provides the key to physicalizing this conflict; giving breath to a world that only exists within and between; in the nothingness. The spirits themselves operate dramaturgically to serve the story; reflecting the ongoing struggles of the characters while at same time functioning as a force in the real world. The kaupapa behind Blackout concerned Pacific stories, the significance of them and the ones that deserve to be told and more importantly from the perspectives of those concerned. Pacific Theatre is an historical account of people growing up and living in Aotearoa; from the works of Oscar Kightley leading the way with a number of other Pacific 
Island (Māori included) writers and Pakeha influences, to tell the stories of a purely Pacific Island experience that wouldn't be found anywhere else. A hybrid of theatre that told our stories, in our voice, because not only must they be told but they must be remembered. I live as a part of the second generation of New Zealand born Pacific Islanders and our experience, whilst similar in aspects to those of our parents, I believe deserves our own stories and its own generation of Samoan-New Zealand theatre makers. For myself, this meant a journey into the world of a young Samoan, living today with unique pressures, which forms the narrative of Blackout, but a journey which also extended to the research and development of the final script. 


\section{REFERENCES}

Badel, Peter. “Queensland NRL Stars Speak out on Suicide,” The Sunday Mail (Qld). June 14, 2015. Web. 22 Jan. 2016.

Balme, Christopher B. Pacific Performances: Theatricality and Cross-Cultural Encounter in the South Seas. Basingstoke: Palgrave Macmillan, 2006.

Barnett, David. "When Is a Play Not a Drama? Two Examples of Postdramatic Theatre Texts.” New Theatre Quarterly 24, no. 1 (2008): 14-23.

Barrowclough, Anne. "Rugby League’s Tragic Legacy,” The Australian. May 29, 2015. Web. 22 Jan. 2016.

Barton, Joe. "Polynesian Stars Want More Help for Youngsters.” Stuff.co.nz, May 3, 2013, sec. Sport. Web. 1 Feb. 2016.

Bayer, Kurt. “Coach Calls for Forum on Rugby Head Injuries after Teen’s Death.” New Zealand Herald, July 8, 2014, sec. National. Web. 11 Jan. 2016.

Bergson, Zach. "Sports and Money: Economic Impact of The Rugby World Cup.” Reynolds Center, September 14, 2015. Web. 19 Jan. 2016.

Bhabha, Homi. “Of Mimicry and Man: The Ambivalence of Colonial Discourse.” October 28 (1984): 125 .

Brown, Michael. “NRL: Deaths Raise Welfare Questions.” New Zealand Herald, May 4, 2013, sec. Sport. Web. 12 Jan. 2016.

Cadzow, Jane. "Tragic Story of Rising NRL Star Mosese Fotuaika.” Stuff.co.nz, May 26, 2013, sec. Sport. Web. 19 Jan. 2016.

Carter, Anton. "Taking Centre Stage: Pacific Theatre in New Zealand" in Mallon, Sean, and Pandora Fulimalo Pereira." In Pacific Art Niu Sila: The Pacific Dimension of Contemporary New Zealand Arts, edited by Sean Mallon and Pandora Fulimalo Pereira, 147-59. Te Papa Press, Museum of New Zealand, 2002. 
Clark, Shekyna. "Mt Albert Grammar: Bryan Williams.” Online Video Clip. YouTube. YouTube, 23 Oct. 2013. Web. 18 Jan. 2016.

Cleaver, Dylan. “B.G Williams - 'Beegee’ Our First Samoan Superstar.” New Zealand Herald, August 1, 2011 , sec. Sport. Web. 12 Jan. 2016.

Crawley, Paul. "Eels Face Huge Fine for Three Heavy Hits.” The Daily Telegraph, 24 Mar. 2015. Web. 11 Jan. 2016.

Deane, Steve. “Shontayne Hape: My Battle with Concussion.” New Zealand Herald, May 31, 2014, sec. National. Web. 6 Feb. 2016.

Dijk, Bert Van. Towards a New Pacific Theatre: Practice-Led Enquiry Into a Model of Theatre Making That Relates to the Geography, Culture and Spiritual Values of Aotearoa/New Zealand: A Thesis Submitted to the Victoria University of Wellington in Partial Fulfilment of the Requirements for the Degree of Doctor of Philosophy in Theatre. Victoria University of Wellington, 2010. 256.

During, Simon. "Postcolonialism and Globalisation: A Dialectical Relation after All?" Postcolonial Studies 1, no. 1 (April 1, 1998): 31-47. Web. 15 Jan. 2016.

Edwards, Jessie. “Cold, Damp House Needs to Go.” Stuff, 16 Jun. 2016. Web. 27 April, 2016.

Efi, Tuiatua Tupua Tamasese. Su'esu'e Manogi - In Search of Fragrance: Tui Atua Tupua Tamasese Ta'isi and the Samoan Indigenous Reference / Edited and Compiled by Tamasailau M. Suaalii-Sauni ...[et Al.]. Samoa: Centre for Samoan Studies, National University of Samoa, 2008.

Efi, Tui Atua Tupua Tamasese Taisi. "In Search of Meaning, Nuance and Metaphor in Social Policy.” Social Policy Journal of New Zealand, no. 20 (2003): 49.

English, Tom. “Rugby’s Concussion Issue under the Spotlight.” BBC Sport, 1 Jun. 2014. Web. 6 Feb. 2016. 
Fanning. "Nuzum's Death Confirms Rugby Has a Crisis on Its Hands.” Independent.ie. 17, May. 2016.

Fanning, Brendan. “'He’d Go Wandering. He’d Fall Over. He Had No Control over Anything,." Brendan Fanning on Rugby, June 1, 2014.

Fatialofa, Peter, and Phil Gifford. Fats: Peter Fatialofa and the Manu Samoa Story. RPL Books/Rugby Publishing Limited, 1996.

Fenno, Nathan. “Chris Borland’s Early Retirement Shifts Focus of Head Injuries in NFL.” Latimes.com. Web. Accessed January 11, 2016.

Field, Michael. "Polynesian Men a Global Sports Commodity.” Stuff.co.nz, May 26, 2013, sec. Sport. Web.

Fotheringham, Richard, Rachel Forgasz, Laura Ginters, Mary Ann Hunter, Lisa Warrington, and Geoffrey Milne. "ADS at Thirty: Three Decades of Australasian Drama, Theatre, Performance and Scholarly Research.” Australasian Drama Studies, April 2012, 6-19.

Fresno-Calleja, Paloma. "Playing (with) Stereotypes in Postcolonial Pacific Theatre." The Journal of Commonwealth Literature 45, no. 2 (June 1, 2010): 171-88.

Government of Samoa. "Report on the Status of the Rights the Child in Samoa," 2005.

Grainger, Andrew. "Rugby Island Style: Paradise, Pacific People, and the Racialisation of Athletic Performance.” Junctures: The Journal for Thematic Dialogue 0, no. 12 (2009). Web.

Grainger, Andrew. "Rugby, Pacific Peoples, and the Cultural Politics of National Identity in New Zealand.” The International Journal of the History of Sport 26, no. 16 (December 1, 2009): 2335-57.

Grainger, Andrew David. “The Browning of the All Blacks: Pacific Peoples, Rugby, and the Cultural Politics of Identity in New Zealand," May 7, 2008. Web. 
Grainger, Andrew D., Mark Falcous, and Joshua I. Newman. "Postcolonial Anxieties and the Browning of New Zealand Rugby.” The Contemporary Pacific 24, no. 2 (2012): 267-95.

Hereniko, Vilsoni. "Clowning as Political Commentary: Polynesia, Then and Now." The Contemporary Pacific 6, no. 1 (1994): 1-28.

Hogg, Robert. “Masculinity and Violence: The Men Who Play Rugby League.” The Conversation. Accessed January 19, 2016.

Hokowhitu, Brendan. “Physical Beings': Stereotypes, Sport and the 'Physical Education’ of New Zealand Ma-ori." Culture, Sport, Society 6, no. 2-3 (June 1, 2003): 192-218.

Hokowhitu, Brendan. "Race Tactics: The Racialised Athletic Body.” Junctures: The Journal for Thematic Dialogue 0, no. 1 (2003).

Hokowhitu, Brendan. “Tackling Māori Masculinity: A Colonial Genealogy of Savagery and Sport." The Contemporary Pacific 16, no. 2 (2004): 259-84.

Hokowhitu, Brendan. "Understanding the Māori and Pacific Body: Towards a Critical Physical Education Pedagogy.” New Zealand Physical Educator 41, no. 3 (November 2008): 81-91,3.

Horton, Peter. "Pacific Islanders in Global Rugby: The Changing Currents of Sports Migration.” The International Journal of the History of Sport 29, no. 17 (November 1, 2012): 2388-2404.

Houlahan, Mark. "Romeo and Tusi: An Eclectically Musical Samoan/Māori Romeo and Juliet from Aotearoa/New Zealand." Contemporary Theatre Review 19, no. 3 (August 1, 2009): 279-88.

Huffer, Elise, and Asofou So’o. Governance in Samoa = Pulega I Samoa / Elise Huffer and Asofou So'o, Editors. Canberra: Asia Pacific Press at the Australian National University and Institute of Pacific Studies, University of the South Pacific, 2000. 
Jackson, Glenn. “The Mind Game: Playing with an Invisible Pain.” The Sydney Morning Herald. Accessed January 21, 2016.

James, Steve. "Rugby Union Is at Last Using Its Head over Concussion,” June 1, 2015, sec. Sport. Web.

Johnson, Steve. “Concussion in Rugby No Longer a 'badge of Honour.” Financial Times, September 10, 2015.

Johnston, Duncan. "Five Kiwi Moments of Playing on While Injured | Stuff.co.nz.” Accessed February 10, 2016.

Jolly, Margaret. “Moving Masculinities: Memories and Bodies Across Oceania.” The Contemporary Pacific 20, no. 1 (2008): 1-24.

Keane, Rory. “A Special Investigation into Pacific Islands Poaching.” Mail Online. Accessed January 15, 2016.

Kightley, Oscar. Dawn Raids. Playmarket, 1997.

Kightley, Oscar, and Erolia Ifopo. Romeo \& Tusi. Playmarket, 2000.

Kightley, Oscar, and Simon Small. Fresh Off the Boat. Play Press, 2005.

Kitamura, Makiko, and Danielle Rossingh. "Rugby Is Having an NFL Moment as Concussions Bring Legal Scrutiny.” Bloomberg.com. Accessed February 6, 2016. Knowler, Richard. "Broken Foot Nothing on Fractured Rib - McCaw | Stuff.co.nz." Accessed February 10, 2016.

Kramer, Augustin. The Samoa Islands: An Outline of a Monograph with Particular Consideration of German Samoa / Augustin Kramer; Translated by Theodore Verhaaren. Auckland, NZ: Polynesian Press, 1994.

Lehmann, Hans-Thies. Postdramatic Theatre. New York: Routledge, 2006.

Lilomaiava-Doktor, Sa iliemanu. "Beyond 'Migration’: Samoan Population Movement (Malaga) and the Geography of Social Space (Vā)." The Contemporary Pacific 21, no. 1 (2008): 1-32. 
Liu, James H. New Zealand Identities: Departures and Destinations. Victoria University Press, 2006.

Lomu, Jonah. Jonah: My Story. 1st. ed. Auckland, NZ: Hodder Moa Beckett, 2004.

Lutton, Phil. "NRL Mourns Loss of Another Young Talent Gone Too Soon.” The Sydney Morning Herald. Web. Accessed January 21, 2016.

Lutton, Phil “Youngster's Death Gives Perspective amid NRL’s Torment.” The Sydney Morning Herald. Accessed January 21, 2016.

Macpherson, Cluny. "From Moral Community to Moral Communities: The Foundations of Migrant Social Solidarity among Samoans in Urban Aotearoa/New Zealand.” Pacific Studies 25, no. 1 (March 1, 2002): 71-93.

Macpherson, Cluny, Paul Spoonley, and Melani Anae. Tangata O Te Moana Nui: The Evolving Identities of Pacific Peoples in Aotearoa /New Zealand. Palmerston North, NZ: Dunmore Press, 2001.

Mageo, Jeannette. “Toward Historicizing Gender in Polynesia: On Vilsoni Hereniko’s 'Woven Gods' and Regional Patterns.” Pacific Studies 22, no. 1 (1999): 93.

Mahuika, Nepia. "The Realms of Tapa and Koura." JNZL: Journal of New Zealand Literature 31 (2013): 180+.

Mallon, Sean. O Measina a Samoa. Potton, 2002.

Mallon, Sean, and Pandora Fulimalo Pereira. Pacific Art Niu Sila: The Pacific Dimension of Contemporary New Zealand Arts. Te Papa Press, Museum of New Zealand, 2002.

Maufort, Marc, and David O’Donnell (MA.). Performing Aotearoa: New Zealand Theatre and Drama in an Age of Transition. Peter Lang, 2007.

Mayeda, David Tokiharu, and Lisa Pasko. "Youth Violence and Hegemonic Masculinity among Pacific Islander and Asian American Adolescents.” Critical Criminology 20, no. 2 (May 12, 2011): 121-39. 
McCaw, Richard. "How I Beat the Pain to Play in the World Cup Final | The Rugby Site’s Blog.” The Rugby Site (therugbysite.com), 2012.

McConnell, Robin. Michael Jones: The Authorised Biography. RPL Books/Rugby Publishing Limited, 1994.

McDonald, Brent. “Developing ‘Home-Grown’ Talent: Pacific Island Rugby Labour and the Victorian Rugby Union.” The International Journal of the History of Sport 31, no. 11 (July 24, 2014): 1332-44.

Mohdin, Aamna. “To Deal with Its Concussion Crisis, the NFL Is Starting to Learn from Rugby.” Quartz. Accessed February 6, 2016.

Mua’au, sd. 'The Va with Nanai Mua'au’, (Personal Interview) December 2016.

Mulholland, Malcolm. State of the Māori Nation: Twenty-First Century Issues in Aotearoa. Reed Publishing (NZ), 2006.

Muliaina, Mils, and Lynn McConnell. Mils Muliaina: Living the Dream. Hachette New Zealand, 2009.

O’Donnell, David. "Staging the va - Eco-Critical Spaces in the Work of Lemi Ponifasio," (Conference Paper - Australasian Drama Studies Conference, Victoria University June 2014) (Unpublished).

O’Donnell, David, and Bronwyn Tweddle. “Toa Fraser: Shifting Boundaries in Pacific Island Comedy.” Australasian Drama Studies, no. 42 (April 2003): 123.

Palenski, Ron. “2. - Rugby Union - Te Ara Encyclopedia of New Zealand.” Web page. Accessed February 1, 2016.

Panapa, Lameko, and Murray Phillips. "Ethnic Persistence: Towards Understanding the Lived Experiences of Pacific Island Athletes in the National Rugby League.” The International Journal of the History of Sport 31, no. 11 (July 24, 2014): 1374-88.

Park, Julie. “'The Worst Hassle Is You Can’t Play Rugby’: Haemophilia and Masculinity in New Zealand." Current Anthropology 41, no. 3 (2000): 444-53. 
Paul, Gregor. "Rugby: Pacifika Players Dominating Ranks.” New Zealand Herald, March 4, 2007, sec. Sport.

Pearson, Sarina. "Pacific Camp: Satire, Silliness (and Seriousness) on New Zealand Television.” Media, Culture E Society 27, no. 4 (2005): 55 1-75.

Peters, Sam, and Daniel Schofield. “Rugby’s Ticking Timebomb! Fears Grow as Evidence Links Brain Damage and Dementia to Increasing Number of Serious Head Injuries Suffered by Top Players.” Mail Online, August 31, 2013.

Phillips, Jock. A Man's Country?: The Image of the Pakeha Male: A History, 1996.

Playmarket (Organization). Urbanesia: Four Pasifika Plays. New Zealand Play Series. Wellington, NZ: Playmarket, 2012.

Pollock, Allyson. “World Rugby Isn’t Doing Enough to Protect Young Players from Head Injuries.” The Guardian, September 21, 2015, sec. Opinion.

Rappaport, Lisa. “Concussion Rates Highest for Kids in Rugby, Hockey and Football.” Reuters, December 16, 2015.

Rees, Paul. "Rugby World Cup: 'We Bring the X-Factor ... without Us It Would Be the Same Few.” The Guardian, September 10, 2015, sec. Sport.

Russo, Steven. “14 MOST RIDICULOUS INJURIES PLAYERS HAVE PLAYED THROUGH.” Rugby League Week, October 15, 2015.

Ryan, Greg. The Making of New Zealand Cricket, 1832-1914 / Greg Ryan. London; Portland, OR: Frank Cass, 2003.

Schofield, Daniel. "England v Samoa: Why the World Should Repay Debt to the Pacific Islands,” November 21, 2014, sec. Sport.

Schofield, Daniel. Pacific Player Abuse 'Despicable.”' Stuff. Accessed January 12, 2016.

Schofield, Daniel. "Rugby Concussions Soar by 59 per Cent, Says Report," February 11, 2015, sec. Sport. 
Sharrad, Paul. Albert Wendt and Pacific Literature: Circling the Void / Paul Sharrad. New York: Manchester University Press, 2003.

Sheard, Kenneth, and Eric Dunning. Barbarians, Gentlemen and Players: A Sociological Study of the Development of Rugby Football. Routledge, 2013.

"Siapo - the Samoan Cloth Made from Bark." Accessed April 27, 2016.

Sinavaiana, Caroline Gabbard. “Traditional Comic Theater in Samoa: A Holographic View.” Thesis --University of Hawai'i at Manoa, 1992.

Sinclair, Keith. A Destiny Apart: New Zealand's Search for National Identity. Wellington, NZ: Allen \& Unwin in association with the Port Nicholson Press, 1986.

Somerville, Alice Te Punga, ed. “EPILOGUE:: A Time and a Place.” In Once Were Pacific, NED - New edition., 213-16. M Ori Connections to Oceania. University of Minnesota Press, 2012.

Somerville, Alice Te Punga ed. “Manuhiri, Fānau:: Pasifika Write Connections.” In Once Were Pacific, NED - New edition., 139-54. M Ori Connections to Oceania. University of Minnesota Press, 2012.

Somerville, Alice Te Punga. Once Were Pacific: M Ori Connections to Oceania. NED - New edition. University of Minnesota Press, 2012.

Somerville, Alice Te Punga ed. "When Romeo Met Tusi:: Disconnections.” In Once Were Pacific, NED - New edition., 155-76. M Ori Connections to Oceania. University of Minnesota Press, 2012.

Steinberg, Leigh. "How Can Tiny Samoa Dominate The NFL?” Forbes. Accessed February 3, 2016.

Suaalii-sauni, Tamasailau M., Willson Scott, Maualaivao Albert Wendt, Vitolia Mo’a, Naomi Fuamatu, and Upolu Luma Va'ai. Whispers and Vanities: Samoan Indigenous Knowledge and Religion. Huiia Publishers, 2015. 
Sygall, David. "Cronulla Sharks Star Andrew Fifita Reveals Suicide Bid in NRL Footy Show Interview.” The Sydney Morning Herald. Accessed January 21, 2016.

Tagaloa, Fanaafi Aiono-Le. Tapuai: Samoan Worship / Fanaafi Aiono-Le Tagaloa. Sl: Fanaafi Aiono - Le Tagaloa, 2003.

Tagata Pasifika. Tagata Pasifika Special: Bryan Williams. Accessed January 12, 2016.

Tait, Morgan. "Rugby Death: Tears for 'Gentle Giant.” New Zealand Herald, July 7, 2014, sec. National.

Tamasese, Kiwi, Carmel Peteru, Charles Waldegrave, and Allister Bush. "Ole Taeao Afua, the New Morning: A Qualitative Investigation into Samoan Perspectives on Mental Health and Culturally Appropriate Services.” The Australian and New Zealand Journal of Psychiatry 39, no. 4 (April 2005): 300-309.

Taonga, New Zealand Ministry for Culture and Heritage Te Manatu. “3. - Te Ao Mārama - the Natural World - Te Ara Encyclopedia of New Zealand.” Web page. Accessed February 2, 2016.

Teaiwa, Teresia, and Sean Mallon. “Ambivalent Kinships?: Pacific People in New Zealand.” In New Zealand Identities: Departures and Destinations, edited by James H. Liu, 207-29. Victoria University Press, 2006.

Te'evale, Tasileta. "We Are What We Play: Pacific Peoples, Sport and Identity in Aotearoa." In Tangata O Te Moana Nui: The Evolving Identities of Pacific Peoples in Aotearoa /New Zealand, edited by Cluny Macpherson, Paul Spoonley, and Melani Anae, 212-27. Palmerston North, NZ: Dunmore Press, 2001.

Tolley, Claire. "Five Deaths from Head Injuries in Amateur Rugby Union.” The Guardian, December 13, 2013, sec. Sport.

Walter, Brad. "League Stars Mourn Death of Tigers Prop.” The Sydney Morning Herald, February 1, 2013. 
Warrington, Lisa. "Brave 'New World': Asian Voices in the Theatre of Aotearoa." Australasian Drama Studies, April 2005, 98-116.

Wendt, Maualaivao Albert. "NZEPC - Albert Wendt - Tatauing the Post - Colonial Body.” Accessed December 16, 2015.

Yates, Siena. “Anatomy of a 'Real’ Man.” Stuff. Accessed April 22, 2016.

“Family Turns off Life Support of Cowboys' Rising Star Alex Elisala.” The Australian. 21, Jan. 2016.

\section{Uncredited Web pages}

100 Greatest All Blacks: Michael Jones. nzherald.co.nz. http://www.nzherald.co.nz/sport/news/article.cfm?c_id=4\&objectid=11214887 Accessed January 12, 2016.

“NFL and Players Reach ‘\$765m Concussion Settlement.” BBC Nerws. http://www.nfl.com/news/story/Oap $1000000235494 /$ article/nfl-explayers-agreeto-765m-settlement-in-concussions-suit Accessed February 6, 2016.

“NZ Rugby: All Blacks.” Active Adventures. http://activeadventures.com/newzealand/about/culture/new-zealand-all-blacks Accessed February 1, 2016.

“Concussion in Rugby Union: Parents, Coaches and Referees Share Their Stories.” https://www.theguardian.com/sport/blog/2013/dec/17/concussion-rugbyparents-players-coaches-referees-stories The Guardian, December 17, 2013, sec. Sport. Web

“Economic Impact Study for England 2015.” http://www.wttc.org/research/economicresearch/economic-impact-analysis/ rugbyworldcup.com. Accessed January 19, 2016. 
"The Conversation No One Wants to Have | NRL Footy Show."

http://www.9jumpin.com.au/show/nrlfootyshow/latest/2015/august/footyshow-depression/ 9Jumpin. Accessed January 21, 2016.

“The FRONTLINE Interview: Dr. Bennet Omalu - League of Denial: The NFL's Concussion Crisis.” http://www.pbs.org/wgbh/pages/frontline/sports/league-ofdenial/the-frontline-interview-dr-bennet-omalu/FRONTLINE. Accessed April 26, 2016.

“Tier 2 Rugby: Pacific Island Internationals in Super Rugby.” http://tier2rugby.blogspot.co.nz/2015/07/pacific-islanders-in-super-rugby.html Accessed January 12, 2016.

“Tier 2 Rugby: The Truth of Just How Wrong the Old All Blacks 'Poaching' Myth Is.” http://tier2rugby.blogspot.co.nz/2014/07/the-truth-how-wrong-old-allblacks.html Accessed January 12, 2016.

\section{You Tube Video}

Pacific Beat St.(Ep 187) - Michael Jones. Accessed January 12, 2016. 